Aus der Abteilung Kardiologie und Pneumologie

(Prof. Dr. med. G. Hasenfuß)

im Zentrum Innere Medizin

der Medizinischen Fakultät der Universität Göttingen

\title{
Vergleich des kardialen Remodelings zwischen Vorlastmodell und Nachlastmodell
}

\author{
INAUGURAL - DISSERTATION \\ zur Erlangung des Doktorgrades \\ der Medizinischen Fakultät der \\ Georg-August-Universität zu Göttingen
}

vorgelegt von

Lena Preuß

aus Halle/Westfalen

Göttingen 2011 
Dekan:

I. Berichterstatter:

II. Berichterstatter/in:

III. Berichterstatter/in:
Prof. Dr. med. Frömmel

Prof. Dr. med. Hasenfuß

Prof. Dr. med. El-Armouche

Prof. Dr. med. Dr. rer. nat. Crozier

Tag der mündlichen Prüfung: 17. August 2011 


\section{Gliederung}

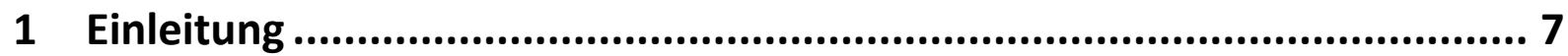

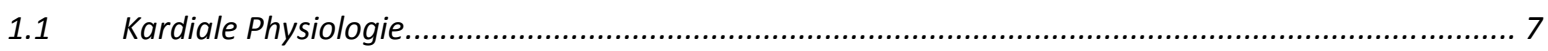

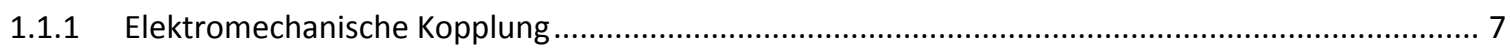

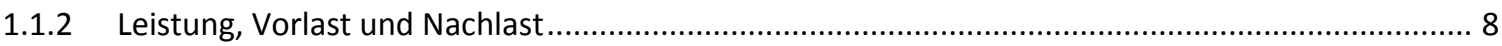

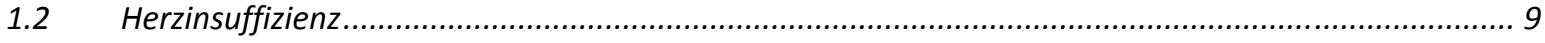

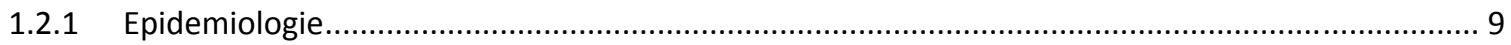

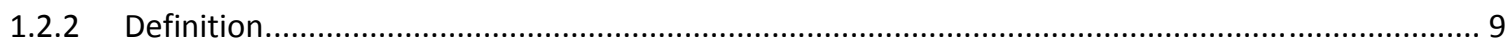

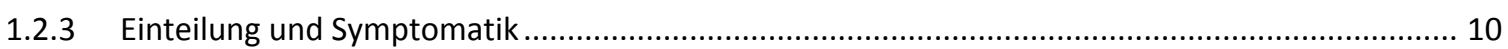

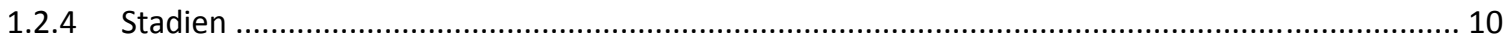

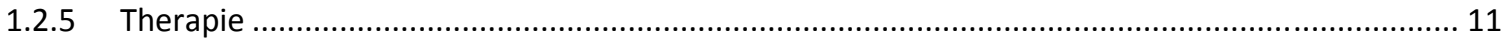

$1.3 \quad$ Kardiale Hypertrophie ........................................................................................................ 11

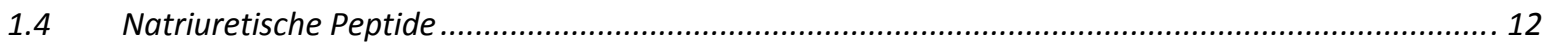

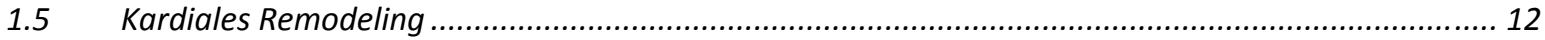

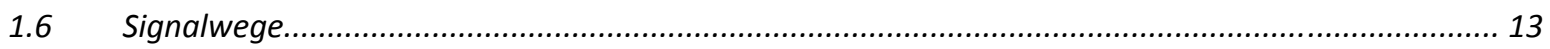

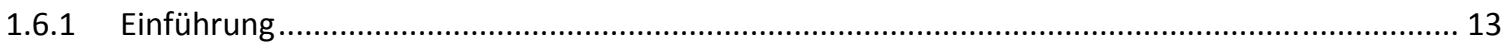

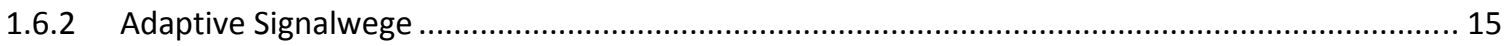

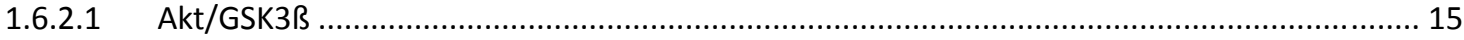

1.6.2.2 ERK

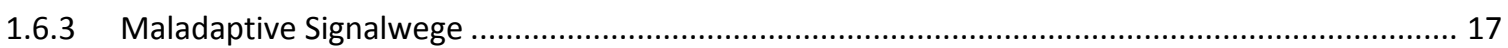

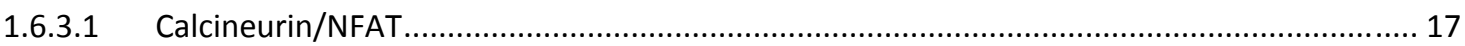

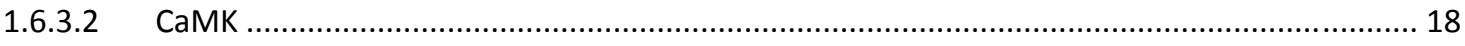

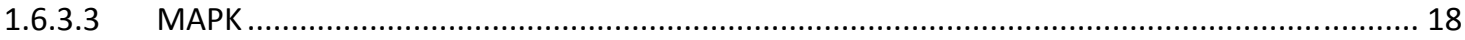

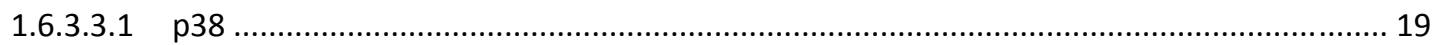

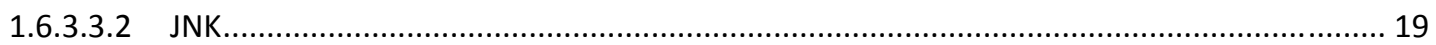

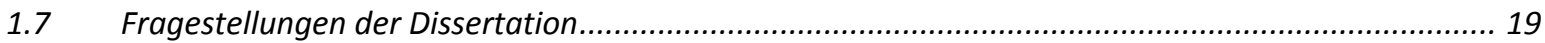

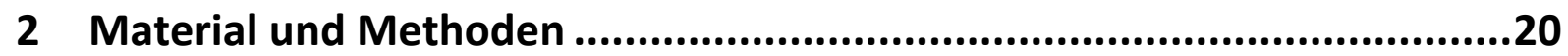

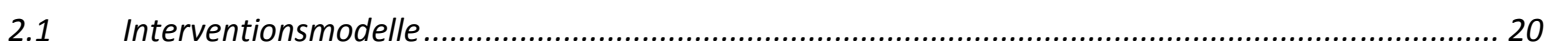

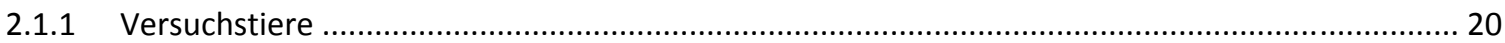

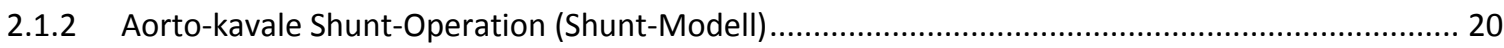

2.1.3 Transverse aortale Konstriktions-Operation (TAC-Modell) ................................................. 21

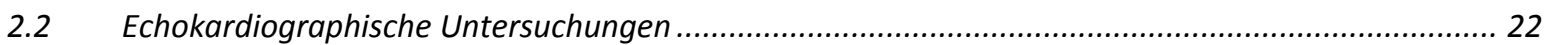


2.3 Hämodynamische Messungen in vivo......

2.3.1 Linksventrikuläre Druck- und Volumen-Messungen mittels Konduktionskatheter ...................... 22

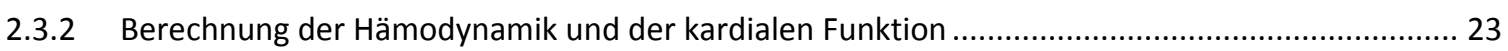

2.3.2.1 Berechnung der Wandspannung mit Hilfe des Laplace-Gesetzes .................................... 23

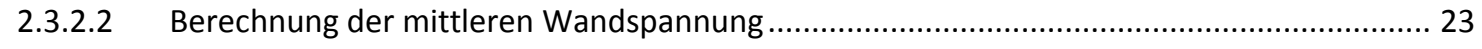

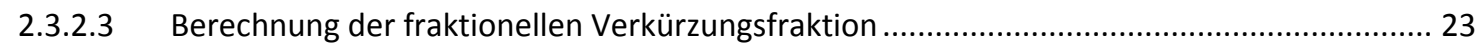

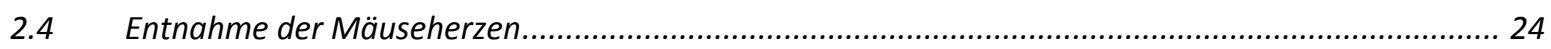

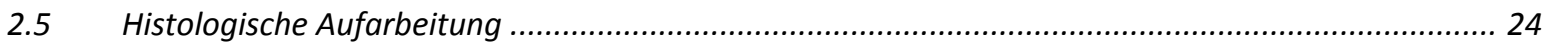

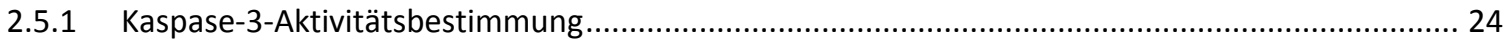

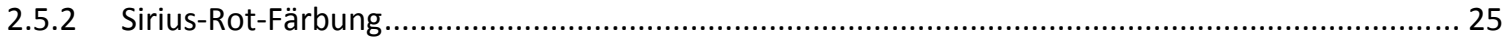

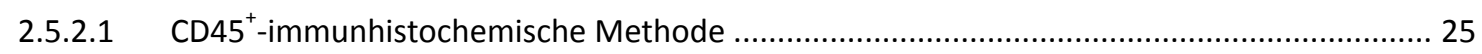

2.5.2.2 TdT-mediated dUTP nick end labeling-Methode (TUNEL-Methode)....................................25

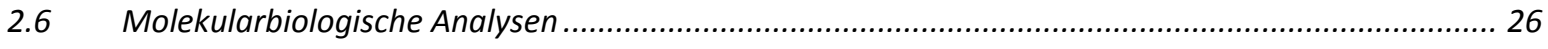

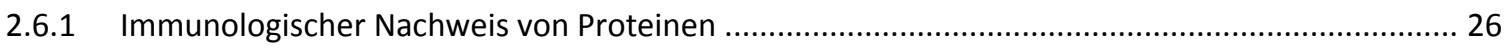

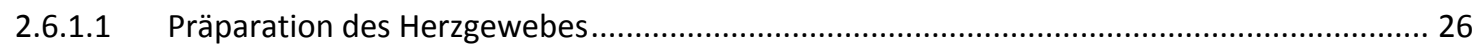

2.6.1.1.1 Homogenisierung des Herzgewebes ................................................................. 26

2.6.1.1.2 Bestimmung der Proteinkonzentrationen .............................................................. 26

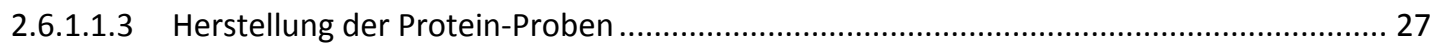

2.6.1.2 SDS-Polyacrylamid-Gelelektrophorese (SDS-PAGE) …............................................... 27

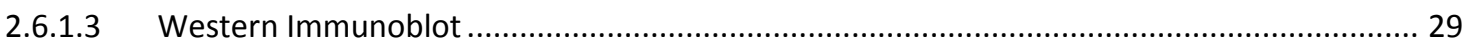

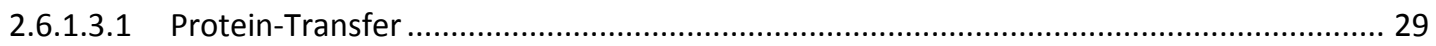

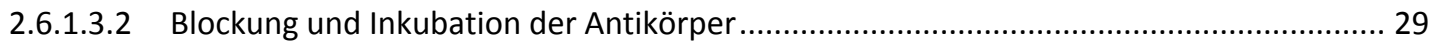

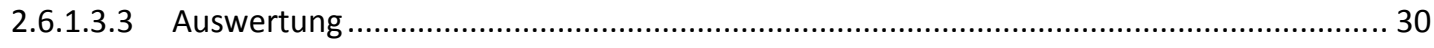

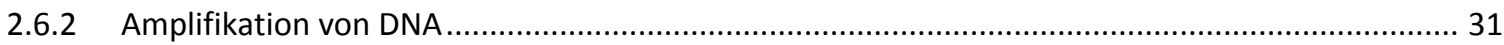

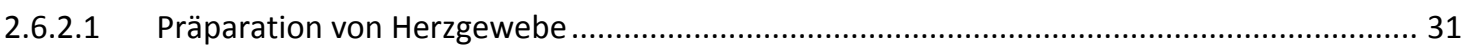

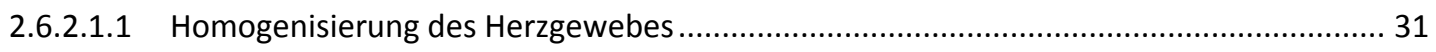

2.6.2.1.2 Bestimmung der Nukleinsäurekonzentrationen ........................................................ 31

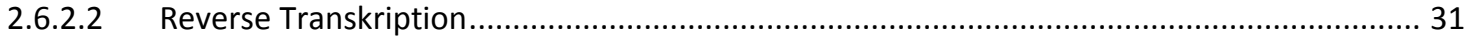

2.6.2.3 Quantitative realtime-Polymerase-Kettenreaktion (quantitative realtime-PCR).................. 32

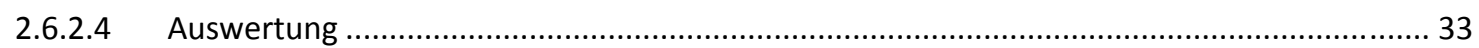

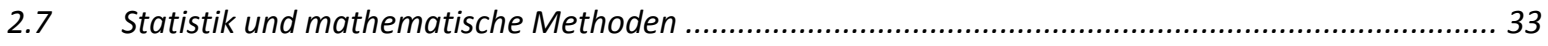

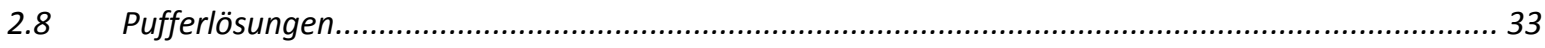

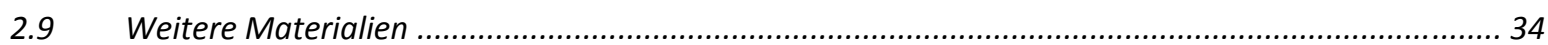


3 Ergebnisse

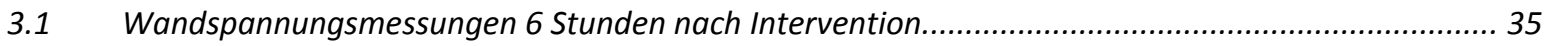

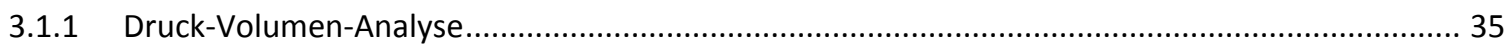

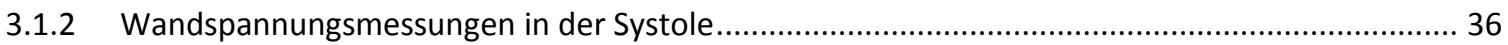

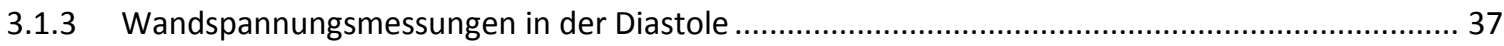

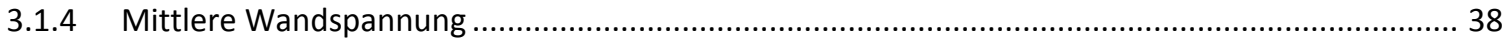

3.2 Echokardiographiedaten im TAC- und Shunt-Modell 24 Stunden und 7 Tage nach Intervention........ 39

3.3 Linksventrikuläre Hypertrophie im TAC- und Shunt-Modell........................................................ 40

3.4 Remodeling im TAC- und Shunt-Modell 7 Tage nach Intervention ............................................41

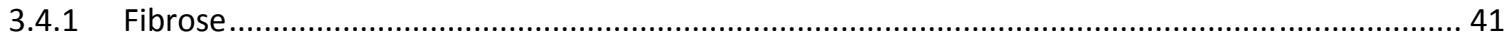

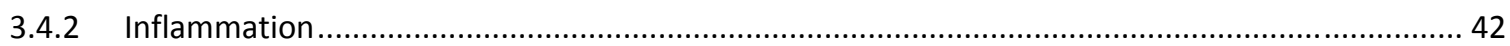

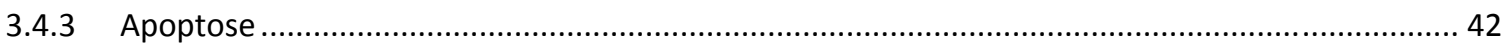

3.5 BNP im TAC- und Shunt-Modell 24 Stunden und 7 Tage nach Intervention .................................. 44

3.6 Adaptive und maladaptive Signalwege im TAC- und Shunt-Modell 24 Stunden und 7 Tage nach

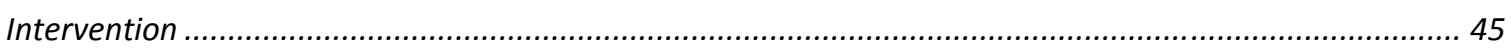

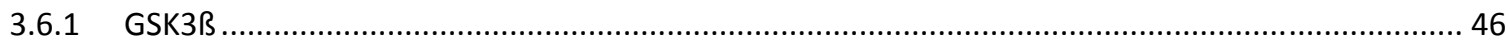

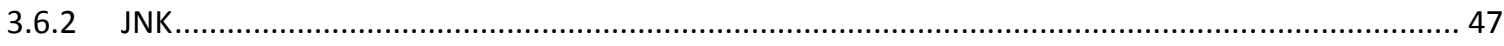

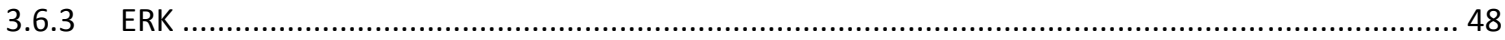

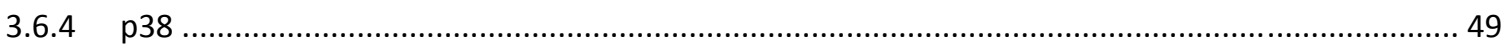

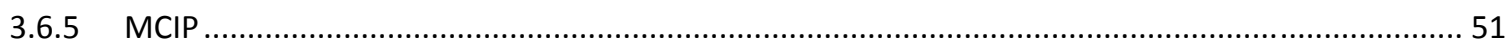

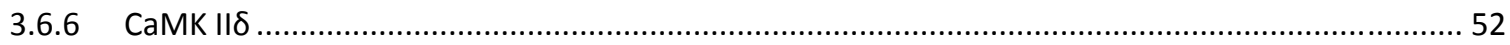

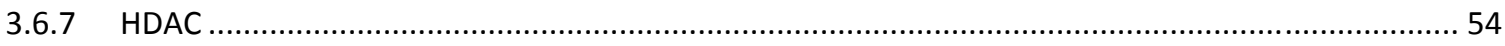

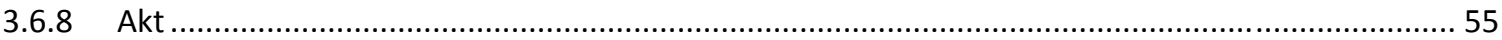

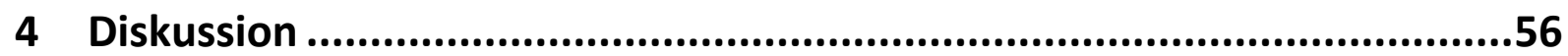

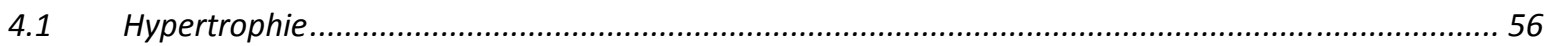

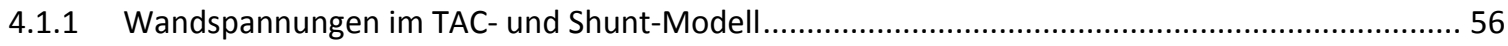

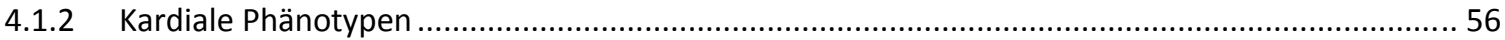

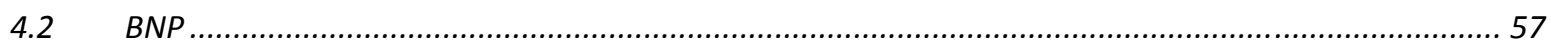

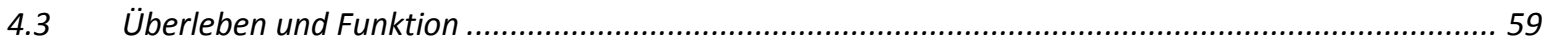

4.3.1 Bedeutung der echokardiographischen Befunde.................................................................59

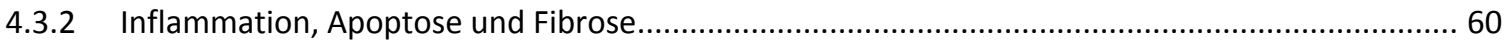

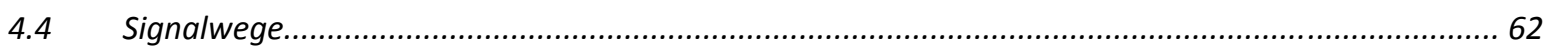

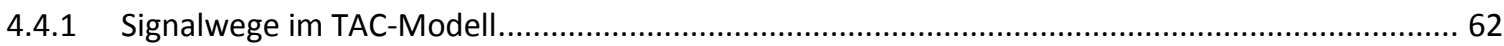

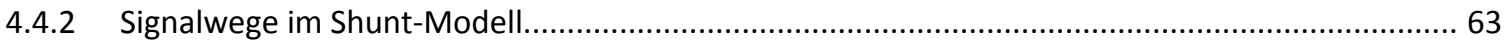




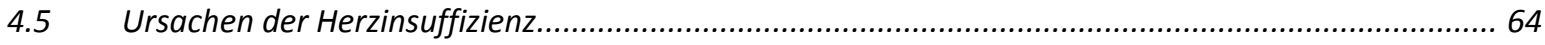

4.5.1 Ursachen der Herzinsuffizienz im TAC-Modell .................................................................. 64

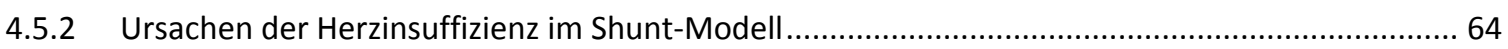

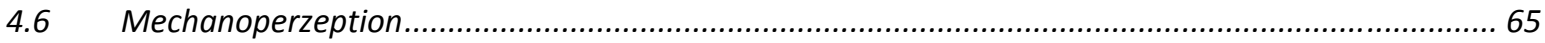

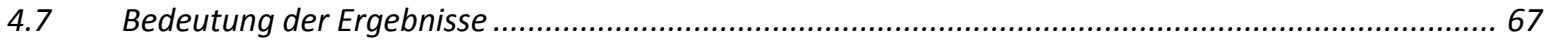

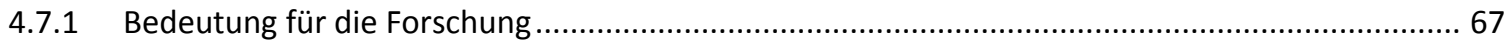

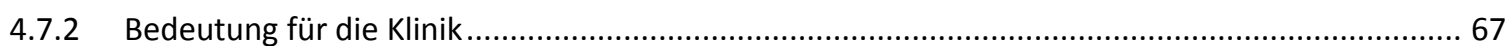

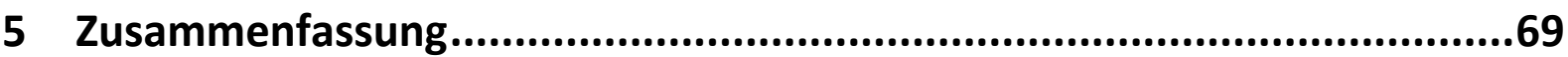

6 Literaturverzeichnis ............................................................................70

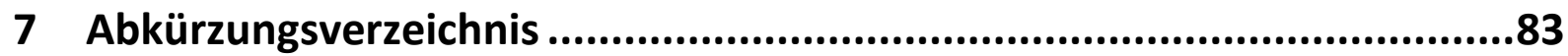

8 Abbildungs- und Tabellenverzeichnis...................................................85 


\section{Einleitung}

\subsection{Kardiale Physiologie}

\subsubsection{Elektromechanische Kopplung}

Die Kontraktion des Herzens ist ein komplexer Prozess, der durch eine elektrische Erregung der Kardiomyozyten induziert wird. Kalzium spielt bei der Übersetzung des elektrischen Signals in die mechanische Bewegung der Myozyten eine zentrale Rolle (Ringer 1883).

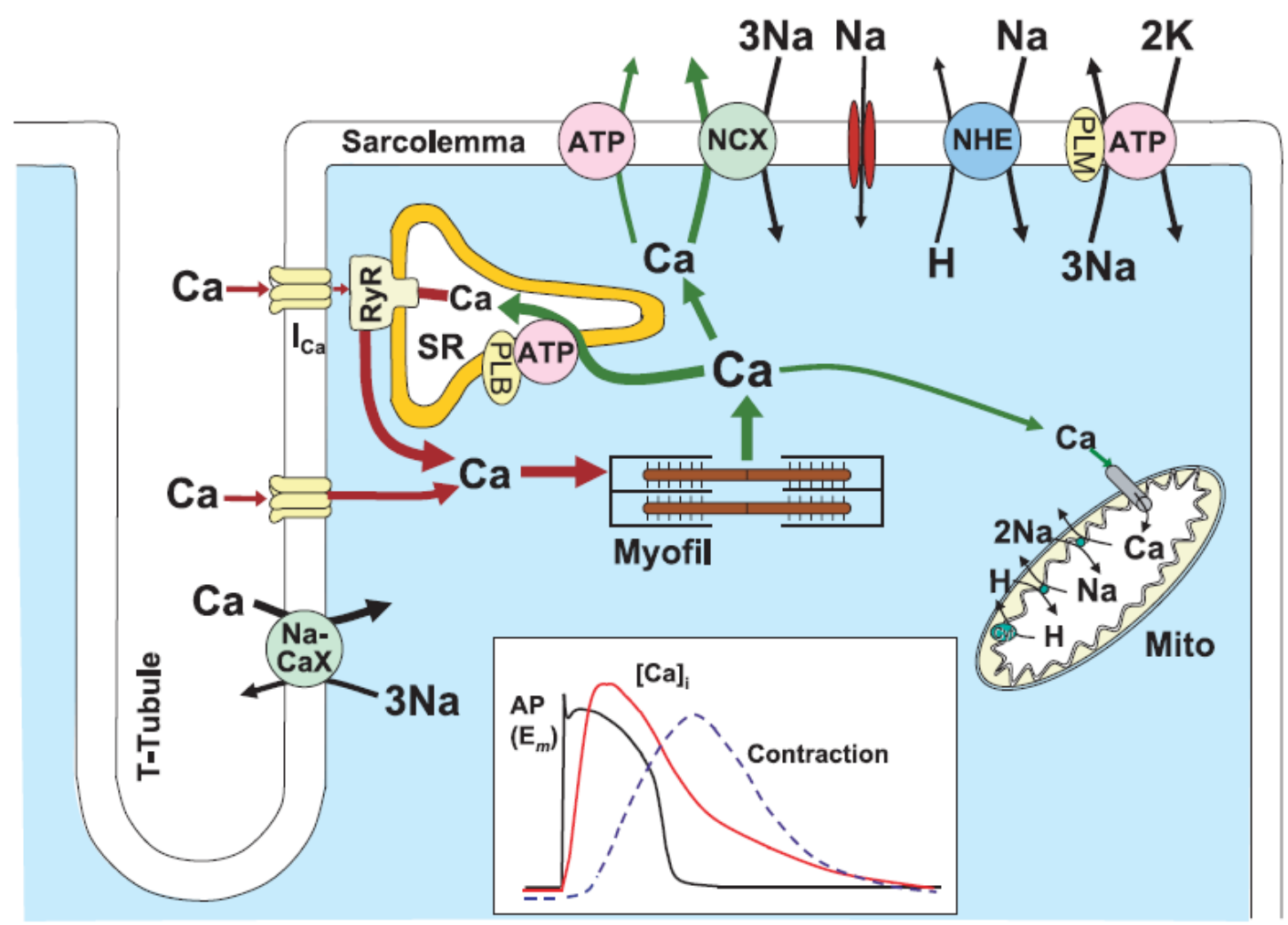

Abbildung 1: Elektromechanische Kopplung in ventrikulären Kardiomyozyten (NCX=Natrium-KalziumAustauscher, ATP=Adenosintriphosphat, ATPase, PLB=Phospholamban, SR=sarkoplamatisches Retikulum), (Bers und Despa 2006, Seite 316).

Während der Depolarisation öffnen sich spannungsabhängige Natrium-Kanäle, die eine intrazelluläre Erhöhung der Natrium-Konzentration entstehen lassen (Bers et al. 2003). Zudem strömt Kalzium durch die spannungsabhängigen L-Typ-Kalziumkanäle (LTCC) in die Zelle ein. Es kommt zu einer intrazellulären Kalziumfreisetzung aus dem sarkoplasmatischen Retikulum (SR) durch Aktivierung der Kalzium-abhängigen Ryanodin-Rezeptoren (RYR) (Bers 2001). Eine weitere (wenn auch geringe) Kalziumquelle stellt der Natrium-Kalzium-Austauscher (NCX) dar (Bers und Weber 2002). Auf Grund dieser 
beiden Kalziumquellen findet während der Systole eine intrazelluläre Kalziumkonzentrationserhöhung statt (Bers 2001). Nach Bindung des Kalziums an Troponin C (TnC) erfolgt eine Konformationsänderung des Troponin-Tropomyosin-Komplexes. Dies ermöglicht eine Interaktion zwischen Aktinund Myosin-Filamenten (Solaro und van Eyk 1996) mit Energiegewinnung aus der Hydrolyse von Adenosintriphosphat (ATP). Es folgt eine mechanische Bewegung und so die Verkürzung der Muskelzelle (Brenner und Eisenberg 1987).

Die Beendigung der Muskelkontraktion erfolgt über die Inaktivierung des L-Typ-Kalzium-Kanals (Kass und Sanguinetti 1984, Zühlke et al. 1999) und die Adaptation des RYR (Györke und Fill 1993, Sham et al. 1998). Etwa 75 \% des zytosolischen Kalziums werden mittels der Kalzium-ATPase des SR (SERCA) zurück in den Kalziumspeicher transportiert (Piacentino et al. 2003), etwa 25 \% des Kalziums verlassen die Zelle über den NCX (Piacentino et al. 2003). Die Kalzium-ATPase transportiert unter ATPHydrolyse zwei Kalziumionen aus dem Zytosol in das SR (Tada 2003). Die Ionen werden an Kalziumbindende Proteine, wie Calsequestrin (CSQ), gebunden und gespeichert. Der Natrium-KalziumAustauscher transportiert ein Kalziumion in den Extrazellulärraum und bringt im Gegenzug drei Natriumionen in die Zelle. Der elektrochemische Gradient wird von der Natrium-Kalium-ATPase aufrechterhalten und ermöglicht den Transport (Crespo et al. 1990). Zu deutlich geringeren Anteilen tragen auch die Kalzium-ATPase im Sarkolemm (Caroni und Carafoli 1980) und ein Kalzium-Uniporter im Mitochondrium zur Eliminierung (Carafoli 1975) des Kalziums bei. Die Eliminierung des zytosolischen Kalziums verringert die TnC-Aktivität am Troponin-Myosin-Komplex und es kommt zur Erschlaffung des Herzmuskels.

Eine bedeutende Funktion im Kalziumkreislauf hat das Enzym Phospholamban (PLB). Durch Bindung von unphosphoryliertem PLB an die Kalzium-ATPase des SR wird diese inhibiert. Die Phoshorylierung von PLB durch die Proteinkinase A (PKA) oder die Kalzium-Calmodulin-abhängige Proteinkinase (CaMK) löst die Bindung von PLB an SERCA und steigert so dessen Kalziumumsatz (Kranias und Di Salvo 1986).

\subsubsection{Leistung, Vorlast und Nachlast}

Die Faktoren Schlagvolumen (SV) und Herzfrequenz (HF) regulieren das Herzzeitvolumen (HZV): HZV=SVxHF (Opie 2001, S. 380-381). Das Schlagvolumen wird maßgeblich sowohl durch die Inotropie der Myozyten als auch durch die Vorlast (Volumenbelastung des linken Ventrikels) und die Nachlast (aortaler Auswurfwiderstand) bestimmt.

Die Vorlast entspricht der Vordehnung des Herzens vor Kontraktionsbeginn. Diese ist abhängig vom Füllungszustand des Herzens. Eine Zunahme der Vorlast des Myokards entspricht einer gesteigerten Volumenbelastung und ist etwa bei einer Mitralklappeninsuffizienz zu beobachten (Serneri et al. 2001). 
Beim Auswurf des Blutvolumens aus dem linken Ventrikel muss das Myokard den aortalen Widerstand überwinden. Der Auswurfwiderstand ist direkt von der myokardialen Wandspannung und indirekt vom peripheren Gefäßwiderstand abhängig und entspricht der Nachlast. Eine Erhöhung der Nachlast liegt etwa bei einer Aortenklappenstenose oder einer arteriellen Hypertonie vor (Hein et al. 2003).

\subsection{Herzinsuffizienz}

\subsubsection{Epidemiologie}

Kardiovaskuläre Erkrankungen sind die führende Todesursache in den westlichen Ländern. In der Gruppe der kardiovaskulären Erkrankungen ist die Herzinsuffizienz vorherrschend (Levy et al. 2002, Hobbs 2004) und stellt ein bedeutsames Problem für das öffentliche Gesundheitssystem dar (Hunt et al. 2001). In den Vereinigten Staaten von Amerika sind etwa 4,9 Millionen Menschen an einer Herzinsuffizienz erkrankt. Zugleich ist die Herzinsuffizienz die häufigste Ursache für die Hospitalisierung von Patienten über dem 65. Lebensjahr (Hunt et al. 2001). Das Lebenszeitrisiko, an einer Herzinsuffizienz zu erkranken, liegt geschlechterunabhängig bei ca. 20 \% (Lloyd-Jones et al. 2002). Bei 2 bis 12 von 1000 Patienten wird jährlich eine Herzinsuffizienz neu diagnostiziert und ist abhängig von Begleiterkrankungen wie etwa der Hypertonie und dem Myokardinfarkt (Lloyd-Jones et al. 2002, Roger et al. 2004).

Trotz der Entwicklung und Optimierung von Therapien liegt die jährliche Letalität bei Patienten mit leichter Symptomatik bei 5 bis $10 \%$, bei Patienten mit fortgeschrittenen Symptomen bei 30 bis $40 \%$. Führende Ursachen für eine kardiale Insuffizienz sind ischämische Schädigungen (36 \%), Kardiomyopathien (34\%), Hypertension (14\%) und Vitien (7 \%) (Cowie et al. 1999, Shariff et al. 2004). Die Gruppe der Kardiomyopathien lässt sich durch Ausschluss von koronarer Herzerkrankung (KHK), Hypertonie, Vitien oder Perikarderkrankungen definieren. Kardiomyopathien basieren häufig auf genetischen Mutationen (Chien 2003).

\subsubsection{Definition}

Die Weltgesundheitsorganisation (WHO) definiert eine Herzinsuffizienz als „Unvermögen des Herzens, bei ausreichendem venösen Angebot und normalem enddiastolischen Ventrikeldruck die peripheren Organe des Organismus suffizient mit oxygeniertem Blut zu versorgen" (McMurray 1996, S.14). 
Die Herzinsuffizienz wird nun eher als klinisches Syndrom unterschiedlicher Ätiologie aufgefasst, welches durch eine Kombination von Anamnese, Symptomen, Bildgebung, Laborergebnissen und Therapieerfolg definiert wird (Remme und Swedberg 2001).

\subsubsection{Einteilung und Symptomatik}

Die funktionelle Einteilung und somit der Schweregrad der kardialen Insuffizienz erfolgt in vier Stadien nach den Kriterien der New York Heart Association (NYHA) (Hoppe und Erdmann 2001). Die vier Stadien basieren auf den Angaben von subjektiven Beschwerden. Weitere Einteilungen lassen sich nach klinischen (systolisch-diastolisch, kompensiert-dekompensiert, akut-chronisch, rechts-links, global) oder pathophysiologischen Kriterien (Volumenbelastung, Druckbelastung, Füllungsbehinderung, Myokardverlust, Kontraktilitätsverlust) vornehmen (Braunwald 1997, S.10-13). Die Pumpschwäche des Herzens gliedert sich in verschiedene Symptomgruppen. Das Vorwärtsversagen geht mit einer Muskelschwäche und einer vermehrten Müdigkeit einher, welche auf einer Verminderung des Herzzeitvolumens mit inadäquatem Blutdruck und peripherer Minderperfusion gründet. Das Rückwärtsversagen des insuffizienten Herzens äußert sich in der Stauung des venösen Blutes. Eine Schwäche des rechten Herzens zeigt sich in Form von Ödemen, einer vergrößerten Stauungsleber und Aszites. Bei Stauung vor dem linken Herzen kommt zur Entstehung eines Lungenödems (Herold 2010, S.199-200).

\subsubsection{Stadien}

Die Entstehung der Herzinsuffizienz erfolgt in drei Phasen. Die erste Phase ist durch eine akute Belastung gekennzeichnet, die durch verschiedene Mechanismen kompensiert wird. Dabei kommt es initial zu intrakardialen (Frank-Starling-Mechanimus) und neurohumoralen Anpassungsmechanismen (Aktivierung des sympathischen Nervensystems und des Renin-Angiotensin-Systems, Mobilisierung verschiedener Zytokine und vasoaktiver Substrate) mit dem Ziel, die Perfusion der Organe aufrecht zu erhalten (Cohn et al. 1984, Francis et al. 1990). Es kommt folglich zu einer Zunahme der kardialen Chrono- und Inotropie und einer peripheren Vasokonstriktion sowie durch Erhöhung der enddiastolischen Füllung (gemäß dem Frank-Starling-Mechanismus) zu einer gesteigerten Pumpfunktion.

Mittelfristig zeigt sich eine kompensierte Herzinsuffizienz durch Hypertrophie der Myozyten (siehe 1.3).

Die dritte Phase stellt die dekompensierte kardiale Insuffizienz dar (Meerson 1961). Bei fortbestehender Belastung folgt nach einiger Zeit der Übergang aus dem Stadium der kompensierten Hypertrophie zur dekompensierten Herzinsuffizienz. Die Konsequenzen dieser Adaption sind vielfältig. Es kann zu Arrhythmien und zentraler Stauung sowie peripherer Ödembildung durch Anstieg der Kapillardrücke kommen. Weitere Risiken der Anpassungsmechanismen sind die erhöhte Nachlast durch 
den zunehmenden peripheren Widerstand und der pathologische Umbau des Myokards (kardialer Remodeling-Prozess). Die Effekte der Katecholaminausschüttung sind eine weitere Verschlechterung der koronaren Ischämie durch Steigerung der kardialen Chrono- und Inotropie sowie die Unterstützung des Myozytenuntergangs (Tan et al. 1991, Communal et al. 1998, Hoppe und Erdmann 2001).

\subsubsection{Therapie}

Bei der Erkrankung an einer kardialen Insuffizienz wird diese medikamentös therapiert (ß-RezeptorBlocker, ACE-Hemmer, AT1-Rezeptorblocker, Diuretika, Aldosteron-Antagonisten, Digitalis). Bei dieser Patientengruppe treten häufig weitere, das kardiovaskuläre System schädigende, Erkrankungen auf. Des Weiteren ist auch häufig eine antiarrhythmische Therapie erforderlich (Hoppe und Erdmann 2001).

\subsection{Kardiale Hypertrophie}

Bei länger andauernder Belastung kommt es zu einer strukturellen Anpassung des Herzens. Physiologisch ist die kardiale Hypertrophie in der Schwangerschaft und bei Sportlern (Pluim et al. 1999). Pathologisch ist die Hypertrophie bei mechanischer Überlastung oder permanenter neuroendokriner Stimulation. Die chronische myokardiale Hypertrophie ist mit einem signifikant erhöhten Risiko in Form von Arrythmie (Berenji et al. 2005), Herzinsuffizienz, und plötzlichem Herztod assoziiert (Casale et al. 1986, Levy et al. 1990, Vakili et al. 2001).

Die Hypertrophie eines Organs wird als eine Zunahme der Zellgröße verstanden. Gemäß des LaplaceGesetzes $K=(P \times 2 d) / r(K=$ Kraft pro Querschnitt der Wand; $P=$ Innendruck; $d$ = Wanddicke; $r$ = Radius) ist das Ziel der Hypertrophie, den Anstieg der Wandspannung durch eine Zunahme der Wanddicke auszugleichen (Hood et al. 1968, Grossman et al. 1975). Eine Hyperplasie (Zellzahlzunahme) findet im Herzen nur in einem sehr geringen Ausmaß statt (Soonpaa und Field 1998).

Die Differenzierung der kardialen lastabhängigen Hypertrophie erfolgt in zwei Formen: Veränderungen durch Druckbelastung und Veränderungen durch Volumenbelastung. Die chronischen pathologischen Druck- bzw. Volumenbelastungen resultieren in unterschiedlichen morphologischen Veränderungen der Herzhypertrophie (Grossman et al. 1975).

Die linksventrikuläre Druckerhöhung führt zu einer konzentrischen Hypertrophie der Kammer. Eine Druckbelastung zeigt sich bei arterieller Hypertension oder Aortenklappenstenose. Die konzentrische Hypertrophie ist definiert als Anstieg der Septumstärke (Carabello 2002) mit dem Einbau parallel angeordneter Sarkomere und nur geringer Ventrikeldilatation (Anversa et al. 1986, Arnolda et al. 1991). 
Die linksventrikuläre Volumenbelastung resultiert in einer exzentrischen Hypertrophie des Herzens. Es zeigt sich eine nur sehr geringe Septumstärkenzunahme, eine Vergrößerung des linksventrikulären Durchmessers (LVEDD) durch den Einbau von Sarkomeren in Reihe und eine Steigerung des Ventrikelvolumens (Anversa et al. 1983, Gerdes et al. 1988, Bruneau und de Bold 1994). Die exzen-trische kardiale Hypertrophie ist Folge von Mitral- oder Aortenklappeninsuffizienz, Vorhof- oder Kammerseptumdefekt. Das Schlagvolumen ist bei der exzentrischen Hypertrophie erhöht, um das im linken Ventrikel verbleibende Blutvolumen zu kompensieren (Carabello et al. 1986).

\subsection{Natriuretische Peptide}

Das atriale natriuretische Peptid (ANP) und das brain-natriuretische Peptid (BNP) sind an der Regulation des Wasserhaushaltes beteiligt. ANP wird überwiegend in speziellen Zellen der Vorhöfe gebildet (de Bold et al. 1981). BNP hingegen wird im ventrikulären Myokard synthetisiert (Hosoda et al. 1991, Ogawa et al. 1991). Die Peptide erzeugen durch renale Steigerung der Natriumausscheidung eine diuretische Wirkung. Durch die Abnahme des intravasalen Volumens und einer zusätzlichen vasodilatatorischen Komponente kommt es zur Senkung des Blutdrucks. Die Inhibition des ReninAngiotensin-Aldosteron-Systems erfolgt durch Hemmung der Aldosteron- und Adiuretin-Freisetzung (de Bold 1985, Yoshimura et al. 1991).

Im Stadium der Hypertrophie ist die BNP-Konzentration im Blut und im Herzgewebe erhöht. Lokal hat BNP im Herzen eine antihypertophe Wirkung. Über das ANP, BNP/NPR-A/cGMP-System werden Hypertrophie-induzierende Signalwege inhibiert (Tokudome et al. 2005), wie zum Beispiel der NFATSignalweg (Fiedler et al. 2002). Lin et al. (1995) konnten zeigen, dass dieser antihypertrophe Mechanismus neben den Kardiomyozyten auch in den kardialen Fibroblasten stattfindet und eine Fibroblastenproliferation verhindert. Weiterhin hat BNP einen inhibitorischen Einfluss auf die Inflammation, Kollagenproduktion und Bildung der Extrazellulärmatrix.

Die Konzentration des BNP im Blut ist heute ein wichtiger diagnostischer Marker, z.B. zum Ausschluss einer linksventrikulären Funktionsstörung bei symptomatischen Patienten. Bei der Erkrankung an einer Herzinsuffizienz können durch die BNP-Bestimmung eine Stratifizierung des Risikos und eine Kontrolle des Krankheitsverlaufes erfolgen (Luchner und Schunkert 2004).

\subsection{Kardiales Remodeling}

Das Konzept des kardialen ventrikulären Remodelings wurde bereits 1985 geprägt (Pfeffer et al. 1985, Opie et al. 2006). Es handelt sich um einen adaptiven Prozess zur Aufrechterhaltung einer regelrechten kardialen Funktion bei etwa Herzklappenfehlern, Herzinfarkt, Kardiomyopathien oder 
Hypertonie (Sutton und Sharpe 2000). Dennoch führt das kardiale Remodeling bei chronischer Aktivierung zur progressiven Dekompensation und Herzinsuffizienz (Frey und Olson 2003).

Das ventrikuläre Remodeling bezeichnet die Gesamtheit der Umbauprozesse, die Veränderungen der Ventrikelform, -größe und -funktion und manifestiert sich in molekularen, zellulären und interstitiellen Veränderungen. Somit sind neben Kardiomyozyten auch Fibroblasten, Extrazellulärmatrix und Koronargefäße beteiligt (Opie et al. 2006, Spinale 2007). Im Rahmen des ventrikulären Remodelings zeigt sich eine Hypertrophie der Myokardzellen, dessen bedeutender Stimulus eine Erhöhung der Wandspannung ist. Die mechanische Dehnung wird von den Myokardzellen registriert und in intrazelluläre Signalwege übertragen, die so eine Hypertrophie der Zellen veranlassen (Heineke und Molkentin 2006). Weiterhin kommt es zu einer vermehrten Fibrosierung (Brilla und Weber 1992) und einer erhöhten Apoptose der Kardiomyozyten (Bing 1994, Condorelli et al. 1999). Die Fibrosierung wird zum Teil durch Inflammationsprozesse hervorgerufen (Kai et al. 2005).

Insbesondere kommt es zu molekularen Umstellungsprozessen im Herzen. Dabei zeigt sich eine Veränderung des Genexpressionsmusters und somit eine Änderung des Kardiomyozytenphänotyps. Diese Änderungen finden unter anderem im Bereich des Energiestoffwechsels (Razeghi et al. 2001), dem Zytoskelett, der extrazellulären Matrix (Heling et al. 2000), der Ionenkanäle (Kääb et al. 1998), der Kalzium-regulierenden und kontraktilen Proteine statt. Die Veränderungen im Bereich der kontraktilen Proteine resultieren in einer reduzierten Kontraktilität (Alpert und Gordon 1962). Die Kalziuminduzierte Kontraktionskraft bleibt unbeeinflusst (Hajjar et al. 1992, Denvir et al. 1995). Die Reduktion der Kontraktionskraft ist auf eine Änderung des intrazellulären Kalziumflusses zurückzuführen. Diesem liegen Veränderungen der Expression der Kalzium-regulierenden Proteine zugrunde. Es zeigt sich im Stadium des Herzversagens eine verminderte SERCA-Expression (Hasenfuß et al. 1994, Dash et al. 2001), eine gesteigerte NCX-Expression (Studer et al. 1994, Flesch et al. 1996) und ein RYR-Leck in der Diastole (Lindner et al. 2002).

\subsection{Signalwege}

\subsubsection{Einführung}

Bei der Entstehung einer kardialen Herzinsuffizienz ist eine Vielzahl von Mechanismen beteiligt. Einerseits spielen sowohl eine lokale als auch eine systemische Freisetzung von neurohumoralen Substanzen eine Rolle (Sadoshima et al. 1993), andererseits kann aber auch die bloße Dehnung (Akazawa und Komuro 2003, Lammerding et al. 2004) eine Herzinsuffizienz verursachen. In den letzten Jahren sind viele intrazelluläre Signalwege beschrieben worden, die an diesem Prozess beteiligt sind (Opie et al.

2006,

Dorn

2009). 


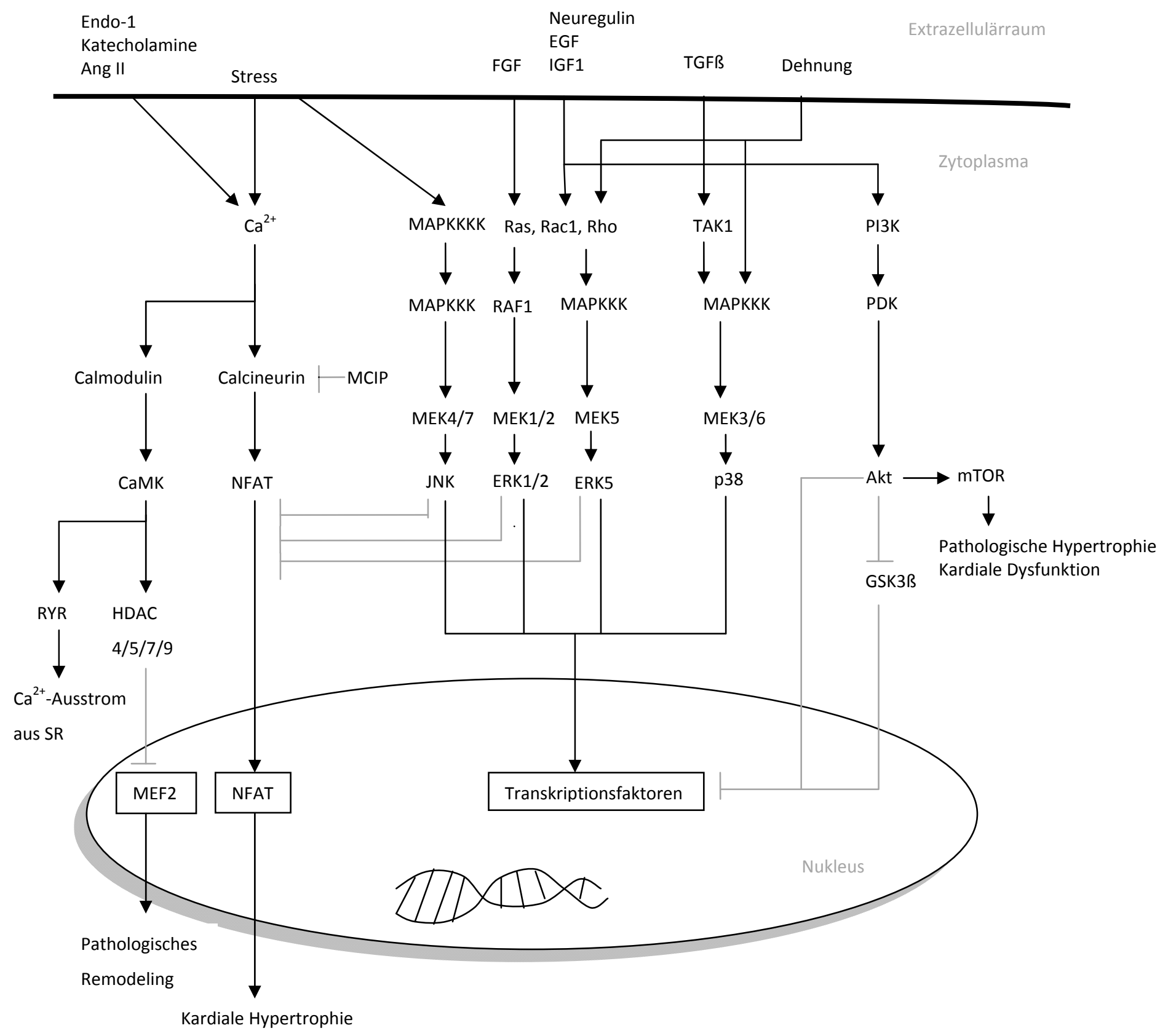

Abbildung 2: Schematische Darstellung der adaptiven und maladaptiven Signalwege (Akt=Proteinkinase B, Ang $\mathrm{II}=$ Angiotensin II, $\mathrm{Ca}^{2+}=$ Kalzium, CaMK= Kalzium-Calmodulin-abhängige Proteinkinase, EGF=epidermaler Wachstumsfaktor, Endo-1=Endothelin 1, ERK= extrazelluläre Signal-regulierende Kinase, FGF=FlbroblastenWachstumsfaktor, GSK3ß= Glykogen-Synthase-Kinase-3ß HDAC=Histon-Deacetylase, IGF1=insulin-like growth factor 1 , JNK= c-Jun N-terminale Kinase, MAPKKK=mitogen aktivierte Proteinkinasekinasekinase, MAPKKKK=mitogen aktivierte Proteinkinasekinasekinasekinase, MCIP=modulatorisches Calcineurininteragierendes Protein, MEF2=myocyte enhancer factor, $\mathrm{MEK}=$ mitogen-aktivierte Proteinkinasekinase, $\mathrm{mTOR}=$ mammalian target of Raptomycin, NFAT= nuclear factor of activated T-cells, PDK=Phosphoinositol-abhängige Kinase, PI3K= Phosphatidylinositol-3-Kinase, RYR=Ryanodin-Rezeptor, TGFß=transformierender Wachstumsfaktor ß) (modifiziert nach Heineke und Molkentin 2006, Seite 591). 
Lange Zeit ging man davon aus, dass einer Herzinsuffizienz immer eine Herzhypertrophie vorausgeht (Levy et al. 1990). Diese These wurde aber experimentell nicht bestätigt, da durch pharmakologische Blockaden einiger zellulärer Signalwege sowohl die Entstehung einer Herzinsuffizienz (Meguro et al. 1999, Oie et al. 2000) als auch ein Ausgleich der hämodynamischen Belastung ohne vorherige Myokardhypertrophie gezeigt werden konnten (Hill et al. 2000, Esposito et al. 2002). Nun geht man davon aus, dass adaptive und maladaptive Signalwege in den Myokardzellen im Gleichgewicht zueinander stehen (Lips et al. 2003, Selvetella et al. 2004). Bei einer Verschiebung zu Gunsten der maladaptiven Signalwege entsteht eine kardiale Insuffizienz.

\subsubsection{Adaptive Signalwege}

\subsubsection{Akt/GSK3ß}

Die Phosphatidylinositol-3-Kinasen (PI3Ks) bilden eine Enzymfamilie, der im Zellwachstum und der Differenzierung der Kardiomyozyten eine kardioprotektive Rolle zugesprochen wird. Hier sind zwei wichtige Gruppen zu nennen: PI3K der Gruppe IA (PI3K $\alpha$ ) und PI3K der Gruppe B (PI3K ß).

Durch Bindung der PI3K an Pleckstrin-homologe Domänen der Phosphoinositol-abhängigen Kinase 1 (PDK1) wird diese aktiviert (Cantley 2002). Die Annäherung der PDK1 an die Proteinkinase B (Akt) verursacht die Phosphorylierung von PDK1 und die Aktivierung Akts (Cantley 2002). Für Akt sind drei verschiedene Genexpressionen bekannt, von denen Akt1 und Akt2 bevorzugt kardial exprimiert werden. Akt1 werden etwa kompensatorische Fähigkeiten bei erhöhter Druckbelastung des Herzens zu gesprochen (DeBosch et al. 2006). Allgemein scheint der Akt-Signalweg eine bedeutende Rolle im physiologischen Wachstum des Herzens einzunehmen (DeBosch et al. 2006).

Nukleäre Überexpression von Akt führt bei Mäusen zu einer Hypertrophie und hat einen protektiven Effekt bei Ischämie (Shiraishi et al. 2004, Rota et al. 2005). Im Akt1-Knock-Out (KO)-Modell zeigt sich bei Druckbelastung eine geringere Ausprägung der pathologischen Hypertrophie (DeBosch et al. 2006). Allerdings werden dem Akt-Weg vereinzelt auch maladaptive Effekte zugeschreiben. So wurde gezeigt, dass eine Überexpression des Akt-Signalweges über sechs Wochen zur Hypertrophie und Dilatation sowie zu histopathologischen Veränderungen in der kardialen Struktur führt (Shiojima et al. 2005).

Ein wichtiges Ziel des Akt-Signalweges ist die Glykogen-Synthase-Kinase-3ß (GSK3ß). Durch Phosphorylierung von Akt wird diese Kinase inaktiviert, die im aktiven Zustand den Translationsfaktor elF2B inhibiert. Zudem hat sie einen hemmenden Effekt auf die Hypertrophie-Transkiptionsfaktoren ßCatenin, c-Myc, nuclear factor of activated T-cells (NFAT) und GATA4 (Cantley 2002, Proud 2004). Die aktive GSK3ß antagonisiert die Calcineurinwirkung auf NFAT durch eine Phosphorylierung von NFAT. 
Es folgt ein verminderter NFAT-Export aus dem Kern und weiterhin eine Hemmung der kardialen Hypertrophie unter Druckbelastung (Antos et al. 2002, Sanbe et al. 2003).

Ein weiteres wichtiges Ziel des Akt-Signalweges ist mammalian target of Raptomycin (mTOR). Durch mTOR-Aktivierung findet eine Verbesserung der Proteinsynthese über die zwei Signalwege p70/85 / S6 Kinase-1 und p54/56 / S6K2 statt (Cantley 2002, Proud 2004). Die Blockierung von mTOR verhindert sowohl eine pathologische Hypertrophie als auch eine kardiale Dysfunktion (McMullen et al. 2004, Shiojima et al. 2005). Die Blockierung mTORs könnte somit einen therapeutischen Nutzen haben.

Insgesamt ist das therapeutische Potenzial des Akt-Signalweges und seiner abhängigen Komponenten noch umstritten, da viele der Faktoren ambivalente Effekte zeigen.

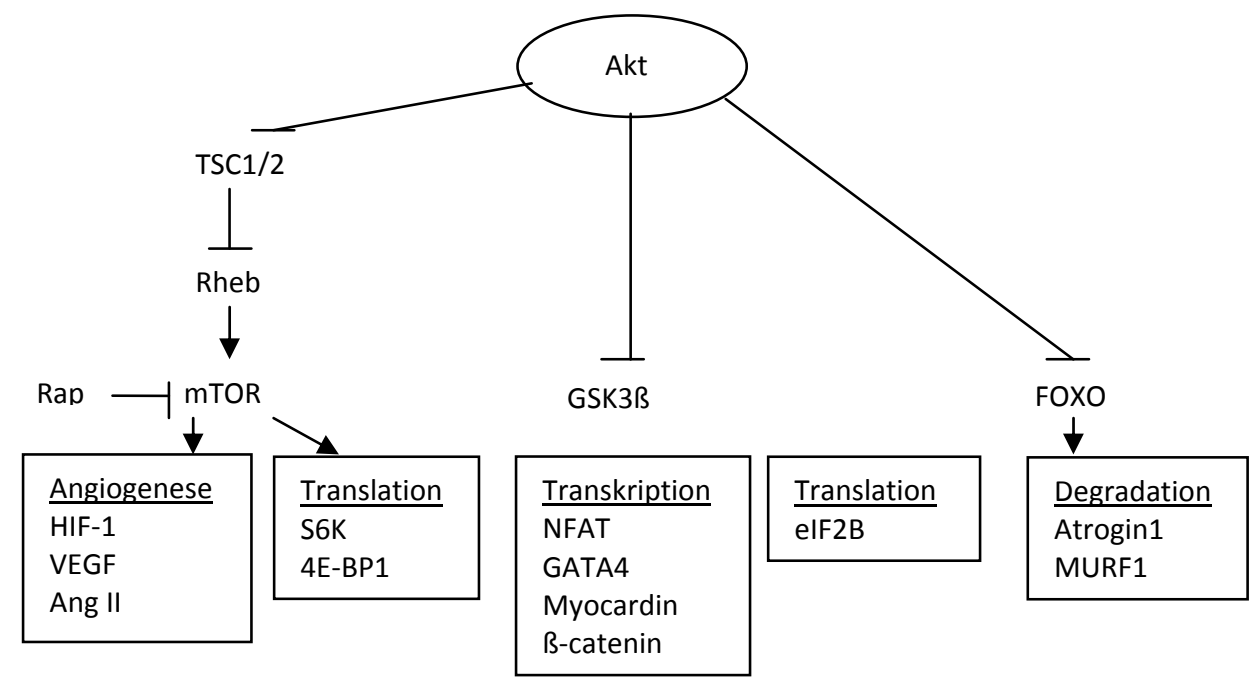

Abbildung 3: Akt-abhängige Signalwege (modifiziert nach Shiojima und Walsh 2006, Seite 3353).

\subsubsection{ERK}

Die extrazellulären Signal-regulierenden Kinasen (ERKs) gehören zur Familie der mitogenaktivierten Kinasen (MAPK) (1.6.3.3) und werden in fünf verschiedene Untergruppen eingeteilt.

Die Aktivierung von ERK1 und ERK2 erfolgt durch deren Phosphorylierung durch vorgeschaltete mitogenaktivierte Proteinkinasenkinasen (MEK) 1 und 2 (Bueno et al. 2000). Bei Überexpression der MEK1 und MEK2 kommt es zu einer adaptativen konzentrischen Hypertrophie des Herzens. Die Interaktion mit dem Calcineurin/NFAT-Signalweg führt ebenfalls zu einer kardialen Hypertrophie (Sanna et al. 2005). Der MEK5/ERK5-Signalweg führt zu einer Vermehrung der in Serie geschalteten kardialen Sarkomere und zu einem exzentrischen dilatativen Wachstum (Nicol et al. 2001). 


\subsubsection{Maladaptive Signalwege}

\subsubsection{Calcineurin/NFAT}

Calcineurin ist eine Kalzium-abhängige Serin/Threonin-Phosphatase, die eine zentrale Rolle in der Stimulation der Myokardhypertrophie spielt (Molkentin et al. 1998). Calcineurin besteht aus einer 57 bis 61 kiloDalton $(\mathrm{kDa})$ großen katalytischen Untereinheit $(\mathrm{CnA})$ und einer $19 \mathrm{kDa}$ großen regulatorischen Untereinheit (CnB). Durch Erhöhung des intrazellulären Kalzium-Spiegels bindet Calcineurin an Calmodulin und dephosphoryliert so Transkriptionsfaktoren der NFAT-Familie. Die Dephosphorylierung initiiert eine Verschiebung der NFAT-Transkriptionsfaktoren in den Zellnukleus und es kommt zu einer Aktivierung der prohypertrophen Genexpression (Wilkins und Molkentin 2004, S. 1178-1191). Die Phosphorylierung der NFAT-Transkriptionsfaktoren durch Kinasen wie GSK3ß, JNK (c-Jun Nterminale Kinase) und p38 antagonisiert die Translokation in den Zellnukleus (Antos et al. 2002, Braz et al. 2003, Liang und Molkentin 2003).

Bei einer gesteigerten Aktivierung von Calcineurin kommt es zu einer Zunahme der Modulatory calcineurin-interacting protein-Expression (MCIP). MCIP hat eine inhibitorische Wirkung auf Calcineurin und verhindert dessen hypertrophe Wirkung (Rothermel et al. 2001, Hill et al. 2002). Dieser inhibitorische Effekt tritt vor allem bei hohen MCIP-Konzentrationen auf. Besonders in späten Stadien der Herzinsuffizienz scheint das Herz von einer MCIP-Überexpression und dessen inhibitorischen Effekt zu profitieren (Nicol et al. 2001). Eine Überexpression von MCIP1 verhindert eine hypertrophe Antwort des Herzens, unterdrückt die Entstehung einer kardialen dilatativen Kardiomyopathie und stabilisiert die kardiale Funktion (Rothermel et al. 2001, Hill et al. 2002). In physiologischen Konzentrationen scheint MCIP ein Bindeglied zwischen Calcineurin und dessen Zielort zu sein und ist in der Lage, unter bestimmten Bedingungen die Calcineurin-Aktivität zu steigern (Vega et al. 2003, Sanna et al. 2006). Die Verwendung des Calcineurin-Inhibitors Cyclosporin A zeigte einerseits eine Verhinderung (Oie et al. 2000) und andererseits eine schnellere Entwicklung (Meguro et al. 1999) einer Herzinsuffizienz.

Die Überexpression von NFAT oder Calcineurin führt in transgenen Mäusen zu einer kardialen Hypertrophie (Molkentin et al. 1998). Die Analysen der Proben von insuffizienten Herzen zeigten eine Erhöhung des Calcineurin A (Lim und Molkentin 2000), die allerdings nicht so deutlich war wie im kardialen hypertrophen Gewebe (Haq et al. 2001). 


\subsubsection{CaMK}

Das kardiale Remodeling wird maßgeblich auf eine Störung des intrazellulären Kalziumstoffwechsels zurückgeführt (Frey und Olson 2003).

Die Kalzium-Calmodulin-abhängige Proteinkinase II (CaMK II) ist an der Regulation des intrazellulären Kalziums durch Wirkung auf verschiedene Schlüsselproteine maßgeblich beteiligt (Dzhura et al. 2000, Wehrens et al. 2004). Die Phosphorylierung des sarkoplasmatischen Schlüsselrezeptors RYR verursacht einen permanenten Kalzium-Ausstrom und führt zu einem Kalzium-Verlust (Ling et al. 2009). CaMK II ist im Herz die dominante Form (Zhang T und Brown 2004). Eine CaMK IIס-Überexpression führt zu Hypertrophie, Störung des intrazellulären Kalzium-Stoffwechsels, kardialer Dilatation und frühzeitigem Tod (Maier et al. 2003, Zhang T et al. 2003, Zhang T et al. 2007).

Der Transkriptionsfaktor myocyte enhancer factor 2 (MEF2) ist ein wichtiges Ziel der CaMK. Der Mechanismus der MEF2-Aktivierung läuft über die CaMK-vermittelte Phosphorylierung von HistonDeacetylasen (HDACs) (Passier et al. 2000, Backs et al. 2006). HDAC4 ist als Transkriptionsrepressor (Backs und Olson 2006) im druckbelasteten Modell am pathologischen Kalzium-Stoffwechsel beteiligt. Nach Phosphorylierung von HDAC4 durch CaMK II dissoziiert der Transkriptionsrepressor vom Transkriptor MEF2 ab und wandert in das Zytoplasma der Zelle ein (Backs et al. 2006). MEF2D ist in seinem aktivierten Zustand am pathologischen Remodeling beteiligt (Kim et al. 2008), da es eine Expression von verschiedenen Hypertrophie-Genen induziert (Zhang T et al. 2007). HDAC5 ist ein weiteres Mitglied der HDAC-Familie und wird ebenfalls mit einer druckinduzierten kardialen Hypertrophie in Verbindung gebracht. Bei Verlust der CaMK II kann HDAC5 auch von CaMK IIY (Ling et al. 2009) oder der Proteinkinase D (PKD) (Vega et al. 2004) phosphoryliert und aktiviert werden.

\subsubsection{MAPK}

Auch die mitogenaktivierten Proteinkinasen (MAPK)-Signalwege sind wichtige Verbindungen zwischen den externen Stimuli und der kardialen Hypertrophie. Die MAPK bilden eine Familie, die sich aus p38, JNKs und ERKs zusammensetzt (Garrington und Johnson 1999).

Die Signalwege werden durch membrangebundene G-Protein-gekoppelte Rezeptoren (GPCRs), Thyrosinkinase-Rezeptoren (insulin-like growth factor (IGF1), Fibroblasten-Wachstumsfaktoren), Cardiotropin-1 (gp 130-Rezeptor), Serin/Threonin-Kinase-Rezeptoren (transforming growth factor $\beta$ (TGFß)) und durch Dehnung des Myokards initiiert (Sugden und Clerk 1998a). Die Signaltransduktion ist ein komplexes Netzwerk von verschiedenen vorgeschalteten Kinasen, die durch drei Faktoren reguliert werden: Stressstimulation, anderen mitogenaktivierten Proteinkinasenkinasen oder Molekülen wie Rho, Ras, Rac und CDC42 (Weston et al. 2002). Die vorgeschalteten Kinasen aktivieren durch Phosphorylierung die drei Unterfamilien (Garrington und Johnson 1999). p38, JNKs und ERKs 
veranlassen durch Phosphorylierung weiterer Transkriptionsfaktoren die Expression hypertropher Gene (Sugden und Clerk 1998b). ERKs haben überwiegend adaptive Effekte (siehe 1.6.2.2).

\subsubsection{1 p38}

p38 wird über verschiedene Enzyme reguliert. Eine Aktivierung des p38-Signalweges resultiert in einer kardialen Hypertrophie (Clerk et al. 1998, Sugden und Clerk 1998b). Die Überexpression von MAPKinasekinase (MKK) 3 und MKK6 führen über die Aktivierung von p38 zu dilatativer Herzinsuffizienz mit Fibrosierung des Arbeitsmyokards, Verdünnung der Ventrikelwände und Reduzierung der kardialen Funktion (Liao et al. 2001). Ein weiterer Regulator der p38 ist die TGFß-aktivierte Kinase (TAK1), unter dessen vermehrter Expression es zu einer Kardiomyopathie kommt (Zhang D et al. 2000).

\subsection{JNK}

JNKs werden durch Erhöhung der kardialen Belastung oder durch membranständige Rezeptoren wie z.B. Rho aktiviert (Davis 2000). Die isolierte JNK-Aktivierung durch MKK7 führt zu einer Kardiomyopathie ohne vorausgegangene Dilatation (Petrich et al. 2002).

Der Verlust des JNK1/JNK2-Gens bzw. die Inhibition des endogenen JNKs resultiert in einer kardialen Hypertrophie. Weiterhin kommt es unter diesen Umständen in Folge einer Drucksteigerung zur Aktivierung des Calcineurin/NFAT-Signalweges (Liang et al. 2003). Der Verlust von JNK1 in einem nachlasterhöhten Herz zeigt sich in einer Minderung der kardialen Funktion und einem Anstieg von TdTmediated dUTP nick end labeling (TUNEL)-positiven Zellen, die eine erhöhte Apoptoserate im Gewebe anzeigen (Tachibana et al. 2006). Weitere Studien zeigen allerdings eine geringere Apoptoserate nach Ausschaltung von JNK1 und JNK2 in Folge von ischämischer Schädigung des Myokards (Kaiser et al. 2005). Die Phosphorylierung des NFAT-Signalweges durch p38 und JNK hat einen reduzierenden Effekt auf die kardiale Hypertrophie (Molkentin 2004). Der JNK-Signalweg zeigt somit pro- und antiapoptotische Wirkungen im Myokard (Kaiser et al. 2005).

\subsection{Fragestellungen der Dissertation}

Anhand eines Volumenbelastungs- und eines Druckbelastungsmodells soll die unterschiedliche kardiale Hypertrophie untersucht werden. Dabei stellen sich folgende Fragen:

- Ist die kardiale Expression des Hypertrophiemarkers BNP in den beiden Modellen vergleichbar?

- Welche adaptiven Signalwege sind in den beiden Modellen aktiviert?

- Welche maladaptiven Signalwege sind in den beiden Modellen aktiviert? 


\section{Material und Methoden}

\subsection{Interventionsmodelle}

\subsubsection{Versuchstiere}

Die in dieser Arbeit verwendeten Tiere wurden gemäß dem Guide for the Care and Use of Laboratory Animals (National Institutes of Health Publication Nr. 85-23, überarbeitet 1996) behandelt. Die operativen Eingriffe (Anlage des aorto-kavalen Shunts und der transversen aortalen Konstriktion sowie die Scheinoperationen) wurden an Mäusen durchgeführt und im Voraus bei der zuständigen Tierschutzbehörde gemeldet (G49.04.). Für die Experimente wurden 12 Wochen alte weibliche FVB/NMäuse verwendet.

\subsubsection{Aorto-kavale Shunt-Operation (Shunt-Modell)}

Das Ziel der aorto-kavalen Shunt-Operation war die Simulation einer Vorlasterhöhung im linken Ventrikel. Hierbei wurde eine Verbindung zwischen der Aorta abdominalis (infrarenal) und der Vena cava inferior angelegt. Das Vorgehen bei der Operation orientierte sich am Protokoll von Garcia und Diebold (1990).
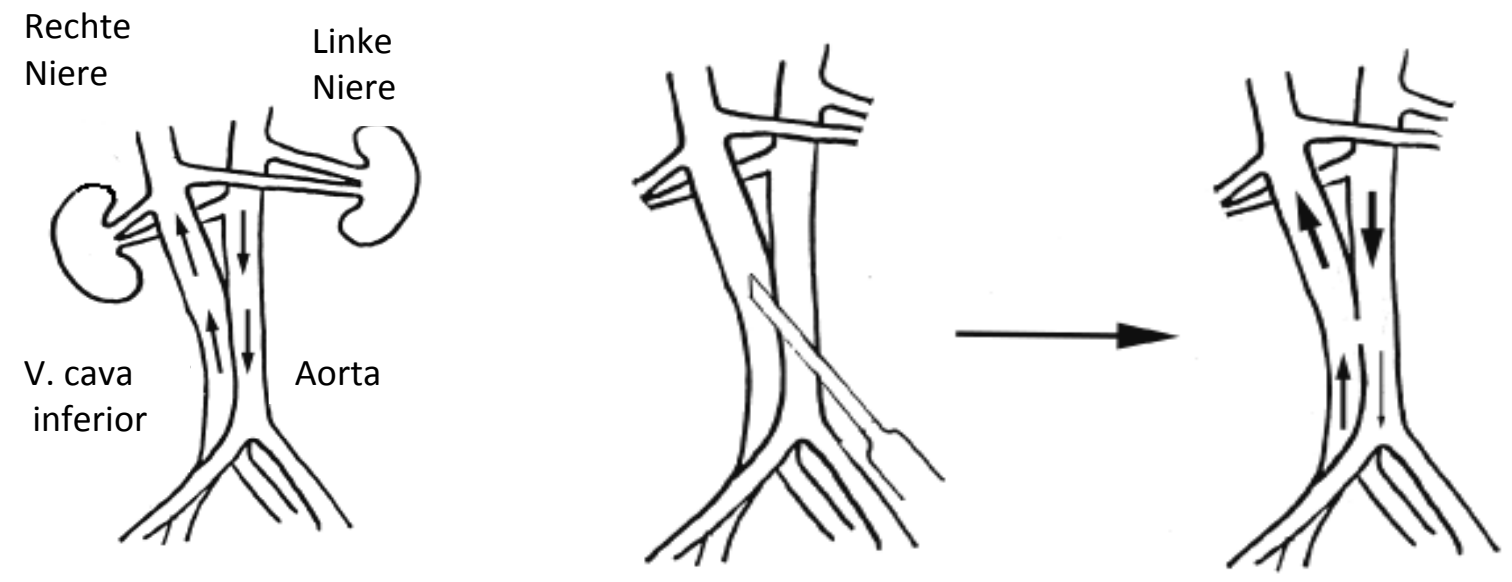

Abbildung 4: Prinzip einer Anlage des aorto-kavalen Shunts zur Simulation einer Vorlasterhöhung im linken Ventrikel (nach Rettschlag 2003, Seite 30).

Nach erfolgreicher Anästhesie mit Isofluran wurden die Mäuse endotracheal intubiert und auf dem Operationstisch fixiert. Die Tiere wurden während der Operation mit 100 \% Sauerstoff und Isofluran über ein Beatmungssystem versorgt. In der darauffolgenden ventralen abdominalen Laparotomie wurden die intraperitoneal liegenden Organe ausgelagert und der Retroperitonealraum eröffnet. Nach Darstellung der Gefäße wurde die Aorta abdominalis kurzzeitig abgeklemmt und mit einer Na- 
del (23G) lateral in die Aorta abdominalis eingestochen, um diese bis in die Vena cava inferior vorzuschieben. Nach Rückzug der Nadel wurde die an der Aorta abdominalis entstandene laterale Einstichstelle mit Cyanacrylatklebstoff (Pattex, Düsseldorf) verschlossen. Danach wurde durch Lösung der Klemme die Blutzirkulation in der Aorta wiederhergestellt. Der Verschluss der Bauchhöhle erfolgte mit Einzelknopfnähten in zwei Schichten.

Eine erfolgreiche Shunt-Anlage konnte bereits während der Intervention zum einen durch das Anschwellen der Vena cava inferior und zum anderen durch die Aufhellung des Blutes im venösen Systemteil des Shunts beurteilt werden. Bei Versuchsende wurde die Effizienz der Shunt-Anlage mit Hilfe einer Messung der rechtsventrikulären Sauerstoffsättigung erneut evaluiert. Tiere mit einer Sauerstoffsättigung über 90 \% wurden in die anschließenden Analysen eingeschlossen. Als Referenz wurde eine Gruppe von scheinoperierten Tieren (Sham-Gruppe) verwendet. Diese Tiere wurden der gleichen Operationsprozedur unterzogen, erhielten aber keine Shunt-Anlage. Nach der Operation erfolgte die Überwachung bis zum Erlangen des vollen Bewusstseins aller Tiere. Sowohl Sham- als auch Shunt-Tiere wurden postoperativ für 7 Tage analgetisch mit Novaminsulfon (Ratiopharm, Ulm) therapiert.

\subsubsection{Transverse aortale Konstriktions-Operation (TAC-Modell)}

Die transverse aortale Konstriktion (TAC) war das zweite Interventionsmodell. Bei diesem Modell kam es durch die Konstriktion der Aorta ascendens zu einem Anstieg der Nachlast und somit zu einer erhöhten Druckbelastung des linken Ventrikels. Die Operation wurde nach Rockman et al. modifiziert (1991).

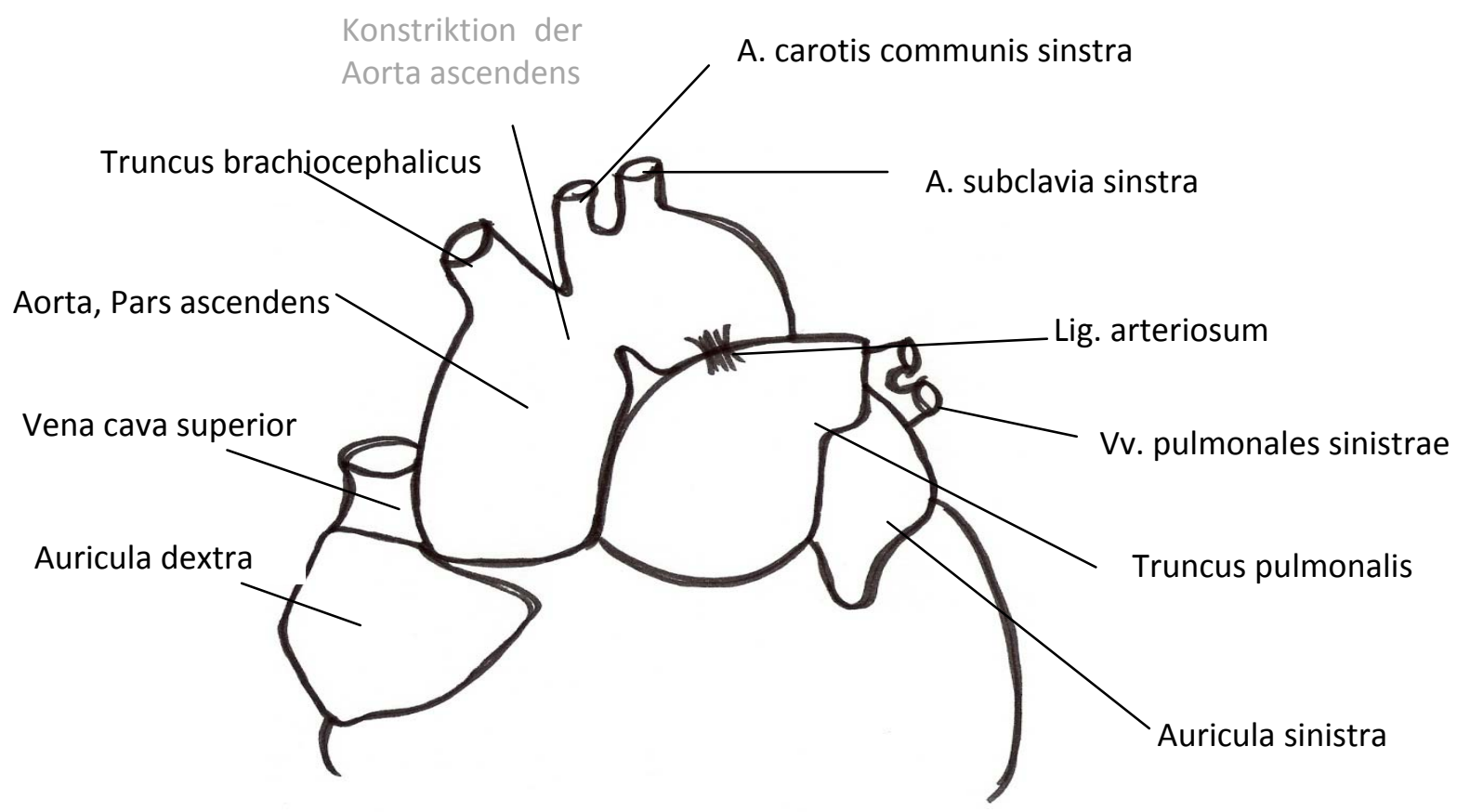

Abbildung 5: Prinzip einer transversen aortalen Konstriktion (modifiziert nach Schünke et al. 2005, Seite 102). 
Zur Narkotisierung wurde den 12 Wochen alten weiblichen Mäusen eine intraperitoneale Injektion mit Ketanest S (Pfizer, Berlin) und Xylazin 2 \% (Bernburg Serumwerk AG, Bernburg) im Verhältnis 100 $\mathrm{mg} / \mathrm{kg}$ (Ketanest) und $5 \mathrm{mg} / \mathrm{kg}$ (Xylazin) gegeben. Nach Fixierung der Tiere in Rückenlage erfolgte die Eröffnung des Mediastinalraums suprasternal unter stereomikroskopischer Sicht. Die Darstellung des Arcus aortae mit den Abgängen des Truncus brachiocephalicus und der Arteria carotis communis erfolgte durch stumpfe Abpräparation. Das Freilegen des Operationsgebietes mit Lösung des Bindegewebes von der Aorta ermöglichte das Umlegen der Region zwischen der Arteria communis und dem Truncus brachiocephalicus mit einem Faden. Als Platzhalter wurde eine Nadel (27G) zwischen Faden und Aorta gelegt. Dieser wurde angezogen und mehrfach verknotet. Hiernach wurde die 27GNadel als Platzhalter wieder entfernt. Der Verschluss des Mediastinalraums erfolgte mit Einzelknopfnähten. Um die Ergebnisse nachher mit einer Referenzgruppe vergleichen zu können, wurden auch hier Mäuse scheinoperiert. Diese Sham-Gruppe wurde dem gleichen Operationsprozess unterzogen, allerdings ohne Reduktion des aortalen Durchmessers. Sowohl Sham- als auch TAC-Tiere erhielten eine einwöchige postoperative Behandlung mit Novaminsulfon.

\subsection{Echokardiographische Untersuchungen}

Die echokardiographischen Untersuchungen (VS-VEVO 660/230 High Resolution Imaging System (Visualsonics, Toronto, Kanada)) wurden im 2D gekoppelten M-Mode durchgeführt. Das Protokoll dieser Untersuchungen folgte Schmidt et al. (2000). Nach Narkotisierung der Tiere durch intraperi-toneale Injektion von 2,5 \% 2-2-2 Tribromoethanol (Avertin ${ }^{\circledR}, 0,01 \mathrm{ml} / \mathrm{g}$ ), welche eine weitere Spontanatmung zuließ, erfolgten die Messungen des LVEDD und des LVESD. Die Leitlinien der American Society of Echocardiography wurden eingehalten. In der Abteilung Kardiologie, Universitätsmedizin Göttingen, wurden die echokardiographischen Untersuchungen von Herrn Michael Kothe (Abteilung Kardiologie, Universitätsmedizin Göttingen) durchgeführt.

\subsection{Hämodynamische Messungen in vivo}

\subsubsection{Linksventrikuläre Druck- und Volumen-Messungen mittels Konduktionskatheter}

Zur in-vivo-Messung der hämodynamischen Parameter wurden die Tiere zunächst mit Isofluran narkotisiert und dann intubiert. Nach Intubation wurden die Tiere mit dem Volumen-kontrollierten MiniVent-Beatmungssystem (150 $\mu \mathrm{l}, 150$ Atemzüge pro Minute) und unter Isofluran-Inhalationsnarkose (1,5 \% vol.) beatmet. Die Tiere wurden auf einem Tierbewärmungssystem unter konstanter rektaler 
Körpertemperatur-Überwachung (TKM 0903, FMI GmBH, Seeheim) gelagert und bei $37^{\circ} \mathrm{C}$ gehalten. Durch einen zervikalen Mittelschnitt wurde die Aorta carotis communis dextra freigelegt und punktiert. Die Einbringung des Katheters erfolgte nach distaler Ligatur und proximaler Abklemmung des Gefäßes. Zur Sicherung des Katheters wurde eine weitere Ligatur um das Gefäß gelegt und die proximale Abklemmung wieder gelöst. Dann wurde der Katheter im linken Ventrikel platziert und die Druck- und Volumen-Messungen durchgeführt. Zum Ende des Experiments erfolgte die Verabreichung von $10 \mu$ einer 5 \%igen Kochsalzlösung intravenös über eine 30G Kanüle in die Vena jugularis sinistra. Die Tötung der Tiere erfolgte durch zervikale Dislokation nach Entfernung des Katheters.

\subsubsection{Berechnung der Hämodynamik und der kardialen Funktion}

\subsubsection{Berechnung der Wandspannung mit Hilfe des Laplace-Gesetzes}

Die Berechnung der Wandspannung im linken Ventrikel wurde mit Hilfe des Laplace-Gesetzes durchgeführt: $\quad K=P \times r / 2 d$

( $K$ = Wandspannung, $P=$ Druck im linken Ventrikel während der Systole oder Diastole, $d=$ Wandstärke, $r$ = Hälfte des LVEDD oder LVESD während der Anspannungs- und Austreibungsphase der Systole, der Erschlaffungs- und Füllungsphase der Diastole).

Die Druckwerte wurden durch die invasiven hämdynamischen Messungen und der Wanddicke bzw. dem Ventrikelradius echokardiographisch bestimmt. Insgesamt wurde zu vier Zeitpunkten die Wandspannung bestimmt (enddiatolisch, mitsystolisch, endsystolisch, mitdiastolisch).

\subsubsection{Berechnung der mittleren Wandspannung}

Aus der systolischen und diastolischen Wandspannung wurde unter Berücksichtigung der Dauer der Systole $\left(W S_{\text {sys }}\right)$ und der Diastole $\left(W S_{\text {dia }}\right)$ eine mittlere Wandspannung $\left(W S_{\text {mean }}\right)$ für den ganzen Kontraktionszyklus berechnet. Dies erfolgte mit Hilfe der folgenden Formel:

$W S_{\text {mean }}=W_{\text {sys }} * t_{\text {sys }}+W S_{\text {dia }} * t_{\text {dia }}$

mit

$\mathrm{WS}_{\mathrm{sys}}=\operatorname{mean}\left[\mathrm{WS}(1)+\mathrm{WS}_{(2)}+\mathrm{WS}_{(3)}\right]$ und $\mathrm{WS}_{\mathrm{dia}}=\operatorname{mean}\left[\mathrm{WS}(4)+\mathrm{WS}_{(1)}\right]$

$t_{\text {sys }}$ bzw. $t_{\text {dia }}$ gab die Länge der Systole bzw. Diastole in einem kompletten kardialen Zyklus an.

\subsubsection{Berechnung der fraktionellen Verkürzungsfraktion}

Die Pumpfunktion des linken Ventrikels wird durch die fraktionelle Verkürzungsfraktion (FS) quantifiziert. Die FS wird durch folgende Gleichung berechnet:

$\mathrm{FS}[\%]=\left[\left(\right.\right.$ LVEDD-LVESD)/LVEDD ${ }^{*} 100$. 


\subsection{Entnahme der Mäuseherzen}

Nach Betäubung mit Isofluran und anschließender Tötung der Tiere wurden die Herzen durch Eröffnung des Thorax dargestellt. Nach Abtrennung der Gefäße und Entfernung des restlichen Blutes erfolgten die Abtrennung der Vorhöfe und die Separierung des rechten vom linken Ventrikel. Dabei wurde eine Gewichtsbestimmung des gesamten Herzens und des linken Ventrikels vorgenommen. Zur Hypertrophiebeurteilung wurde dieses Gewicht auf die Tibia-Länge (gemessen an der präparierten Tibia) normalisiert. Die Gewebeproben wurden dann in flüssigem Stickstoff schockgefroren oder fixiert.

Alle sich hier anschließenden Untersuchungen erfolgten an linksventrikulären Proben.

\subsection{Histologische Aufarbeitung}

Die histologische Aufarbeitung der Mäuseherzen-Gewebe nach Gefrierfixation in flüssigem Stickstoff erfolgte mittels eines Standardverfahrens. Aus den entstandenen Gefrierblöcken wurden $2 \mu \mathrm{m}$ dicke Schnitte gefertigt und danach auf Objektträger gebracht. Die angefertigten Schnitte wurden in vorgefrorenem Aceton 10 Minuten bei $-20^{\circ} \mathrm{C}$ fixiert und anschließend unter dem Abzug getrocknet. Die Schnitte wurden mit PAP PEN Mini eingekreist. Dies verhindert das Verfließen der folgenden aufzutragenden Lösungen. Abschließend wurde eine Waschung in PBS für 5 Minuten durchgeführt.

\subsubsection{Kaspase-3-Aktivitätsbestimmung}

Die Kaspase-3-Immunreaktion (Antikörper \#G7481, Promega, Madison, WI) wurde an fixierten Schnitten durchgeführt. Nach Behandlung mit einem Sekundärantikörper erfolgte die Visualisierung des Signals mittels einer Diaminobenzidin-Reaktion (Nakajima et al. 2004). Ausgewertet wurde die Anzahl an Kaspase-3-positiven Zellen pro $\mathrm{mm}^{2}$.

Die Inaktivierung der endogenen Peroxidase erfolgte mittels eines 3 \%igen WasserstoffperoxidMethanol-Gemisches für 5 Minuten bei Raumtemperatur (RT). Nach Waschung in PBS-T (PBS mit 0,2 \% Triton X-100) für 3x5 Minuten wurden die Proben getrocknet. Die Blockung von Bindungsstellen und die Antikörper-Inkubation erfolgten in PBS mit Ziegenserum für 30 Minuten bei RT. Es folgte die 2- bis 4-stündige Inkubation des Kaspase-3-Antikörpers bei RT. Danach wurden die Schnitte in PBS $3 \times 5$ Minuten gewaschen. Nach 30-minütiger Inkubation des sekundären Antikörpers (IgG) erfolgte eine erneute Waschung in PBS für 3x5 Minuten. Der dritte Antikörper (Gemisch aus Avidin und biotinylated horse-radish peroxidase macromolecular) wurde für 30 Minuten bei RT aufgetragen. Es folgte eine Waschung in PBS in 3x5 Minuten. Die apoptotischen Zellen wurden mit einer Diaminobenzidin-Reaktion (Inkubation: 30 Sekunden bis 1 Minute) visualisiert. 


\subsubsection{Sirius-Rot-Färbung}

Die Färbung der histologischen Schnitte mit Sirius-Rot wurde zur Quantifizierung der Kollagenanteile und somit zur Darstellung der fibrotischen Areale durchgeführt. Nach Wässerung der Schnitte für 5 Minuten wurden diese für 1 Stunde in 1 \% Pikrosirus gefärbt und danach in Aqua destillata (A. dest.) gespült. Mittels einer aufsteigenden Alkoholreihe wurde den Schnitten Wasser entzogen. Danach wurden sie 2x5 Minuten in Xylolersatzmittel getaucht und eingedeckt.

Die Quantifizierung des kollagenen Gewebes erfolgte mittels digital angefertigten Bildern. Die rot angefärbten Anteile des Gewebes wurden mit Adobe Photoshop 5 und Scion Images for Windows Beta 4.0.2 gemessen. Nach randomisierter Auswahl erfolgte die Vermessung von mindestens 400 Kardiomyozyten eines Versuchstieres.

\subsubsection{CD45 ${ }^{+}$-immunhistochemische Methode}

Mit der $\mathrm{CD}^{+} 5^{+}$-immunhistochemischen Methode ist die Erfassung von CD45 ${ }^{+}$-Antikörpern (gegen Leukozyten) (Trowbridge und Thomas 1994) und somit einer Inflammation des Gewebes möglich.

Zu Beginn der immunhistochemischen Färbung wurden die freien Antigene 30 Minuten lang mit $40 \mu \mathrm{l}$ 1 \% BSA (Albumin, Bovine Fraction V Solution 7,5 \%, Sigma-Aldrich, Chemie GmbH, Taufkirchen) bei $\mathrm{RT}$ in PBS geblockt.

Nach Entfernung der Lösung folgte die Inkubation mit dem Primärantikörper (monoclonal rat antimouse antibodies, Klon 30-F11, sc-53665, Abcam, Cambridge, USA; Verdünnung 1:75 in PBS) für 1 Stunde bei RT. Nach 3×5-minütiger Waschung in PBS erfolgte die Inkubation des Sekundärantikörpers über Nacht bei $4{ }^{\circ} \mathrm{C}$ (goat anti-rat antibodies, Molecular Probes, invitrogen, Darmstadt; Verdünnung 1:400 in PBS). Anschließend wurden ungebundene Antikörper mit PBS abgewaschen. Für die Anfärbung der Kerne wurde der Farbstoff Diamidino-4',6'-phenyl-2-indoledichlorhydrat 5 (DAPI, SigmaAldrich, Steinheim; Verdünnung 1:200) verwendet, der 30 Minuten im Dunkeln bei RT inkubierte. Die letzte Waschung wurde mit PBS 3x5 Minuten durchgeführt. Für die Einbettung der Schnitte wurde Vectashield (Mounting Medium For Fluoreszenz, Vector, Burlingame, USA) verwendet.

Die Auswertungen der Proben wurden an einem axioverten Fluoreszenz-Mikroskop (Zeiss) durchgeführt. Die Analysen der CD45 ${ }^{+}$-Leukozyten erfolgten in Bereichen mit morphologisch intaktem Gewebe bei 400 facher Vergrößerung.

\subsubsection{TdT-mediated dUTP nick end labeling-Methode (TUNEL-Methode)}

Zur Identifikation und Quantifizierung von apoptotischen Zellen im Herzmuskelgewebe wurde die TUNEL-Methode verwendet. Das Prinzip dieser Methode ist die Markierung freier 3'-OH Enden von Doppelstrang- und Einzelstrang-DNA-Brüchen mittels der Terminaldesoxynukleotidyltransferase 
(TdT). Für die Durchführung der TUNEL-Analyse wurde ein ApopTag Apoptosis Detection kit (Chemicon International, Billerica, USA) verwendet.

Die Schnitte wurden nach 5-minütiger Bewässerung bei 400W in der Mikrowelle mit 0,1 M Citratpuffer $(\mathrm{pH}=6,0)$ behandelt und kühlten danach 20 Minuten bei RT aus. Nach dreimaliger PBS- Waschung für jeweils 5 Minuten erfolgte die Inkubation mit dem Labeling Mix bei Dunkelheit für 60 Minuten bei $37^{\circ} \mathrm{C}$. Die Schnitte wurden $3 \times 5$ Minuten mit PBS gespült und darauf folgte die Inkubation mit DAPI (1:200 in PBS). Abschließend wurde erneut eine 3×5-minütige Waschung mit PBS durchgeführt. Nach Einbettung mit Vectashield wurden die Schnitte innerhalb der nächsten 24 Stunden mittels des Fluoreszenzmikroskops bei 200facher Vergrößerung mit dem Programm Axio Vision fotografiert und ausgewertet.

\subsection{Molekularbiologische Analysen}

\subsubsection{Immunologischer Nachweis von Proteinen}

\subsubsection{Präparation des Herzgewebes}

\subsection{Homogenisierung des Herzgewebes}

Die Homogenisierung der etwa $80 \mathrm{mg}$ schweren Herzgewebestreifen erfolgte mechanisch. Hierzu wurden sie in 1,5 ml Reaktionsgefäße (Eppendorf, Hamburg) mit $100 \mu \mathrm{l}$ Homogenisierungspuffer versetzt und mittels flüssigen Stickstoffs eingefroren. Nach mechanischer Homogenisierung wurde die entstandene Lösung mehrfach gemischt. Ein weiteres Mal wurde $100 \mu$ l Homogenisierungspuffer hinzugegeben, mittels flüssigen Stickstoffs eingefroren und erneut homogenisiert. Es folgte die Abzentrifugierung der Proben bei 8000 Umdrehungen pro Minute (rpm) für 2 Minuten. Nach Abpipettieren der Überstande und deren Überführung in neue 1,5 ml Reaktionsgefäße wurden die Proben katalogisiert und bei $-20^{\circ} \mathrm{C}$ eingefroren. Die Pellets wurden verworfen.

\subsection{Bestimmung der Proteinkonzentrationen}

Die photometrische Bestimmung der Proteinkonzentration in den aufbereiteten Proben wurde durch den Bicinchonininsäure (BCA) ${ }^{\mathrm{TM}}$ Protein Assay Kit (Pierce Biotechnology, Rockford, USA) ermöglicht. Das Verfahren nach der BCA-Methode (Smith et al. 1985) lässt eine quantitative Aussage über den Proteingehalt der Proben zu. Qualitative Aussagen sind dagegen nicht möglich. Die BCA-Methode der Proteinkonzentrationsbestimmung mittels Photometrie ( $\mu$ Quant Universal MicroplateSpektralphotometer von Bio-Tek Instruments Inc., Winooski, USA) besteht aus zwei Reaktionen. 
1. Die Reduktion im alkalischen Medium von Kupfer(CU) ${ }^{2+} \mathrm{zu} \mathrm{Kupfer}^{1+}$ unter Proteinbeteiligung (Biuret-Reaktion):

$$
\mathrm{Cu}^{2+}+\text { Protein }+\mathrm{OH}^{-} \rightarrow \mathrm{Cu}^{1+}
$$

2. Die Chelatkomplex-Bildung von Kupfer $^{1+}$-Ionen mit BCA-Molekülen. Diese wasserlöslichen Komplexe bringen eine sichtbare Farbveränderung der Lösung hervor, die auch photometrisch nachweisbar ist. Sie weist eine starke Absorption bei $562 \mathrm{~nm}$ auf und ist proportional zu den Proteinkonzentrationen in den aufbereiteten Proben:

$$
\mathrm{Cu}^{1+}+2 \mathrm{BCA} \rightarrow \mathrm{Cu}^{1+}-2 \mathrm{BCA}-\text { Chelatkomplex }
$$

Die Proteinkonzentrationsbestimmung wurde in einer klaren 96well-Mikrotiterplatte (Nunc, Wiesbaden) durchgeführt. Um den Proteingehalt der Lösungen zu bestimmen, wurde zunächst eine Verdünnungsreihe mit bekannten Proteinkonzentrationen angesetzt. In dieser Arbeit wurde der BSAStandard verwendet. Das Rinderserumprotein Albumin lag in der Verdünnungsreihe in den Konzentrationen 2000, 1500, 1000, 750, 500, 250, 125, 25 und 0 mg/ml vor. Aus dieser Verdünnungsreihe wurde während des photometrischen Verfahrens eine Standardkurve errechnet, mit der die unbekannten Proteinkonzentrationen der Proben verglichen wurden.

Nach dem Auftauen und Zentrifugieren der Homogenate erfolgte die Überführung der Überstände in neue Reaktionsgefäße. Die Proben wurden mit A. dest. 1:20 verdünnt. Ebenso wurde mit der Bestimmung des Leerwertes, bestehend aus Homogenisierungspuffer und A. dest., verfahren. Je $25 \mu \mathrm{l}$ der Proben, der Leerprobe und der Verdünnungsreihe wurden mit $200 \mu$ l der BCA-Protein-ReaktionsLösung in Doppelbestimmung in die klare 96well-Mikrotiterplatte gegeben. Die Lösung wurde aus BCA A Reagenz (Natriumkarbonat, Natriumbikarbonat, Bicinchonininsäure, Natriumtartrat in 0,1 M Natriumhydroxid) und BCA B Reagenz (4 \% Kupfersulfatlösung) im Verhältnis 50:1 angesetzt. Es folgte eine 30-minütige Inkubation bei $37^{\circ} \mathrm{C}$. Eventuelle Lufteinschlüsse wurden nach Beendigung der Inkubationszeit beseitigt. Die anschließende Messung der Extinktionen der Proteinlösungen erfolgte bei einer Wellenlänge von $562 \mathrm{~nm}$.

\subsection{Herstellung der Protein-Proben}

Die Herstellung der zu verwendenden Protein-Proben erfolgte aus Zusammensetzung der Proteinlösungen, 0,4 Volumeneinheiten 4xLämmli-Puffer und Homogenisierungspuffer. Die Denaturierung der Proben erfolgte 30 Minuten lang bei $56^{\circ} \mathrm{C}$ auf einem Thermoschüttler. Nach Denaturierung der Proben wurden diese für 24 Stunden bei $-20^{\circ} \mathrm{C}$ eingefroren.

\subsubsection{SDS-Polyacrylamid-Gelelektrophorese (SDS-PAGE)}

Zur Proteinanalytik wurde in dieser Arbeit das Verfahren der diskontinuierlichen SDS-PAGE verwendet (Lämmli 1970). Das Prinzip dieser Methode ist die Auftrennung der Proteine innerhalb eines 
elektrischen Feldes bezüglich ihres Molekulargewichts. Durch Zugabe von Natriumdodecylsulfat (SDS), einem anionischen Tensid, kommt es zur Denaturierung. Die nichtkovalenten Bindungen der Proteine werden zerstört und das Resultat sind Strukturänderungen der Eiweiße von Quartär- oder Tertiärstrukturen zu Sekundär- oder Primärstrukturen. Das in der Trägermatrix verwendete Polyacrylamid fungiert als Netz. In der vorliegenden Arbeit wurden zur Auftrennung der Eiweiße $\quad 10 \%$ ige Trenngele verwendet.

\section{Stoff}

$30 \%$ Acrylamid-Bisacrylamid

4xTris/SDS, pH 8,8

Ammoniumpersulfat (APS)

Aqua destillata

Tetramethylethylendiamin (TEMED)

\section{Konzentration/Menge}

$3,33 \mathrm{ml}$

$2,5 \mathrm{ml}$

$0,33 \mathrm{ml}$

4,15 ml

$0,007 \mathrm{ml}$

Tabelle 1: Stoffe und Konzentration/Menge zur Herstellung eines 10 \%igen Trenngels.

Nach Einfüllen der 10 \%igen Trenngel-Matrix in das SDS-PAGE Mini-System PROTEAN 2 bzw. 3 (BioRad Laboratories, München) wurde zur Vermeidung der Austrocknung das System mit A. dest. gesättigtem Butanol bedeckt. Nach Polymerisation des Gels (10 bis 15 Minuten) erfolgte mit A. dest. die Reinigung der Kammer. Eventuelle Rückstände wurden mit Blottingpapier GB 003 (Schleicher \& Schüll, Dassel) entfernt. Die Herstellung eines 4 \%igen Sammelgels wurde wie folgt durchgeführt.

\section{Stoff}

$30 \%$ Acrylamid-Bisacrylamid

$4 \times$ Tris/SDS, pH 6,8

Aqua destillata

$10 \%$ APS

TEMED

\section{Konzentration/Menge}

$0,67 \mathrm{ml}$

$1,25 \mathrm{ml}$

$3,08 \mathrm{ml}$

$0,030 \mathrm{ml}$

$0,010 \mathrm{ml}$

Tabelle 2: Stoffe und Konzentration/Menge zur Herstellung eines 4 \%igen Sammelgels.

Das Sammelgel wurde auf das polymerisierte Trenngel in das System gegossen. Nach vollständiger Polymerisierung wurde das System mit Proben $(20 \mu \mathrm{l})$ und vorgefärbtem Proteinstandard ( $8 \mu \mathrm{l}$, BioRad Laboratories, München) beladen. Unter Verwendung von 1xPAGE-Laufpuffer erfolgte die Elektrophorese. Die Durchwanderung des Sammelgels erfolgte bei $20 \mathrm{~mA}$ pro Gel, die weitere Elektrophorese wurde mit 50 mA pro Gel für etwa 1,5 Stunden durchgeführt. 


\subsubsection{Western Immunoblot}

Das Protokoll der Western Immunoblot-Methode folgt Towbin et al. (1979).

\subsection{Protein-Transfer}

Nach der gelelektrophoretischen Auftrennung der Proteine mittels der SDS-PolyacrylamidGelelektrophorese erfolgt der zum immunologischen Nachweis notwendige Transfer der Proteine auf eine Nitrocellulose-Membran (Protan ${ }^{\circledR}$, Nitrocellulose Transfer Membran, Whatman ${ }^{\circledR}$, Dassel).

Für den Transfer wurde das Tank-Blot-System (Bio-Rad Laboratories, München) verwendet und mittels der Sandwich-Methode durchgeführt. Zunächst erfolgte das Einweichen der NitrocelluloseMembran, zweier Schwämme und 4 Whatman GB003 Filter (Schleicher \& Schüll, Dassel) in 1xTransferpuffer. Nach Trennung des Sammelgels vom Trenngel wurden nach der SandwichMethode 1 Schwamm, 2 Filterpapiere, die Nitrocellulose-Membran und das Trenngel ohne Lufteinschlüsse aufeinander gelegt und wiederum mit 2 Filterpapieren und 1 Schwamm bedeckt. Dies wurde in eine Haltevorrichtung eingebracht und in eine mit 1xTransferpuffer gefüllte Transferbox eingespannt. Die Transferzeit betrug 2 Stunden bei 500 mA. Nach Beendigung des Proteintransfers wurde die Nitrocellulose-Membran mit Ponceau-Rot-Lösung (Sigma-Aldrich, München) für 5 Minuten bedeckt. Zum einen um den Nachweis eines erfolgreichen Transfers zu dokumentieren, zum anderen um Proteine auf der Membran zu fixieren.

\subsection{Blockung und Inkubation der Antikörper}

Die Entfärbung erfolgte kurz mit 1xTBS-Tween (TBST). Die anschließende Blockung der möglichen Bindungsstellen über 2 Stunden bei Raumtemperatur bzw. über Nacht bei $4{ }^{\circ} \mathrm{C}$ auf der Membran wurde mit 1xTBST und $5 \%$ Magermilchpulver durchgeführt. Nach 5-minütiger Waschung der Nitrocellulose-Membran in 1xTBST geht die Inkubation des Primärantikörpers in 1xTBST und 0,5 \% Magermilchpulver voraus. Die Nitrocellulose-Membran wurde 3x5 Minuten in 1xTBST gewaschen. Es folgte die Inkubation ebenfalls in 1xTBST und 0,5 \% Magermilchpulver für 1 Stunde bei RT mit einem Sekundärantikörper, abhängig vom Primärantikörper. Auch hier folgte eine dreimalige Waschung der Nitrocellulose-Membran für jeweils 5 Minuten in 1xTBST. Die Inkubationszeit und Verdünnung des jeweiligen Primär- bzw. Sekundärantikörpers ist Tabelle 3 bzw. Tabelle 4 zu entnehmen.

Die Ergebnisse wurden mit Hilfe von SuperSignal ${ }^{\circledR}$ West Pico Chemiluminescent Substrate (Pierce Biotechnology, Rockford, USA) dokumentiert. Die stabile Peroxid-Lösung und Luminol wurden im Verhältnis 1:1 gemischt und auf die Nitrocellulose-Membran aufgetragen. Nach 5-minütiger Inkubation wurde die Membran, um einen späteren Kontakt mit dem Röntgenfilm (Super RX, Fujifilm, Düsseldorf) zu vermeiden, in eine Klarsichtfolie gelegt. Die Belichtungszeiten der Röntgenfilme variierten 
sehr stark. Dies machte eine anfängliche Belichtungszeit von etwa 45 Sekunden erforderlich, um einen ersten Eindruck der Banden-Intensität zu bekommen.

\begin{tabular}{|c|c|c|c|}
\hline Primärantikörper & Verdünnung & Inkubation & Quelle \\
\hline Anti-AKT & 1:1000 & über Nacht bei $4^{\circ} \mathrm{C}$ & $\begin{array}{l}\text { NEB (New England Biolabs), } \\
\text { Ipswich, USA }\end{array}$ \\
\hline Anti-Phospho-AKT & 1:1000 & über Nacht bei $4^{\circ} \mathrm{C}$ & NEB, Ipswich, USA \\
\hline Anti-CaMK II & $1: 5000$ & über Nacht bei $4^{\circ} \mathrm{C}$ & $\begin{array}{l}\text { freundlicherweise zur Ver- } \\
\text { fügung gestellt von Don M. } \\
\text { Bers }\end{array}$ \\
\hline Anti-Phospho-CaMK II & $1: 5000$ & über Nacht bei $4^{\circ} \mathrm{C}$ & ABR, Rockford, USA \\
\hline Anti-Calsequestrin & $1: 5000$ & 2 Stunden bei RT & ABR, Rockford, USA \\
\hline Anti-Phospho-HDAC5 & $1: 1000$ & über Nacht bei $4^{\circ} \mathrm{C}$ & Genescript, Piscataway, USA \\
\hline Anti-p38 & $1: 4000$ & über Nacht bei $4^{\circ} \mathrm{C}$ & NEB, Ipswich, USA \\
\hline Anti-Phospho-p38 & $1: 1000$ & über Nacht bei $4^{\circ} \mathrm{C}$ & NEB, Ipswich, USA \\
\hline Anti-ERK & $1: 3000$ & über Nacht bei $4^{\circ} \mathrm{C}$ & NEB, Ipswich, USA \\
\hline Anti-Phospho-ERK & $1: 3000$ & über Nacht bei $4^{\circ} \mathrm{C}$ & NEB, Ipswich, USA \\
\hline Anti-JNK & $1: 500$ & über Nacht bei $4{ }^{\circ} \mathrm{C}$ & NEB, Ipswich, USA \\
\hline Anti-Phospho-JNK & $1: 250$ & über Nacht bei $4^{\circ} \mathrm{C}$ & NEB, Ipswich, USA \\
\hline Anti-GSK3ß & $1: 2500$ & über Nacht bei $4^{\circ} \mathrm{C}$ & $\begin{array}{l}\text { BD-Transduction Laborato- } \\
\text { ries, San Jose, USA }\end{array}$ \\
\hline Anti-Phospho-GSK3ß & $1: 2000$ & über Nacht bei $4^{\circ} \mathrm{C}$ & NEB, Ipswich, USA \\
\hline Anti-GAPDH & $1: 50000$ & 1 Stunde bei RT & BioTrend Chemikalien, Köln \\
\hline
\end{tabular}

Tabelle 3: Primärantikörper

$\begin{array}{ll}\text { Sekundärantikörper } & \text { Verdünnung } \\ \text { Anti-mouse lgG, Horserad- } & 1: 10000 \\ \text { ish peroxidase-linked whole } & \\ \text { Antibody (from sheep) } \\ \text { Anti-rabbit IgG Horseradish 1:10000 } \\ \text { peroxidase-linked whole } \\ \text { Antibody (from donkey) }\end{array}$

\section{Inkubation}

1 Stunde bei RT

1 Stunde bei RT
Quelle

Amersham Biosciences, Freiburg

Amersham Biosciences,

Tabelle 4: Sekundärantikörper

\subsection{Auswertung}

Zur Auswertung der vorhandenen Daten wurde das Chemolumineszenz-Detektionssystem (Amersham Biosciences, Freiburg) verwendet. Nach Belichtung der Röntgenfilme erfolgten die Digitalisie- 
rung und Quantifizierung mittels CCD-Kamerasystem (Multiimager, Alpha Innotech). Zur Normalisierung wurde GAPDH (Glycerinaldehyd-3-phosphat-Dehydrogenase) als Housekeeping-Gen verwendet.

\subsubsection{Amplifikation von DNA}

\subsubsection{Präparation von Herzgewebe}

\subsection{Homogenisierung des Herzgewebes}

Zur Homogenisierung von je etwa 30mg Herzgewebe wurde das Probenstück in ein Reaktionsgefäß mit $300 \mu \mathrm{l}$ RLT-Puffer gegeben und mit Hilfe eines Homogenisators (Rotor Stator Homogenisator, ART Labortechnik, Mühlheim) fragmentiert. Die mRNA-Extraktion aus dem entstandenen Homogenat erfolgte mit RNeasy kit und RNase-free DNAse Set (Qiagen, Hilden) nach Protokoll des Herstellers.

\subsection{Bestimmung der Nukleinsäurekonzentrationen}

Die Konzentrationsbestimmung der Nukleinsäuren erfolgte photometrisch (BioPhotometer, Eppendorf, Hamburg) nach folgender Formel:

$\mathrm{C}(\mu \mathrm{g} / \mu \mathrm{l})=(\mathrm{E} 260-\mathrm{E} 320) \times \mathrm{f} \times \mathrm{C}$

$\mathrm{C}=$ Konzentration der Nukleinsäuren in der Probe, $\mathrm{E}=$ Extinktion, $\mathrm{f}=$ Verdünnungsfaktor, $\mathrm{c}=$ nukleinsäurespezifischer Koeffizient in $\mu \mathrm{g} / \mu \mathrm{l}$

$\rightarrow$ Für RNA: c $=0,04 \mu \mathrm{g} / \mu \mathrm{l}$

$\rightarrow$ Für dsDNA: c $=0,05 \mu \mathrm{g} / \mu \mathrm{l}$

$\rightarrow$ Für esDNA: $\mathrm{c}=0,25 \mu \mathrm{g} / \mu \mathrm{l}$

E 260/280 = $\geq 1,8$ (Angabe der Reinheit)

(Die Absorption der Nukleinsäuren liegt bei 260 nm, der Proteine bei $280 \mathrm{~nm}$ und der Salze bei 320 nm.)

\subsubsection{Reverse Transkription}

Die Transkription beschreibt die RNA-Herstellung unter Verwendung einer DNA-Vorlage. Bei dem Prinzip der reversen Transkription erfolgt die Umschreibung von mRNA in komplementäre cDNA mit Hilfe einer RNA-abhängigen DNA-Polymerase. Die entstandenen cDNA sind das Ausgangsmaterial für die Polymerase-Kettenreaktion (PCR).

In der vorliegenden Arbeit wurde die Synthese des ersten DNA-Stranges aus der extrahierten mRNA mit iScript cDNA synthesis kit von BioRad (München) durchgeführt. Die cDNA wurde in der PCR weiterverwendet. 


\subsubsection{Quantitative realtime-Polymerase-Kettenreaktion (quantitative realtime-PCR)}

Die Methode der PCR (Saiki et al. 1988) erlaubt die gezielte Amplifikation von ausgewählten DNAAbschnitten. Das Prinzip der PCR besteht aus drei Phasen (Denaturierung, Annealing, Elongation). Nach Denaturierung der DNA-Stränge und Markierung der ausgewählten DNA-Sequenz mittels zweier Oligonukleotide (Primer, Annealing) wird eine thermostabile DNA-Polymerase hinzugegeben. Hier handelt es sich um das hitzestabile Enzym des Archaeabakteriums Thermus aquaticus (TaqPolymerase). Die Taq-Polymerase synthetisiert komplementäre Stränge der ausgewählten Sequenz in 5'-3'-Richtung (Elongation).

Die quantitative realtime-PCR basiert auf dem Prinzip der unter 2.6.2.2 beschriebenen PCR. Sie erlaubt zusätzlich die zahlenmäßige Erfassung der DNA-Vermehrung während eines PCR-Zyklus in Echtzeit (realtime). Die Messung erfolgt in der Elongationsphase der realtime-PCR. Dabei binden fluoreszierenden Farbstoffe sequenzunspezifisch an die dsDNA und ermöglichen so einen Nachweis des Replikationszuwachses.

In der vorliegenden Arbeit wurde diese Methode an einem BioRad iQ-Cycler der Firma BioRad Laboratories (München) durchgeführt. Es erfolgte zunächst die Mischung von $1 \mu \mathrm{l}$ cDNA-Probe und $19 \mu \mathrm{l}$ SYBR GRN SUPERMIX (BioRad Laboratories, München) auf einer 96-Well-realtime-PCR-Platte (BioRad Laboratories, München). Im Produkt SYBR GRN SUPERMIX ist u.a. der fluoreszierende Farbstoff Cyaninfarbstoff SYBR Green I enthalten. Nach Blaulicht-Stimulation bei einer Wellenlänge von $480 \mathrm{~nm}$ wird eine Emission des Farbstoffes bei $530 \mathrm{~nm}$ erwartet. Die quantitative realtime-PCR wurde nach folgendem Schema durchgeführt:

40 Zyklen $-\left(\begin{array}{cc}\text { Denaturierung } & 95^{\circ} \mathrm{C}, 60 \text { Sekunden } \\ \text { Annealing } & 95^{\circ} \mathrm{C}, 15 \text { Sekunden } \\ \text { Elongation } & 60{ }^{\circ} \mathrm{C}, 10 \text { Sekunden } \\ \text { Endelongation } & 72{ }^{\circ} \mathrm{C}, 15 \text { Sekunden }\end{array}\right.$

Die verwendeten Oligonukleotide (Primer) waren:

GAPDH $\quad 5^{\prime} \rightarrow 3^{\prime}:$ GCAGTGGCAAAGTGGAGATT,

$3^{\prime} \rightarrow 5^{\prime}: \quad$ TCTCCATGGTGGTGAAGACA; 


$\begin{array}{lll}\text { BNP } & 5^{\prime} \rightarrow 3^{\prime}: & \text { TCTCCAGAGCAATTCAAGAT, } \\ & 3^{\prime} \rightarrow 5^{\prime}: & \text { AACAACTTCAGTGCGTTACA; } \\ \text { MCIP } & 5^{\prime} \rightarrow 3^{\prime}: & \text { ACTGGAAGGTGGTGTCCTTGTC, } \\ & 3^{\prime} \rightarrow 5^{\prime}: & \text { TCCAGCTTGGGCTTGACTGAG }\end{array}$

\subsubsection{Auswertung}

Zur Auswertung der erhobenen Daten wurde die Lightcycler Data Analysis Software verwendet. Die Signalintensität der Fluoreszenz wird pro Zyklus einmal gemessen. Hieraus entsteht eine Fluoreszenzkurve. Die Quantifizierung erfolgt durch den Kurvenanteil, der das exponentielle Wachstum repräsentiert. Eine Standardkurve wird durch Zuordnung bekannter Standards zur jeweiligen Zykluszahl angefertigt. Die Auswertung erfolgt mittels Kurven in einem Koordinatensystem, dessen y-Achse logarithmisch skaliert ist („Fit Points“-Methode). Durch manuelle Festlegung zweier Punkte können mit Hilfe der Standardkurve die entsprechenden Konzentrationen berechnet werden. GAPDH dient zur Normalisierung.

\subsection{Statistik und mathematische Methoden}

Die Daten wurden mit GraphPad-Prism, Version 5.0 statistisch ausgewertet. Der Student-T-Test wurde zur Berechnung von statistischen Signifikanzen verwendet. Die verwendeten Signifikanzniveaus sind in den Diagrammen angegeben. Die Berechnung der Wandspannung und des Fractional Shortenings (FS) sind unter 2.3.2.2 bis 2.3.2.3 angegeben.

Die Standardabweichungen wurden in den Diagrammen mittels Fehlerbalken gekennzeichnet.

\subsection{Pufferlösungen}

Phosphate Buffered Saline (PBS): $8 \mathrm{~g} \mathrm{NaCl}, 0,2 \mathrm{~g} \mathrm{KCl}, 1,44 \mathrm{~g} \mathrm{Na}_{2} \mathrm{HPO}_{4}$ und 0,24 $\mathrm{g} \mathrm{KH}_{2} \mathrm{PO}_{4}$ in $800 \mathrm{ml}$, mit $\mathrm{HCl}$ auf pH 7,4 einstellen, auf $1000 \mathrm{ml}$ mit Aqua bidest. auffüllen und autoklavieren.

Homogenisierungspuffer: 1 \% (v/v) NP 40 (IGEPAL CA-630), 10 \% (v/v) Glycerol, 137 mM Natriumchlorid (NaCl), 20 mM TrisSalzsäure (Tris- $\mathrm{HCl}$ ) pH7,4, $20 \mathrm{mM}$ Natriumfluorid (NaF), $1 \mathrm{mM}$ Natrium-Orthovanadat, $1 \mathrm{mM}$ Natrium-Pyrophosphat, 50 mM ß-Glycerophosphat, 10 mM Ethylen-Diamin-Tetra-Essigsäure) ( EDTA) pH 8, 1 mM Ethylenglycol-bis-(2-aminoethyl)-

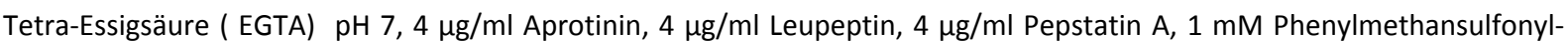
Fluorid (PMSF), mit A. dest. auffüllen.

Lämmli-Puffer, 4x: 200 mM EGTA, 20 \% Natriumdodecylsulfat (SDS), 1 M Tris pH 6,8, 16 mM Dithiothreitol (DTT), auf pH 6,8 eingestellt, $100 \%$ Glycerol, 1 \% Bromphenolblau, mit A. dest. auffüllen. 
Transferpuffer, 1x: 200 mM Tris, 150 mM Glycin, $20 \%$ (v/v) Methanol, pH 8,3.

PAGE-Laufpuffer, 5x: 125 mM Trishydroxymethyl-aminoethan (Tris-Base), 96 mM Glycin, 0,5 \% (w/v) Natriumdodecylsulfat (SDS).

TBS-Tween (TBST), 10x: 200 mM Tris, 2 M Natriumchlorid, pH 7,5.

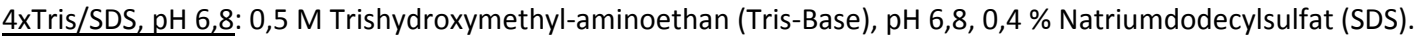

4xTris/SDS, pH 8,8: 1,5 M Trishydroxymethyl-aminoethan (Tris-Base), pH 8,8, 0,4 \% Natriumdodecylsulfat (SDS).

\subsection{Weitere Materialien}

Verwendete Computerprogramme, Geräte, weitere Gebrauchswaren, Reaktionssysteme, Antikörper, Medikamente und Chemikalien sind im laufenden Text mit Herstellerfirma und Herstellungsort bezeichnet. Weitere Chemikalien sind im Folgenden aufgelistet.

$\begin{array}{ll}\text { Chemikalien } & \text { Hersteller, Ort } \\ \text { Aprotinin } & \text { Roche, Mannheim } \\ \text { Bromphenolblau } & \text { AppliChem, Darmstadt } \\ \text { Dithiothreitol (DTT) } & \text { Sigma-Aldrich, München } \\ \text { Glycerol } & \text { Merck, Darmstadt } \\ \text { Glycin } & \text { Carl Roth, Karlsruhe } \\ \text { Leupeptin } & \text { Biomol, Hamburg } \\ \text { Natriumchlorid (NaCl) } & \text { Merck, Darmstadt } \\ \text { Natriumdodecylsulfat (SDS) } & \text { Sigma-Aldrich, München } \\ \text { Natriumfluorid (NaF) } & \text { Sigma-Aldrich, München } \\ \text { Natrium-Orthovanadat } & \text { Sigma-Aldrich, München } \\ \text { NP 40 (IGEPAL CA-630) } & \text { Sigma-Aldrich, München } \\ \text { Methanol } & \text { Merck, Darmstadt } \\ \text { Phenylmethansulfonyl-Fluorid (PMSF) } & \text { Sigma-Aldrich, München } \\ \text { Tetramethylethylendiamin (TEMED) } & \text { Sigma-Aldrich, München } \\ \text { Trishydroxymethyl-aminoethan (Tris-Base) } & \text { Carl Roth, Karlsruhe } \\ \text { Tris-Salzsäure (Tris-HCl) } & \text { Carl Roth, Karlsruhe } \\ & \end{array}$

Tabelle 5: Weitere verwendete Chemikalien 


\section{Ergebnisse}

\subsection{Wandspannungsmessungen 6 Stunden nach Intervention}

Zur Beurteilung der Belastung wurden die Wandspannungen im Sham-, TAC- und Shunt-Modell 6 Stunden nach Intervention gemessen. Die Berechnungen der Wandspannungen erfolgten mittels des Laplace-Gesetzes. Der linksventrikuläre Druck wurde mit einem Konduktionskatheter gemessen und die linksventrikuläre Dimension sowie die Wandstärke echokardiographisch bestimmt. Die Wandspannungsmessung erfolgte in vier Phasen des kardialen Zyklus (mitsystolisch, endsystolisch, mitdiastolisch und enddiastolisch).

\subsubsection{Druck-Volumen-Analyse}

Hämodynamische Verhältnisse

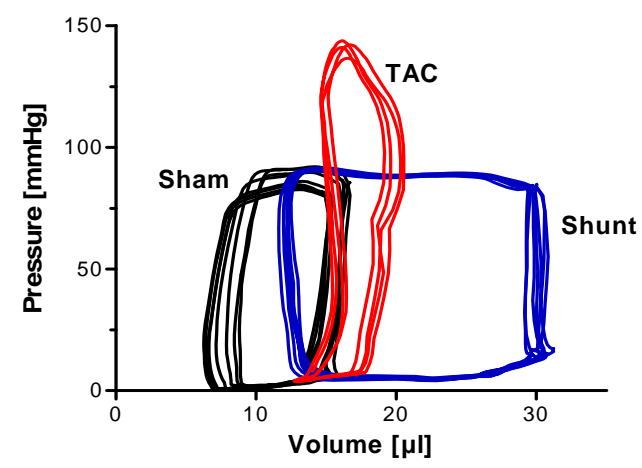

Abbildung 6: Hämodynamische Verhältnisse im Sham-, TAC- und Shunt-Modell 6 Stunden nach Intervention.

Die Messungen der hämodynamischen Verhältnisse 6 Stunden nach Intervention zeigten im TACModell während der Systole eine linksventrikuläre Druckerhöhung um $41 \%(P<0,05)$. Eine signifikante Veränderung des enddiastolischen Druckes oder des enddiastolischen Volumens wurde nicht gemessen. In der Gruppe der Shunt-Tiere war keine Veränderung des systolischen Drucks, aber eine Erhöhung des linksventrikulären Druckes $(277 \%, \mathrm{P}<0,05)$ und des linksventrikuären Volumens $(97 \%$, $\mathrm{P}<0,05)$ in der diastolischen Phase sichtbar. 
A) linksventrikulärer endsystolischer Druck

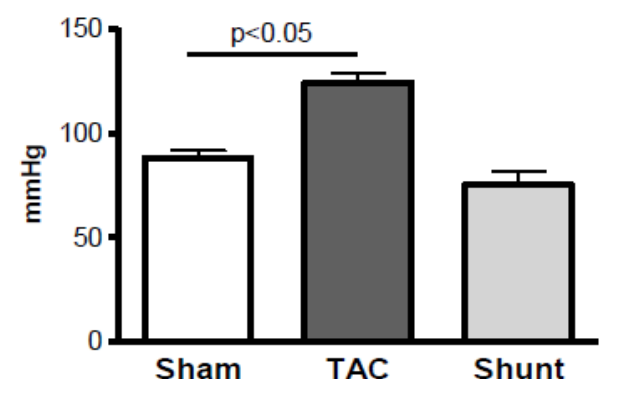

B) linksventrikulärer enddiastolischer Druck

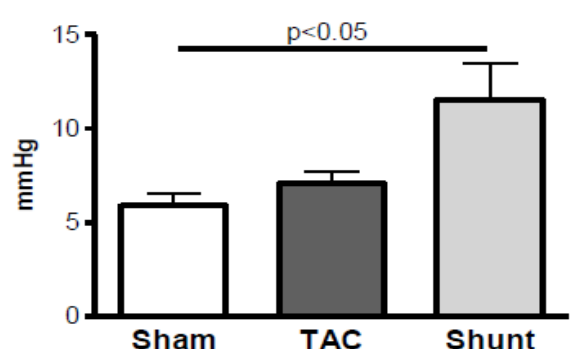

C) linksventrikuläres enddiastolisches Volumen

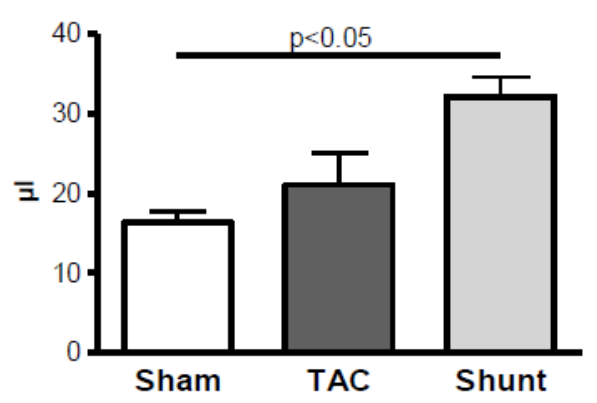

Abbildung 7: Parameter der hämodynamischen Parameter im Sham-, TAC- und Shunt-Modell 6 Stunden nach Intervention ( $\mathrm{n}=3$ pro Gruppe): A) linksventrikulärer endsystolischer Druck, B) linksventrikulärer enddiastolischer Druck, C) linksventrikuläres enddiastolisches Volumen.

\subsubsection{Wandspannungsmessungen in der Systole}

\section{A) mitsystolische Wandspannung}

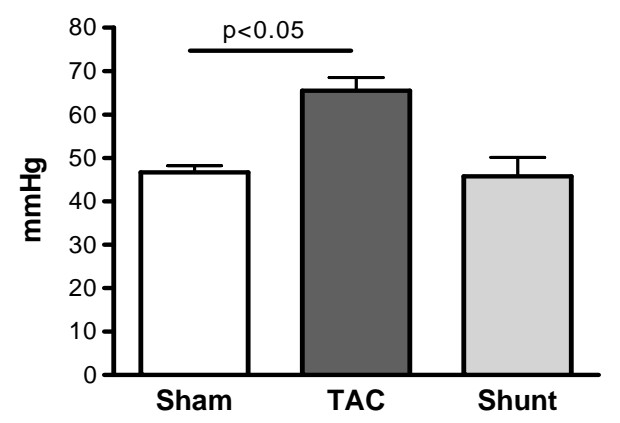

B) endsystolische Wandspannung

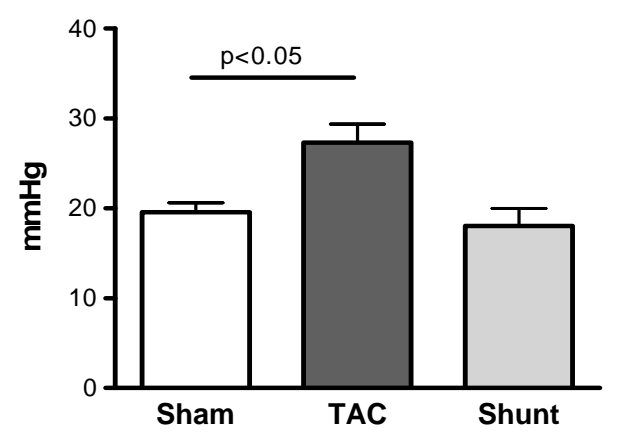

Abbildung 8 : Wandspannungsmessungen im Sham-, TAC- und Shunt-Modell, 6 Stunden nach Intervention ( $n=3$ pro Gruppe) in den Phasen der Systole: A) mitsystolische Phase, B) endsystolische Phase.

Zur Evaluation der Belastung in den Modellen wurde die Wandspannung berechnet (siehe 2.3.2.1). Die Messungen der Wandspannung während der mitsystolischen Phase im linken Ventrikel zeigten im Sham-Modell durchschnittlich $47 \mathrm{mmHg}$. Im TAC-Modell wurde in der mitsystolischen Phase eine 
Wandspannung im linken Ventrikel von $66 \mathrm{mmHg}$ gemessen und somit eine signifikante Druckerhöhung um $40 \%(P<0,05)$ gezeigt. Im Shunt-Modell ließen sich in der systolischen Phase keine signifikanten Wandspannungsveränderungen erkennen (durchschnittlich $46 \mathrm{mmHg}$ im linken Ventrikel).

In der endsystolischen Phase wurde im Sham-Modell eine durchschnittliche Wandspannung von 20 mmHg gemessen. Die Analyse der Daten des TAC-Modells ergab im linken Ventrikel eine Wandspannung von 27 mmHg, was einem signifikanten Anstieg um $35 \%(P<0,05)$ entspricht. Auch hier war im Shunt-Modell im Vergleich zur Gruppe der Sham-Tiere keine signifikante Veränderung im linken Ventrikel zu beobachten.

Insgesamt waren signifikante Anstiege bezüglich der systolischen Wandspannung nur im Modell der Nachlasterhöhung zu beobachten. Im Shunt-Modell kam es zu keinen signifikanten Veränderungen in der Systole.

\subsubsection{Wandspannungsmessungen in der Diastole}

A) mitdiastolische Wandspannung

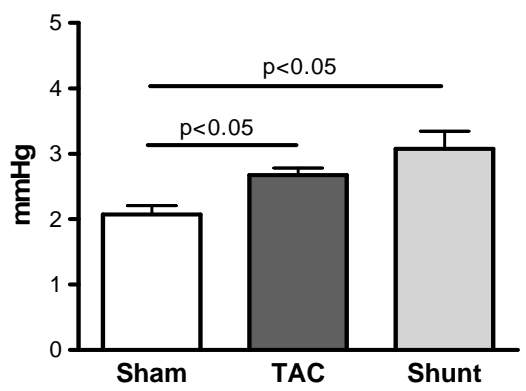

B) enddiastolische Wandspannung

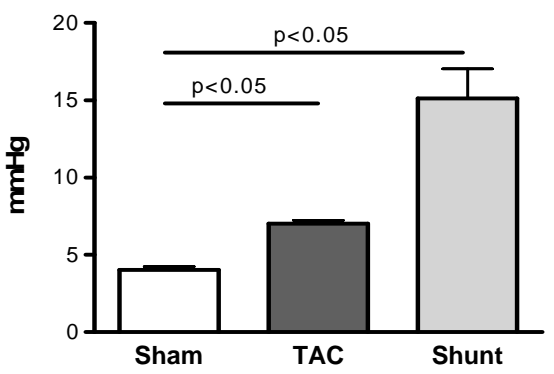

Abbildung 9: Wandspannungsmessungen im Sham-, TAC- und Shunt-Modell 6 Stunden nach Intervention ( $n=3$ pro Gruppe) in den Phasen der Diastole: A) mitdiastolische Phase, B) enddiastolische Phase.

Die Messungen in den zwei diastolischen Phasen des Herzens zeigten sowohl im Shunt- als auch im TAC-Modell signifikante Veränderungen.

Im Sham-Modell wurde in der mitdiastolischen Phase eine Wandspannung von 2,1 mmHg berechnet. Sowohl im TAC- als auch Shunt-Modell zeigte sich 6 Stunden nach Intervention ein signifikanter Anstieg der Wandspannung (TAC: 2,7 mmHg, $\mathrm{P}<0,05$; Shunt: 3,1 mmHg, $\mathrm{P}<0,05$ ).

In der enddiastolischen Phase des linken Ventrikels stellte sich in der Sham-Gruppe eine Wandspannung von $4 \mathrm{mmHg}$ dar, die sich im TAC-Modell um $75 \%(P<0,05)$ und im Shunt-Modell um $277 \%$ $(P<0,05)$ signifikant erhöht fand.

Im Gegensatz zu den Analysen der systolischen Phasen konnte vor allem enddiastolisch ein deutlicher Anstieg der Wandspannung im Modell der Vorlasterhöhung ermittelt werden. Die geringe Wand- 
spannungserhöhung im Nachlastmodell ist am ehesten als eine Reduktion des Auswurfes bei erhöhtem Widerstand zu interpretieren.

\subsubsection{Mittlere Wandspannung}

\section{Mittlere Wandspannung}

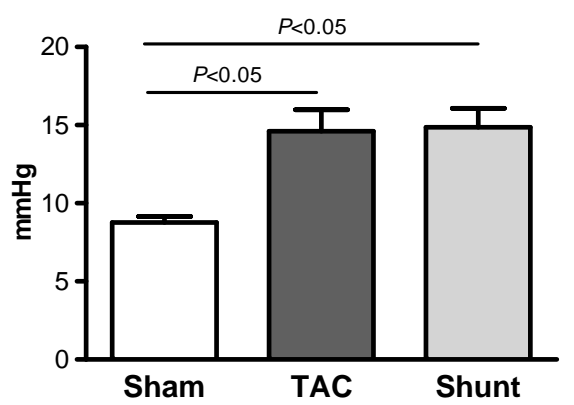

Abbildung 10: Mittlere Wandspannung im Sham-, TAC- und Shunt-Modell 6 Stunden nach Intervention.

Aus der systolischen und diastolischen Wandspannung wurde, unter Berücksichtigung der Dauer der Systole und der Diastole, eine mittlere Wandspannung für den ganzen Kontraktionszyklus berechnet. Insgesamt zeigten die Untersuchungen eine Zunahme der mittleren Wandspannung im TAC-Modell um $67 \%(P<0,05)$ und im Shunt-Modell um $69 \%(P<0,05)$. Hieraus lässt sich schließen, dass es in den beiden Modellen zu einer ähnlichen Lasterhöhung während eines Herzzyklus kam. Im TAC-Modell war dies überwiegend in der systolischen Phase zu sehen, im Shunt-Modell zeigte sich dies nur in der Diastole. 


\subsection{Echokardiographiedaten im TAC- und Shunt-Modell 24 Stunden und 7 Tage nach Intervention}

A) LVEDD nach 24 Stunden

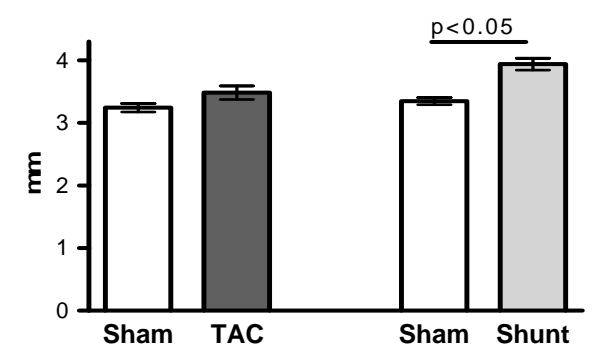

C) Septumstärke nach 24 Stunden

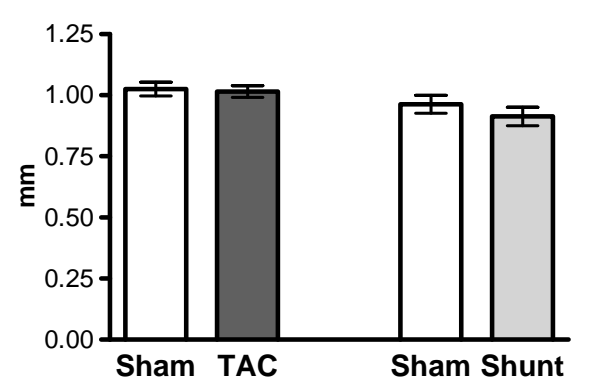

E) FS nach 24 Stunden

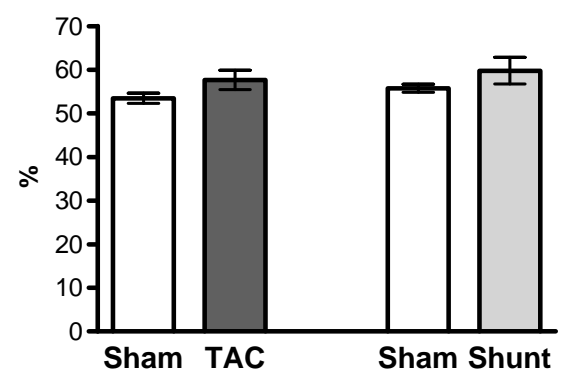

B) LVEDD nach 7 Tagen

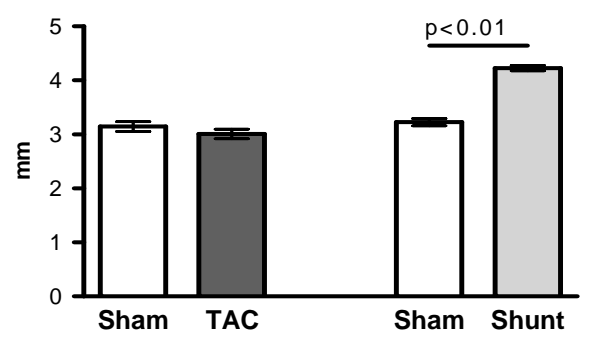

D) Septumstärke nach 7 Tagen

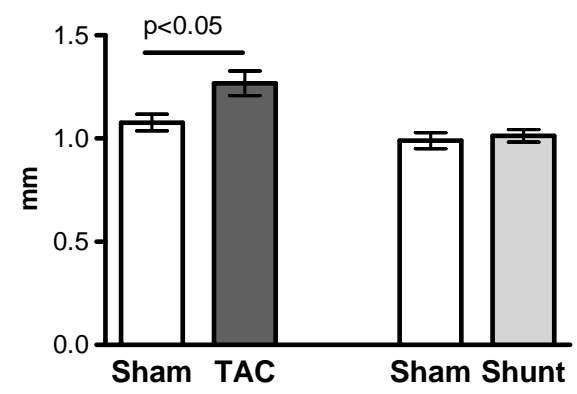

F) FS nach 7 Tagen

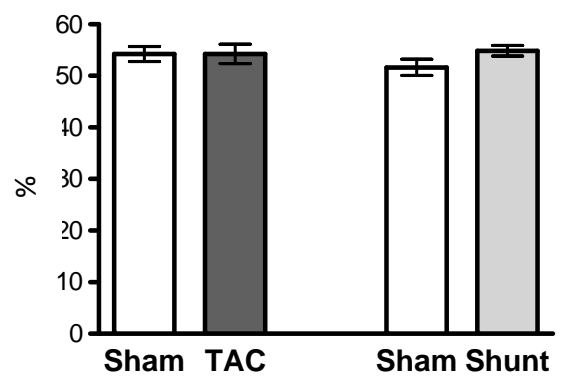

Abbildung 11: Echokardiographische Messungen in der Sham-, TAC- und Shunt-Gruppe: A) LVEDD 24 Stunden nach Intervention, B) LVEDD 7 Tage nach Intervention, C) Septumstärke 24 Stunden nach Intervention, D) Septumstärke 7 Tage nach Intervention, E) FS 24 Stunden nach Intervention, F) FS 7 Tage nach Intervention.

Die Ergebnisse der echokardiographischen Untersuchungen 24 Stunden nach Intervention zeigten im Shunt-Modell eine signifikante linksventrikuläre enddiastolische Dilatation (24 Stunden: $18 \%$ $(P<0,05), 7$ Tage: 31 \% $(p<0.01))$ im Vergleich zur Sham-Gruppe. Das TAC-Modell wies in den echokardiographischen Untersuchungen keinen signifikant erhöhten LVEDD auf. 
Die Analysen der Septumstärke 24 Stunden nach Intervention zeigten sowohl im Shunt- als auch im TAC-Modell keine signifikanten Veränderungen. Nach 7 Tagen wurde eine signifikante Stärkenzunahme des Septums im TAC-Modell $(18 \%, \mathrm{P}<0,05)$ gemessen. Im Shunt-Modell ergaben die Analysen zu diesem Zeitpunkt keine signifikanten Veränderungen.

Die kardiale Funktion wurde 24 Stunden und 7 Tage nach Intervention mit Hilfe der FS bestimmt. Zu beiden Messungszeitpunkten zeigten sich sowohl im TAC-Modell als auch im Shunt-Modell keine Einschränkungen bezüglich der linksventrikulären Funktion. 24 Stunden nach Intervention lag die FS im TAC-Modell bei 58 \% (Kontrollgruppe 53 \%) und im Shunt-Modell bei 60 \% (Kontrollgruppe 56 \%)und somit tendenziell leicht über den Werten der Kontrollgruppen. Die FS in den beiden Modellen war statistisch aber nicht signifikant erhöht. Auch nach 7 Tagen zeigte sich keine Veränderung der kardialen Funktion (TAC-Modell: 54 \%, Kontrollgruppe: 54 \%; Shunt-Modell: 55 \%, Kontrollgruppe: 52 $\%)$.

Insgesamt zeigen die echokardiographischen Untersuchungen im Shunt-Modell eine exzentrische und im TAC-Modell eine konzentrische Hypertrophie mit jeweils erhaltener linksventrikulärer Funktion.

\subsection{Linksventrikuläre Hypertrophie im TAC- und Shunt-Modell}

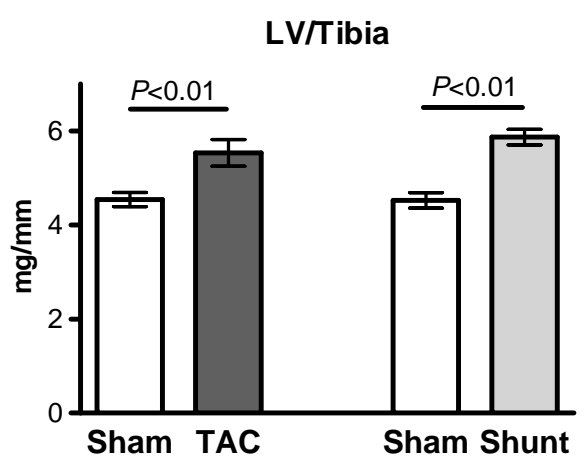

Abbildung 12: Gewicht des linken Ventrikels der Sham-, TAC- und Shunt-Gruppe 7 Tage nach Intervention auf die Tibia-Länge normalisiert $(n=8 / 10 / 6 / 6)$.

Zur in-vitro-Quantifizierung der linksventrikulären Hypertrophie erfolgte 7 Tage nach Intervention die Entnahme der Tierherzen und die Normalisierung des linksventrikulären Gewichtes auf die TibiaLänge der Tiere. Im Shunt-Modell stellte sich eine signifikante Hypertrophie von $29 \%(P<0,01)$ dar. Im TAC-Modell ergab sich ebenfalls eine signifikante linksventrikuläre Hypertrophie von $22 \%$ $(P<0,01)$. Zwischen dem TAC- und Shunt-Modell bestand im Ausmaß der Hypertrophie somit kein signifikanter Unterschied. 
Bei gleicher kardialer mittlerer Wandspannung zeigt sich somit ein vergleichbares Maß an Hypertrophie in beiden Modellen.

\subsection{Remodeling im TAC- und Shunt-Modell 7 Tage nach Intervention}

Um strukturelle Veränderungen darzustellen, eignete sich die histologische Aufarbeitung der 7 Tage nach Intervention entnommenen Herzen.

\subsubsection{Fibrose}

7 Tage nach Intervention wurde an histologischen Schnitten mittels Sirius-Rot-Färbung das Ausmaß der Fibrose untersucht. Hier zeigte sich im Shunt-Modell kein signifikanter Anstieg der Fibrosierung, während es hingegen im TAC-Modell zu einer signifikanten Bindegewebsvermehrung im Myokard kam. Die perivaskuläre Fibrose stieg im TAC-Modell um $490 \%(P<0,01)$ an.

\section{A) Sirius-Rot Färbung des perivaskulären Gewebes}

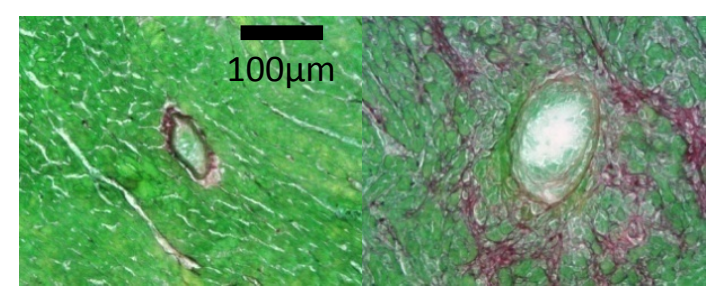

Sham

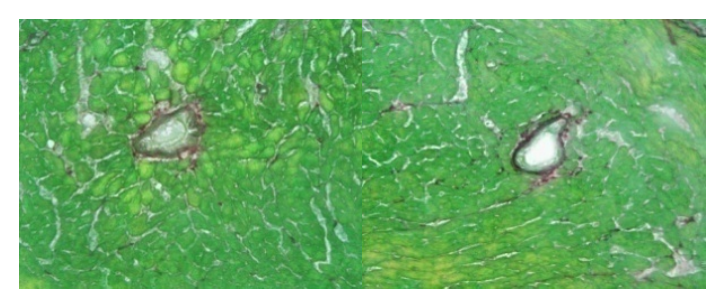

Sham
TAC

\section{Shunt}

B) perivaskuläre Fibrosierung

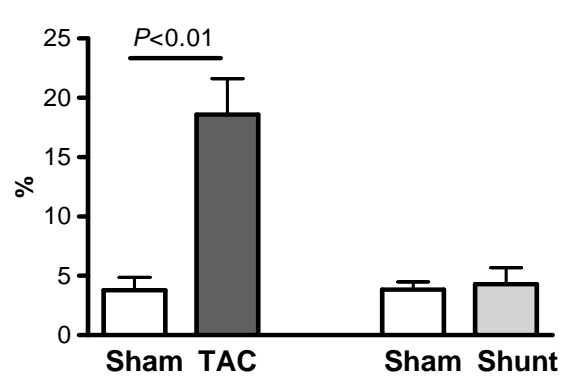

Abbildung 13: Fibrosierung im Sham-, TAC- und Shunt-Modell 7 Tage nach Intervention ( $n=5 / 6 / 5 / 6)$ : A) histologische Aufarbeitung des perivaskulären Gewebes (Sirius-Rot Färbung), B) Balkendiagramm-Darstellung. 


\subsubsection{Inflammation}

Im Zusammenhang mit der kardialen Fibrosierung steht die Entzündungsreaktion, die in beiden Modellen mittels der CD45 ${ }^{+}$-immunhistochemischen Methode untersucht wurde. Es wurde die Anzahl der $\mathrm{CD} 45^{+}$-Zellen pro $\mathrm{mm}^{2}$ gezählt. Es zeigte sich im Shunt-Modell keine signifikante Anreicherung der CD45 ${ }^{+}$-Leukozyten pro $\mathrm{mm}^{2}$. Allerdings stellte sich im TAC-Modell eine signifikante Erhöhung der CD45 ${ }^{+}$-Leukozyten-Population um $114 \%(P<0,001)$ dar.

\section{A) Anti-CD45 ${ }^{+}$-immunhistochemische Aufarbeitung}

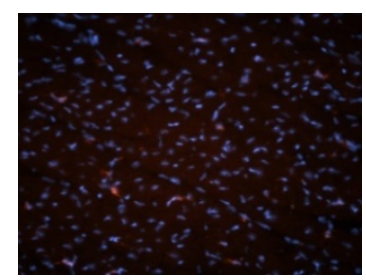

Sham

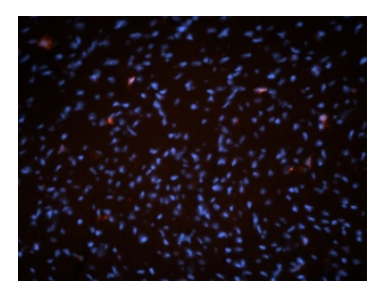

Sham

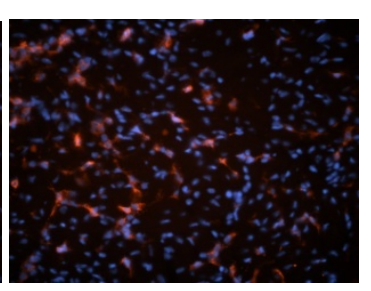

TAC

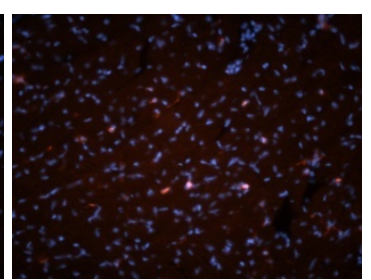

Shunt
B) Inflammation

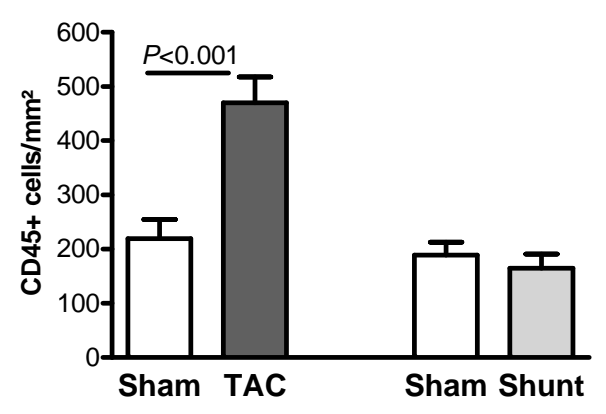

Abbildung 14: Inflammation im Sham-, TAC- und Shunt-Modell 7 Tage nach Intervention ( $n=5 / 6 / 5 / 6)$ : A) Anti$\mathrm{CD}^{+} 5^{+}$-immunhistochemische Aufarbeitung der Proben (rot=Leukozyten, blau=Zellkerne), B) DiagrammDarstellung.

\subsubsection{Apoptose}

Zur Analyse des Apoptose-Verhaltens der Kardiomyozyten 7 Tage nach Intervention wurden die TUNEL-Methode und eine Messung der im Rahmen einer Apoptose aktiven Kaspase 3 durchgeführt.

Die Ergebnisse zeigen eine signifikant erhöhte Apoptose-Rate sowohl im Shunt- als auch im TACModell. Die im Rahmen einer Apoptose aktive Kaspase 3 wurde im TAC-Modell in 0,064 Zellen pro $\mathrm{mm}^{2}$ nachgewiesen. Dies entspricht einem Anstieg der Apoptose-Rate um $1933 \%(P<0,001)$. Im Shunt-Modell zeigte sich eine Zunahme um $700 \%(P<0,001)$ bei der Anzahl von Myozyten mit aktive Kaspase $3 \mathrm{im}$ Vergleich zur Sham-Gruppe. Auch mit der TUNEL-Methode zeigte sich ein Anstieg der Apoptose: im TAC-Modell mit $0,00154(P<0,01)$ und im Shunt-Modell mit $0,00054(P<0,01)$ positiven Zellkernen pro 100 Zellkernen. Eine Analyse der beiden Interventionsmodelle miteinander zeigt eine signifikant höhere Apoptoserate im TAC-Modell, verglichen mit dem Shunt-Modell (+176\% Kaspase 3 $(p=0,01),+185 \%$ TUNEL $(p=0,01))$. 
A) histologische Nachweis der aktiven Kaspase 3

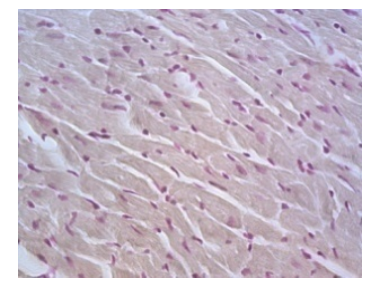

Sham

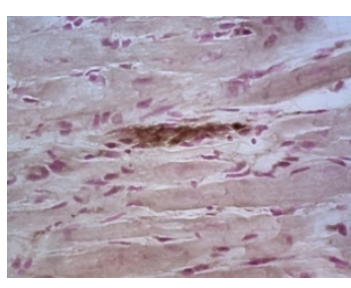

TAC
B) Apoptose (aktive Kaspase 3)

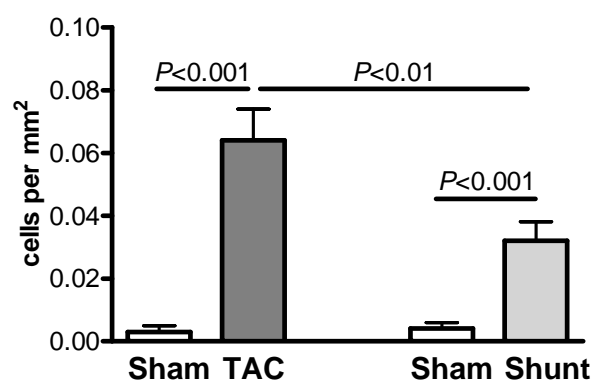

C) Apoptose (TUNEL)

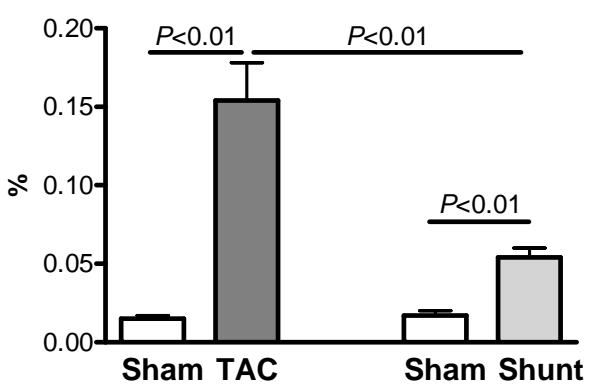

Abbildung 15: Apoptose der Kardiomyozyten im Sham-, TAC- und Shunt-Modell 7 Tage nach Intervention $(n=5 / 6 / 5 / 6): A)$ histologische Aufarbeitung und Nachweis der aktiven Kaspase 3 (Diaminobenzidin-Reaktion), B) Diagramm-Darstellung der aktiven Kaspase 3, C) Diagramm-Darstellung der Apoptose-Rate durch Markierung der terminal desoxynucleotidyl transferase dUTP nick and labeling (TUNEL) (Anzahl der positiven Zellen pro 100 Zellkernen).

Insgesamt war im TAC-Modell 7 Tage nach Intervention ein deutlicher Remodeling-Prozess zu beobachten. Es waren sowohl eine erkennbare Fibrose und Inflammation als auch eine signifikante Erhöhung der Apoptose-Rate zu sehen.

Das Shunt-Modell hingegen wies weder eine signifikante Fibrose noch Inflammation auf. Jedoch war eine signifikant erhöhte Apoptose-Rate zu beobachten, die allerdings geringer ausfiel als die im Modell der Nachlasterhöhung. 


\subsection{BNP im TAC- und Shunt-Modell 24 Stunden und 7 Tage nach Intervention}

A) BNP-Expression nach 24 Stunden

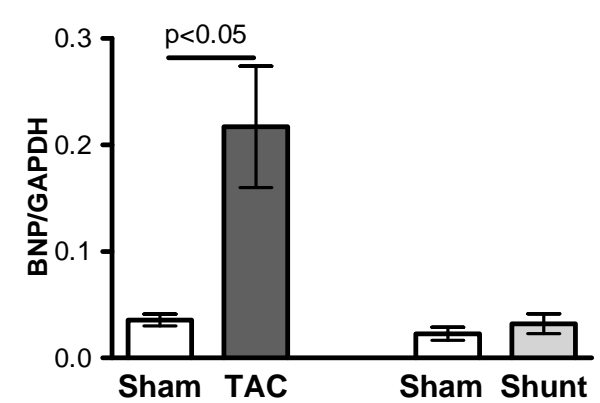

B) BNP-Expression nach 7 Tagen

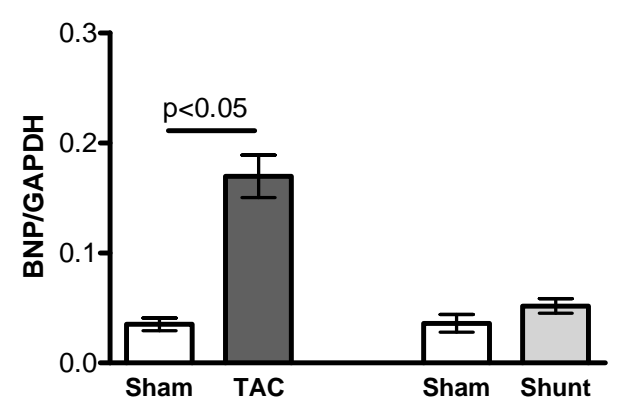

Abbildung 16: Expression des BNP im Sham-, TAC- und Shunt-Modell, normalisiert auf GAPDH: A) 24 Stunden nach Intervention ( $n=6 / 6 / 6 / 7), B) 7$ Tage nach Intervention $(n=8 / 10 / 7 / 7)$.

Zur quantitativen Analyse des kardialen Hypertrophiemarkers BNP wurde eine realtime-PCR nach 24 Stunden und 7 Tagen in den Tier-Modellen durchgeführt. Die Expression des in der Glykolyse in jeder Zelle aktiven Enzyms GAPDH wurde zur Normalisierung verwendet.

Die Analyse der BNP-Expression im Shunt-Modell zeigte sowohl nach 24 Stunden als auch nach 7 Tagen keinen signifikanten Anstieg. Im Gegensatz zum Modell der Vorlasterhöhung war im TACModell bereits nach 24 Stunden die BNP-Expression signifikant erhöht und auch 7 Tage nach Intervention wurde ein signifikanter BNP-Anstieg nachgewiesen (24 Stunden: 507 \%, P<0,05; 7 Tage: 384 $\%, \mathrm{P}<0,05)$. Somit zeigte sich, dass die Steigerung von BNP mit einem Anstieg der Nachlast zusammenhing. 


\subsection{Adaptive und maladaptive Signalwege im TAC- und Shunt-Modell 24 Stunden und 7 Tage nach Intervention}

Die Analysen der adaptiven und maladaptiven Signalwege im TAC- und Shunt-Modell 24 Stunden und 7 Tage nach Intervention wurden mittels der Western Immunoblot-Methode durchgeführt. Zur Detektierung und Quantifizierung wurden spezifische Antikörper für die unphosphorylierten und phosphorylierten Formen von Akt, GSK3ß, CaMKIID, HDAC und den MAP-Kinasen ERK, p38 und JNK verwendet. Ausnahme war die Untersuchung des maladaptiven Signalwegs Calcineurin/NFAT, bei dem die MCIP-Expression als indirekte Aktivitätsmessung (Yang et al. 2001) mittels realtime-PCR quantifiziert wurde.

Bei der Analyse der Ergebnisse wurde zuerst untersucht, ob sich eine Veränderung in der Gesamtmenge der Proteinexpression darstellt. Lag nach Untersuchung eines Signalweges keine Veränderung der Gesamtmenge der Proteinexpression vor, so wurde das Verhältnis vom phosphorylierten Anteil zur gesamten Menge des betreffenden Proteins berechnet. Dies traf auf die Proteine GSK3ß, JNK, ERK, Akt und HDAC zu. Zeigte sich allerdings eine Veränderung in der Gesamtmenge der Proteinexpression, normalisiert auf GAPDH oder Calsequestrin, so wurde der phosphorylierte Anteil des Proteins auf die Gesamtmenge des Proteins und auf GAPDH normalisiert. Eine Veränderung der Gesamtproteinmenge bestand in den Signalwegen CaMK II $\mathrm{dnd}$ p38.

Indikator für eine erhöhte biologische Aktivität war der Anstieg des phosphorylierten Anteils eines Proteins, normalisiert auf GAPDH. Zur Beurteilung der Relevanz einzelner Veränderungen wurden zwei Zeitpunkte untersucht (24 Stunden und 7 Tage). Nur eine Aktivierung bzw. eine Inhibition eines Signalweges zu beiden Zeitpunkten wurde als relevante Veränderung in einem Modell bezeichnet. Kurzfristige (einzeitige) Veränderungen könnten auch durch perioperative Prozesse oder durch lastunabhängige Faktoren bedingt sein. 


\subsubsection{GSK3ß}

\section{A) GSK3ß und pGSK3ß nach 24 Stunden}

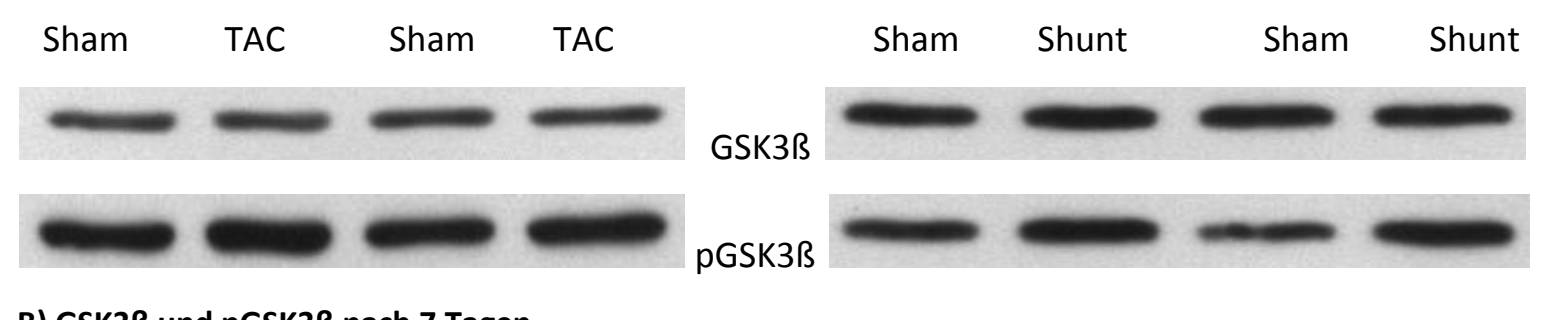

B) GSK3ß und pGSK3ß nach 7 Tagen

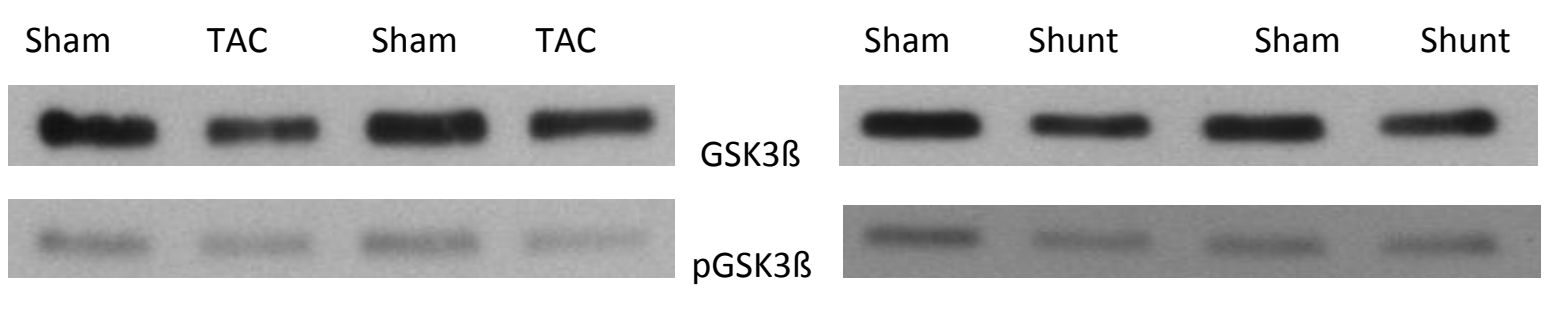

C) pGSK3ß/GSK3ß nach 24 Stunden

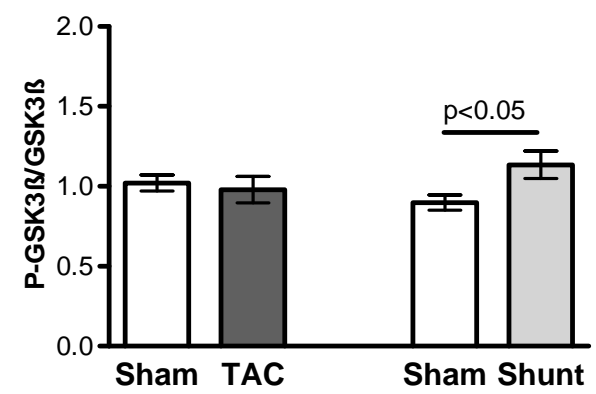

D) pGSK3ß/GSK3ß nach 7 Tagen

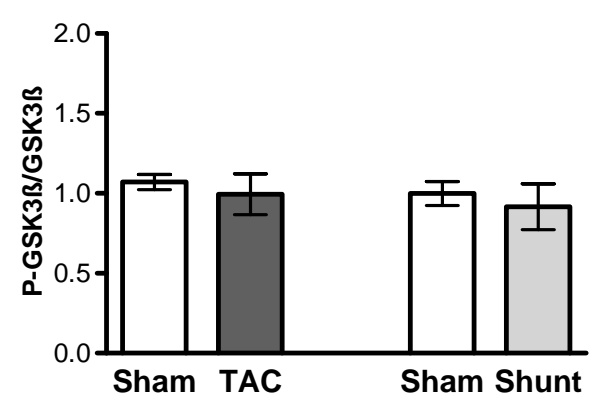

Abbildung 17: Darstellung des Proteins GSK3ß und seiner phosphorylierten Form im Sham-, TAC- und ShuntModell mittels Western-Immunoblot-Methode ( $n=6$ pro Gruppe): A) 24 Stunden nach Intervention, B) 7 Tage nach Intervention. Verhältnis des phosphorylierten GSK3ß-Anteils im Sham-, TAC- und Shunt-Modell zur GSK3ßGesamtexpression im Balken-Diagramm ( $n=6$ pro Gruppe): C) 24 Stunden nach Intervention, D) 7 Tage nach Intervention.

Die Untersuchung von GSK3ß zeigte keine Veränderungen in der Gesamtmenge der Proteinexpression sowohl nach 24 Stunden als auch nach 7 Tagen. 24 Stunden nach Intervention stellte sich im Shunt-Modell ein signifikanter Anstieg $(26,3 \%, \mathrm{P}<0,05)$ im phosphorylierten Anteil des Proteins dar. Im TAC-Modell konnten keine signifikanten Veränderungen gezeigt werden. 


\subsubsection{JNK}

A) JNK und pJNK nach 24 Stunden
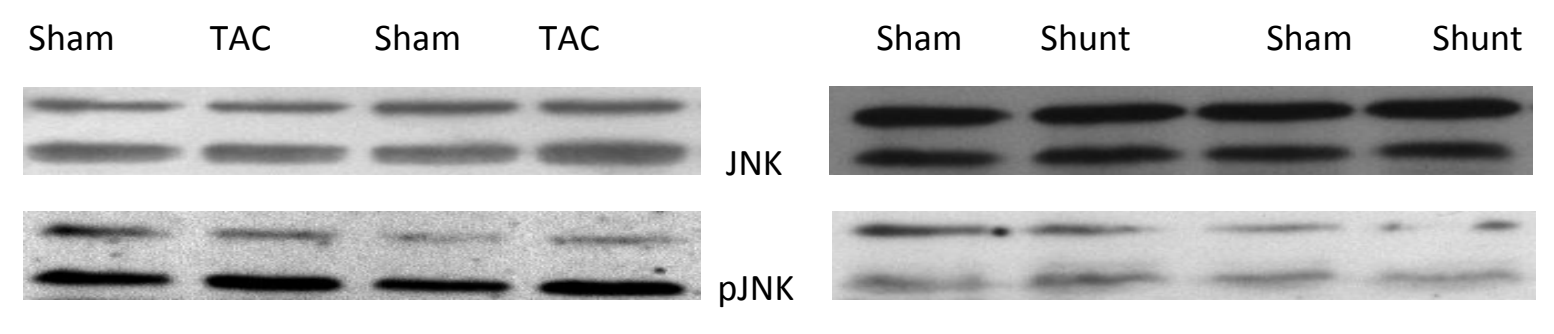

B) JNK und pJNK nach 7 Tagen

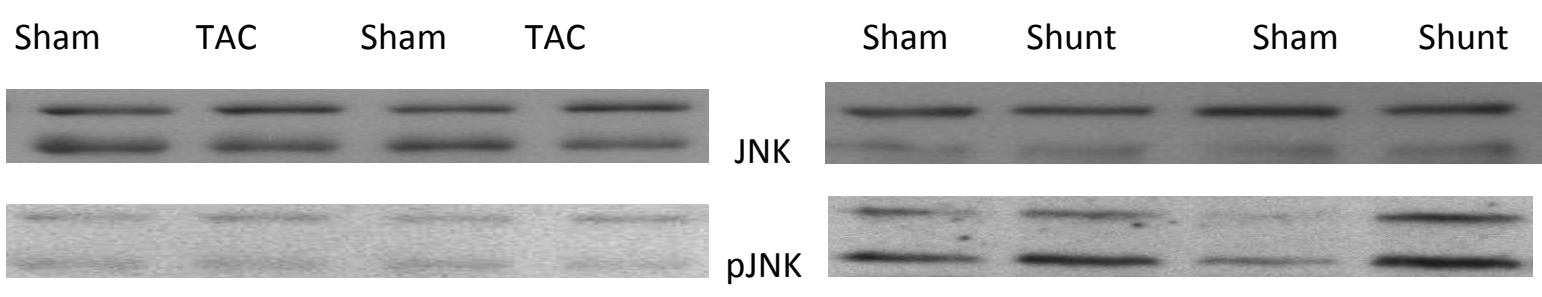

C) pJNK/JNK nach 24 Stunden

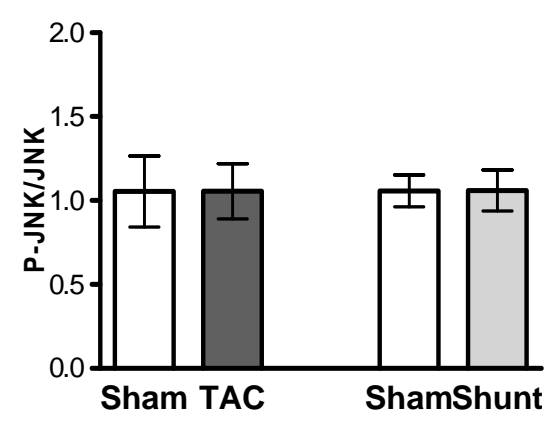

D) pJNK/JNK nach 7 Tagen

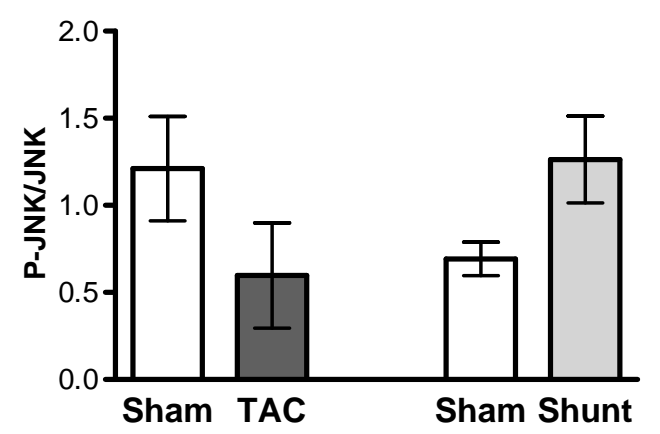

Abbildung 18: Darstellung des Proteins JNK und seiner phosphorylierten Form im Sham-, TAC- und ShuntModell mittels Western-Immunoblot-Methode ( $n=6$ pro Gruppe): A) 24 Stunden nach Intervention, B) 7 Tage nach Intervention. Verhältnis des phosphorylierten JNK-Anteils im Sham-, TAC- und Shunt-Modell zur JNKGesamtexpression im Balken-Diagramm ( $n=6$ pro Gruppe): C) 24 Stunden nach Intervention, D) 7 Tage nach Intervention.

Die Expression der Gesamtproteinmenge von JNK unterlag bei den Untersuchungen keinen signifikanten Veränderungen. Daher wurde das Verhältnis der phosphorylierten Form zur Gesamtmenge des Proteins berechnet. Hierbei zeigten sich weder im TAC- noch im Shunt-Modell signifikante Veränderungen zu beiden gemessenen Zeitpunkten. Allerdings wurde nach 7 Tagen im TAC-Modell tendenziell eine Reduktion und im Shunt-Modell tendenziell ein Anstieg der phosphorylierten Form des Proteins JNK beobachtet. Diese Tendenzen waren jedoch nicht signifikant. 


\subsubsection{ERK}

A) ERK und pERK nach 24 Stunden
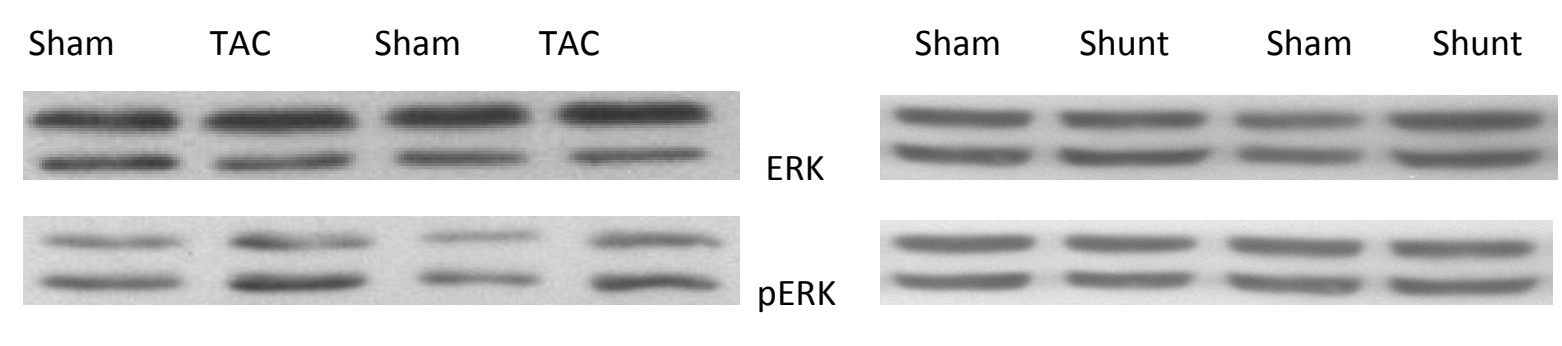

B) ERK und pERK nach 7 Tagen

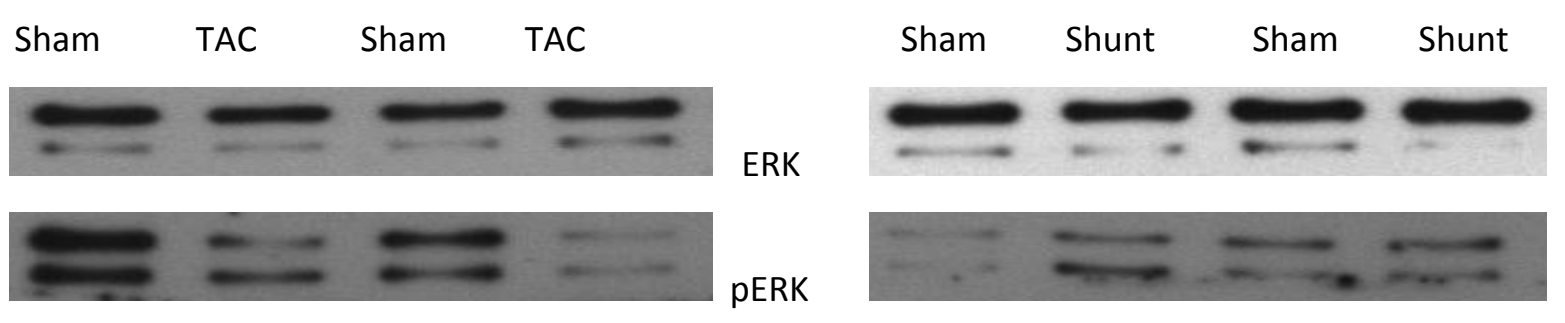

A) pERK/ERK nach 24 Stunden

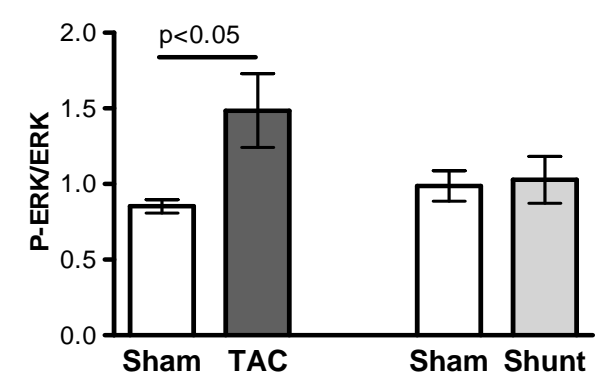

B) pERK/ERK nach 7 Tagen

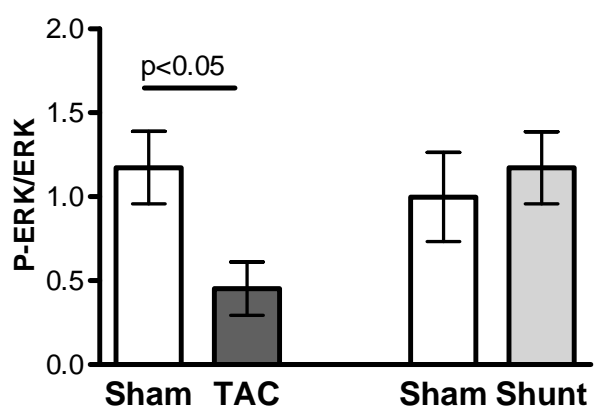

Abbildung 19: Darstellung des Proteins ERK und seiner phosphorylierten Form im Sham-, TAC- und ShuntModell mittels Western-Immunoblot-Methode ( $n=6$ pro Gruppe): A) 24 Stunden nach Intervention, B) 7 Tage nach Intervention. Verhältnis des phosphorylierten ERK-Anteils im Sham-, TAC- und Shunt-Modell zur ERKGesamtexpression im Balken-Diagramm ( $n=6$ pro Gruppe): C) 24 Stunden nach Intervention, D) 7 Tage nach Intervention.

Auch die Untersuchung des Proteins ERK zeigte nach der Untersuchung keine Veränderung der Gesamtmenge. Im TAC-Modell stellte sich allerdings 24 Stunden nach Intervention ein signifikanter Anstieg des phosphorylierten Anteils $(74 \%, \mathrm{P}<0,05)$ ein. 7 Tage nach Intervention war nun das pERK/ERK-Verhältnis im TAC-Modell aber signifikant vermindert (61 \%, P<0,05). Im Shunt-Modell waren weder nach 24 Stunden noch nach 7 Tagen signifikante Veränderungen zu beobachten. 


\subsection{4 p38}

A) p38, pp38 und GAPDH nach 24 Stunden

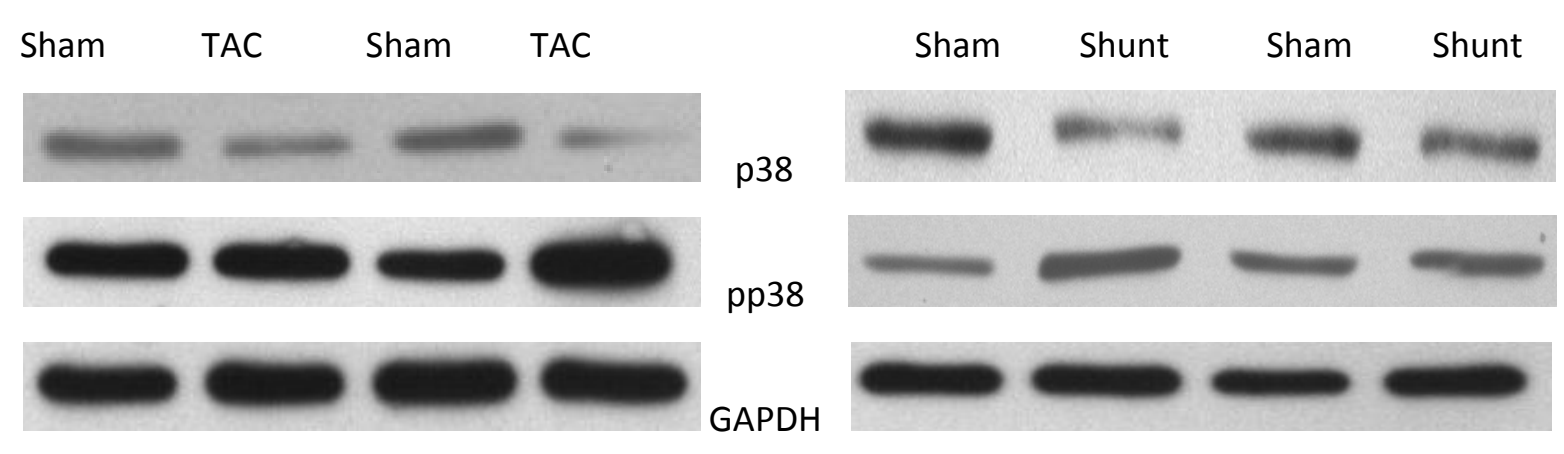

B) p38, pp38 und GAPDH nach 7 Tagen

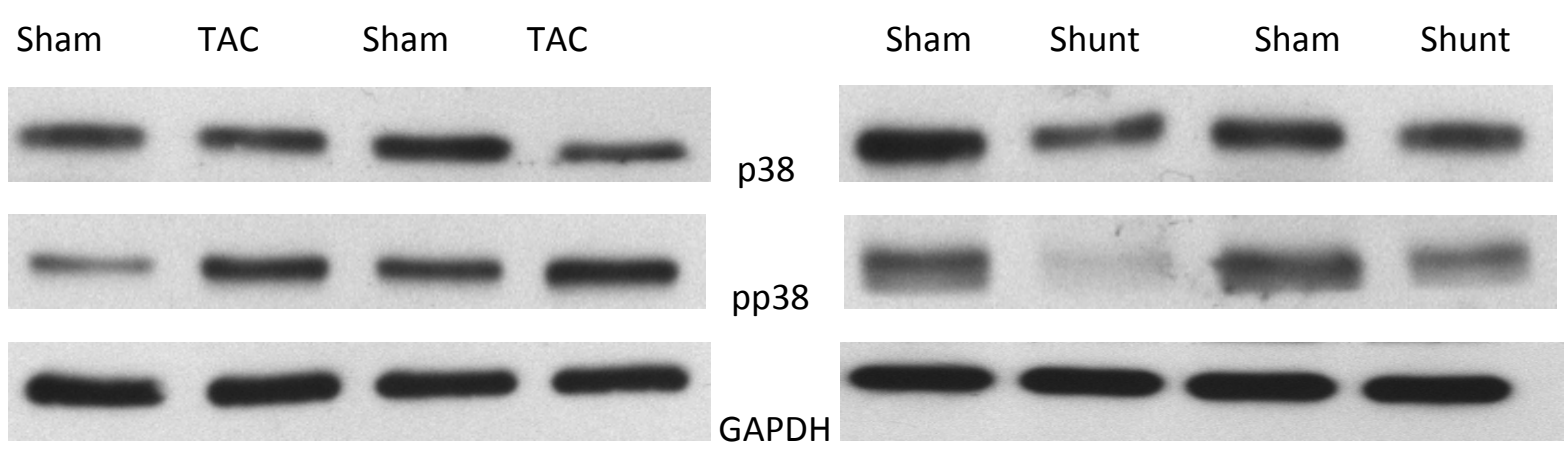

Abbildung 20: Darstellung des Proteins p38 und seiner phosphorylierten Form im Sham-, TAC- und ShuntModell sowie GAPDH, das zur Normalisierung diente, mittels Western-Immunoblot-Methode ( $n=6$ pro Gruppe): A) 24 Stunden nach Intervention, B) 7 Tage nach Intervention. 
A) p38/GAPDH nach 24 Stunden

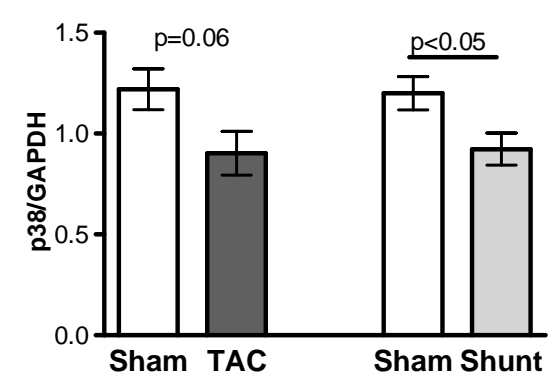

C) pp38/p38 nach 24 Stunden

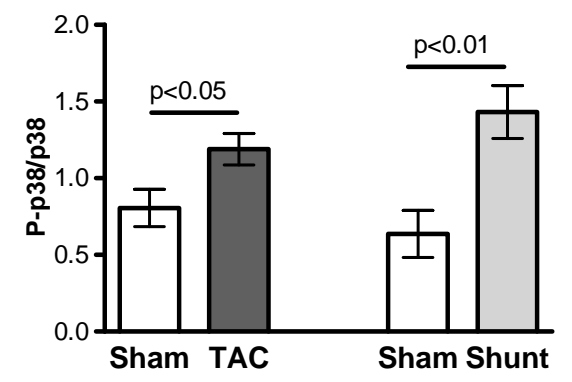

E) pp38/GAPDH nach 24 Stunden

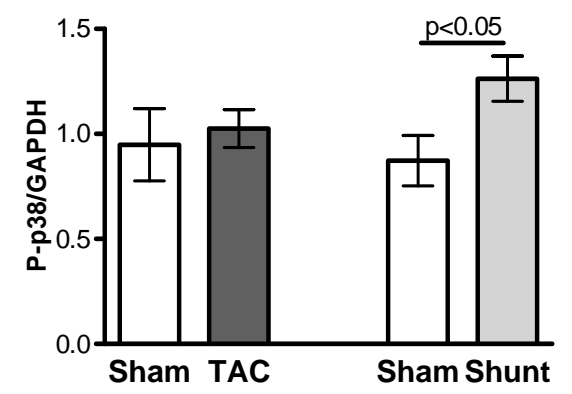

B) p38/GAPDH nach 7 Tagen

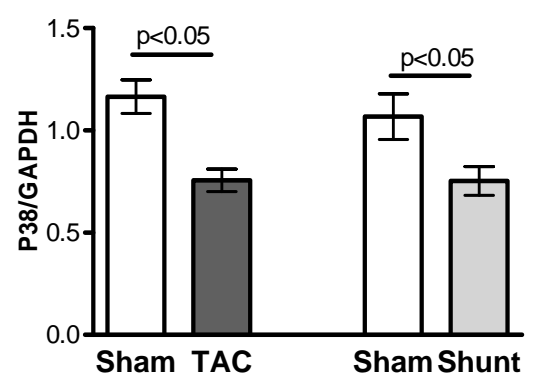

D) pp38/p38 nach 7 Tagen

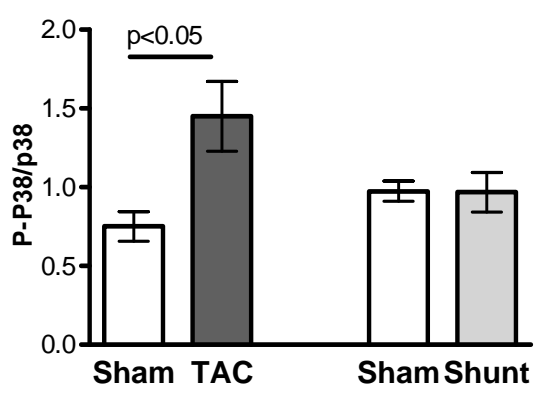

F) pp38/GAPDH nach 7 Tagen

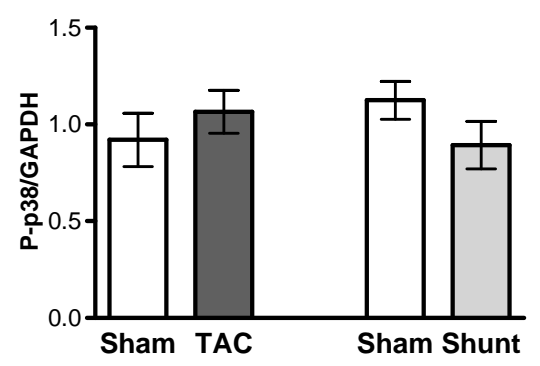

Abbildung 21: Verhältnis des p38-Anteils im Sham-, TAC- und Shunt-Modell zur GAPDH-Expression im BalkenDiagramm ( $n=6$ pro Gruppe): A) 24 Stunden nach Intervention, B) 7 Tage nach Intervention. Verhältnis des phosphorylierten p38-Anteils im Sham-, TAC- und Shunt-Modell zur p38-Gesamtexpression im BalkenDiagramm ( $n=6$ pro Gruppe): C) 24 Stunden nach Intervention, D) 7 Tage nach Intervention. Verhältnis des phosphorylierten p38-Anteils im Sham-, TAC- und Shunt-Modell normalisiert auf die GAPDH-Expression im Balken-Diagramm ( $n=6$ pro Gruppe): E) 24 Stunden nach Intervention, F) 7 Tage nach Intervention.

Die Analyse der Gesamtmenge des Proteins p38 zeigte bei der Normalisierung auf GAPDH sowohl eine signifikante Reduktion zu beiden Messungszeitpunkten im Shunt-Modell als auch eine signifikante Reduktion 7 Tage nach Intervention im TAC-Modell. Im Shunt-Modell stellte sich ein Expressionsrückgang nach 24 Stunden um $23 \%(P<0,05)$ und nach 7 Tagen um $29 \%(P<0,05)$ dar. Die Phosphorylierung von p38 war trotz einer geringeren Expression der Gesamtproteinmenge des untersuchten Proteins im TAC-Modell zu beiden Zeitpunkten der Messungen signifikant erhöht (24 Stunden: 48 \% $(P<0,05)$; 7 Tage: 93 \% $(P<0,05))$. Im Shunt-Modell konnte ein signifikanter Anstieg in diesem Verhältnis nur nach 24 Stunden nachgewiesen werden $(125 \%, \mathrm{P}<0,01)$. 
Insgesamt war die biologische Aktivität (p38/GAPDH) im Shunt-Modell nur nach 24 Stunden um $45 \%$ $(P<0,05)$ gesteigert. Nach 7 Tagen konnte sowohl im Shunt- als auch im TAC-Modell keine Veränderung dargestellt werden.

\subsubsection{MCIP}

A) MCIP/GAPDH nach 24 Stunden

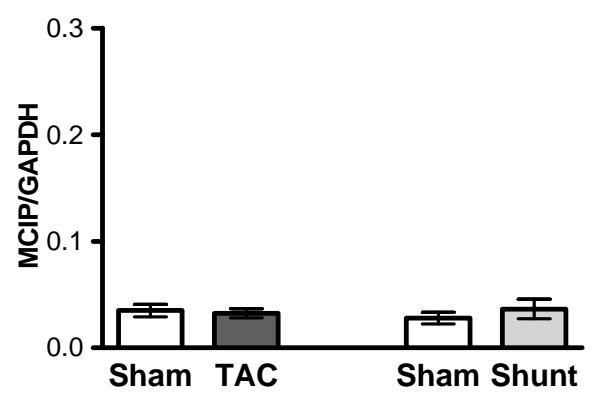

B) MCIP/GAPDH nach 7 Tagen

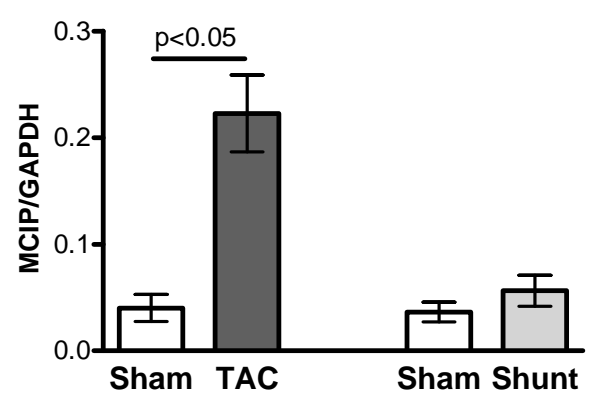

Abbildung 22: Verhältnis von MCIP im Sham-, TAC- und Shunt-Modell zur GAPDH-Expression ( $\mathrm{n}=6$ pro Gruppe): A) 24 Stunden nach Intervention. B) 7 Tage nach Intervention.

Zur Untersuchung des Calcineurin-Signalweges wurde die MCIP-Genexpression gemessen, da diese ein indirekter Parameter der Calcineurin-Aktivität ist (Vega et al. 2003). Um eine eventuell signifikante Änderung in der Expression des Proteins MCIP zu ermitteln, wurde hier auf GAPDH normalisiert. Die Analyse wurde mittels realtime-PCR durchgeführt. Nach 24 Stunden wurde weder im TAC- noch im Shunt-Modell eine signifikante Veränderung beobachtet. Die Untersuchung des Shunt-Modells nach 7 Tagen zeigte ebenfalls keine Signifikanz. Jedoch ergab die Messung zum zweiten Zeitpunkt im TAC-Modell einen Anstieg der MCIP-Expression um $455 \%(P<0,05)$. 


\subsubsection{CaMK II}

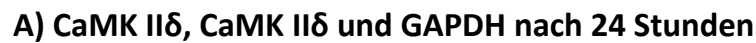
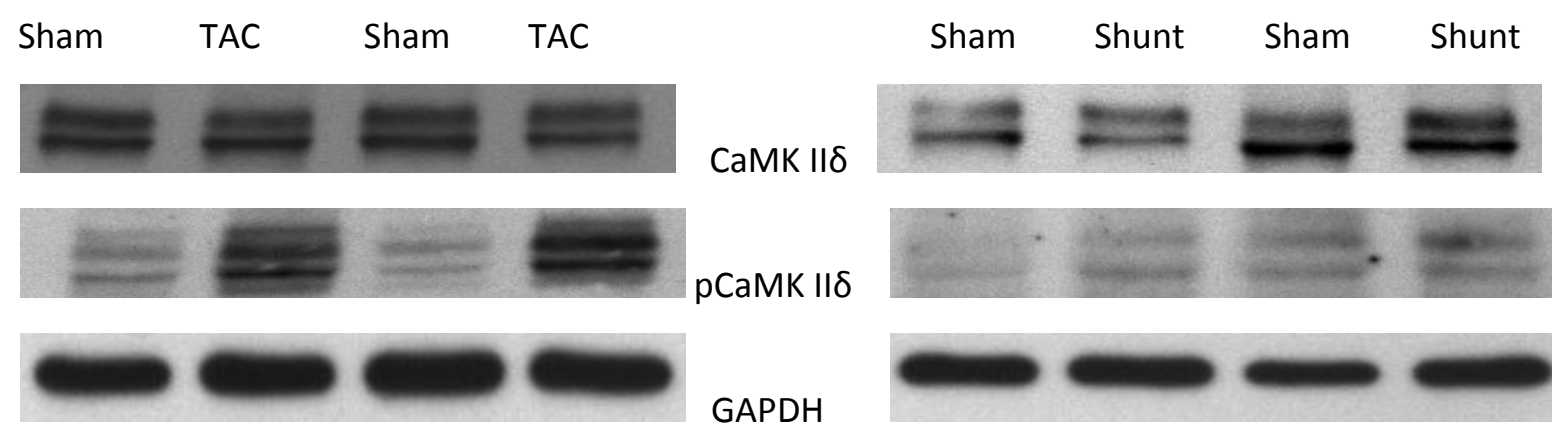

B) CaMK II $\delta$, CaMK II $\delta$ und GAPDH nach 7 Tagen

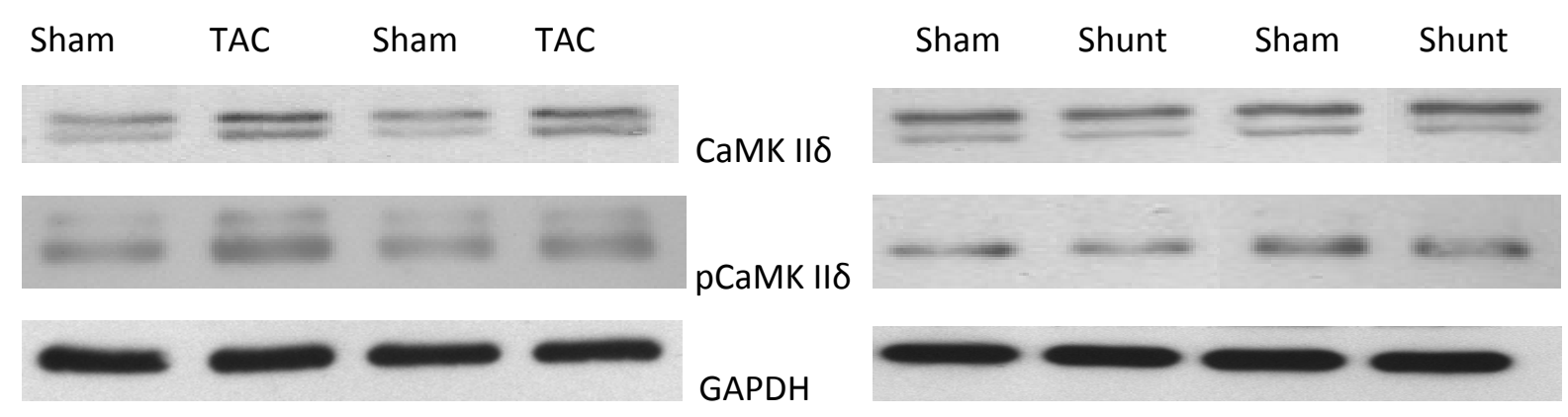

Abbildung 23: Darstellung des Proteins CaMK II $\delta$ und seiner phosphorylierten Form im Sham-, TAC- und ShuntModell sowie GAPDH, das zur Normalisierung diente, mittels Western-Immunoblot-Methode ( $n=6$ pro Gruppe): A) 24 Stunden nach Intervention, B) 7 Tage nach Intervention. 
A) pCaMK II $\delta /$ CaMK II $\delta$ nach 24 Stunden

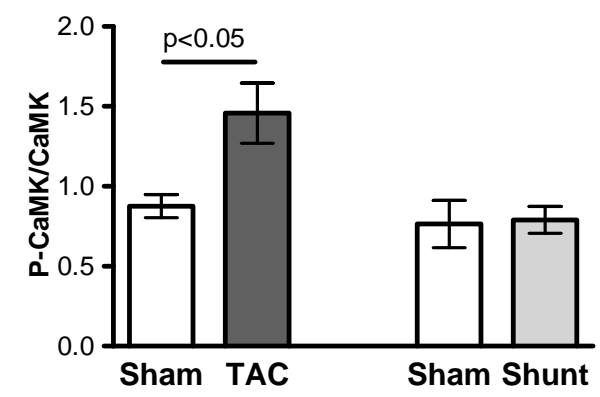

C) pCaMK III/GAPDH nach 24 Stunden

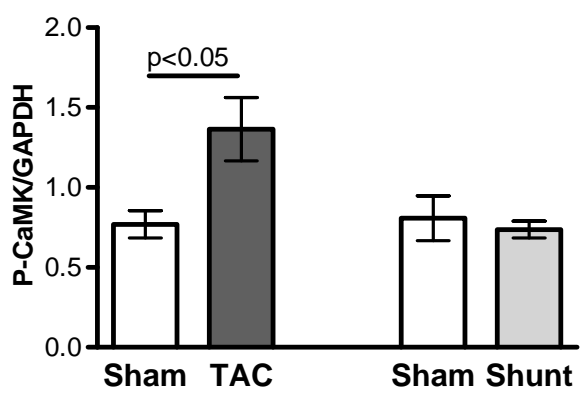

E) CaMK IIס/GAPDH nach 24 Stunden

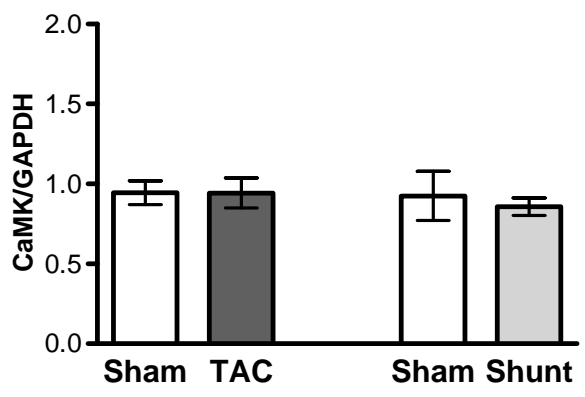

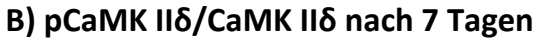

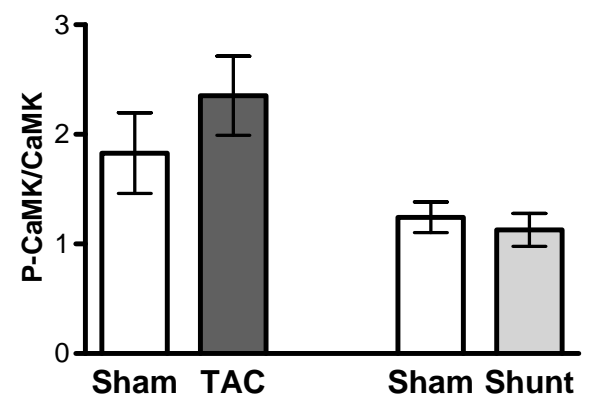

D) pCaMK IIס/GAPDH nach 7 Tagen

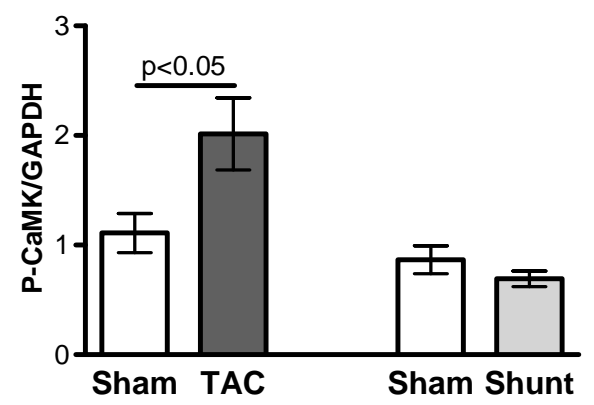

F) CaMK II /GAPDH nach 7 Tagen

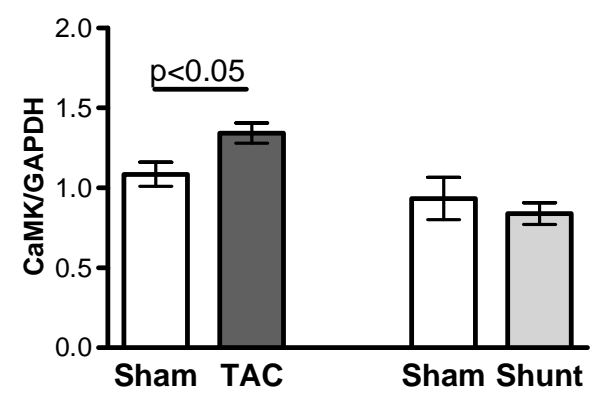

Abbildung 24: Verhältnis des phosphorylierten CaMK IIס-Anteils im Sham-, TAC- und Shunt-Modell zur CaMK IIס-Gesamtexpression im Balken-Diagramm ( $\mathrm{n}=6$ pro Gruppe): A) 24 Stunden nach Intervention, B) 7 Tage nach Intervention. Verhältnis des phosphorylierten CaMK IIס-Anteils im Sham-, TAC- und Shunt-Modell normalisiert auf die GAPDH-Expression im Balken-Diagramm ( $n=6$ pro Gruppe): C) 24 Stunden nach Intervention, D) 7 Tage nach Intervention. Verhältnis des CaMK IIס-Anteils im Sham-, TAC- und Shunt-Modell zur GAPDH-Expression im Balken-Diagramm ( $n=6$ pro Gruppe): E) 24 Stunden nach Intervention, F) 7 Tage nach Intervention.

Im TAC-Modell zeigte sich zu beiden Zeitpunkten eine Veränderung des CaMK II -Signalweges. Im Shunt hingegen zeigte sich keine Veränderung in der CaMK IIS-Expression oder -phosphorylierung. Im Modell der Nachlasterhöhung zeigte sich nach 24 Stunden eine Zunahme des Verhältnisses von phosphoryliertem CaMK II zu Gesamt-CaMK II (66 \%, P<0,05). Nach 7 Tagen fand sich ein signifikanter Anstieg der CaMK IIס-Gesamtproteinmenge im TAC-Modell (CaMK II/GAPDH: 24 \%, P<0,05).

Bei Betrachtung der biologischen Aktivität (pCaMK IIJ/GAPDH) im TAC-Modell zeigte sich nach 24 Stunden und nach 7 Tagen ein Anstieg (24 Stunden: 78 \% ( $P<0,05)$; 7 Tage: $82 \%(P<0,05)$ ). 
Dabei liegen aber, je nach Zeitpunkt, unterschiedliche Mechanismen zugrunde. Nach 24 Stunden

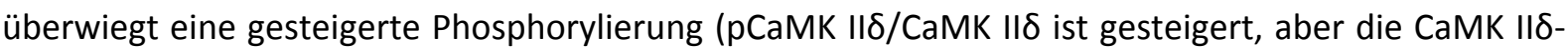
Expression unverändert), während nach 7 Tagen die Expressionsteigerung zur Erhöhung der biolo-

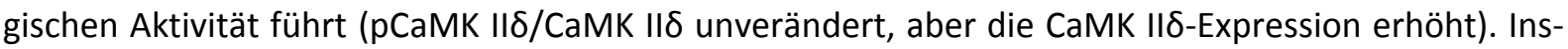
gesamt zeigte sich, dass es bei einer Erhöhung des Drucks, wie es im TAC-Modell simuliert wurde, zu einer permanenten Aktivierung des CaMK IIס-Signalweges kam.

\subsubsection{HDAC}

A) Calsequestrin und pHDAC5 nach 7 Tagen

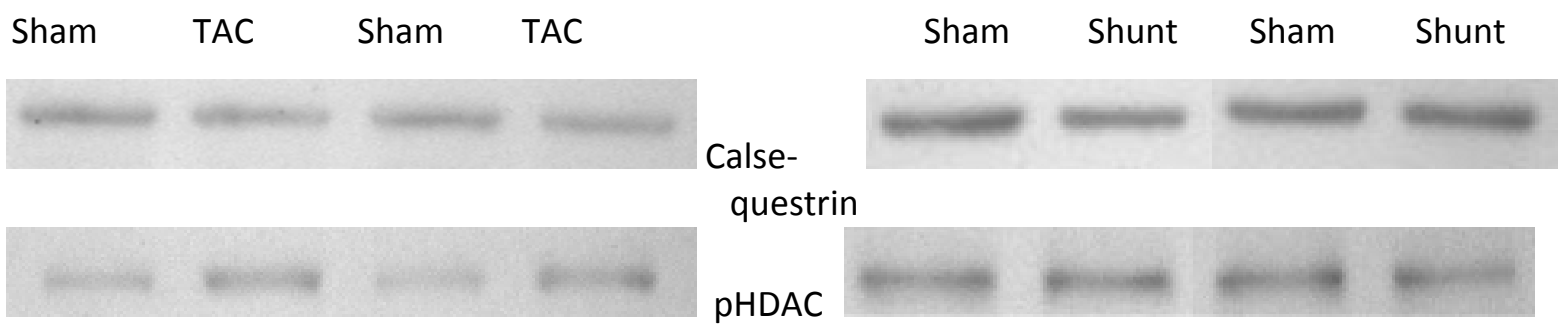

B) pHDAC5/Calsequestrin nach 7 Tagen

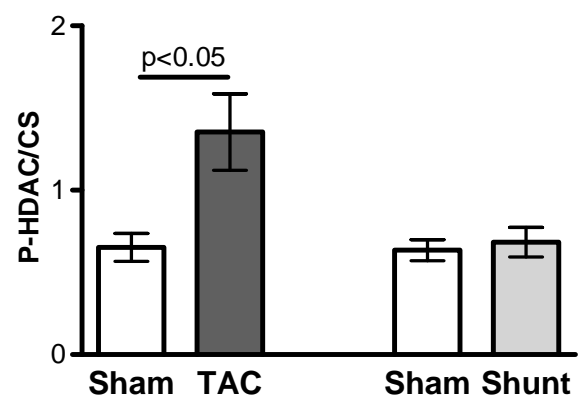

Abbildung 25: A) Darstellung des phosphorylierten Anteils des Proteins HDAC5, normalisiert auf Calsequestrin im Sham-, TAC- und Shunt-Modell 7 Tage nach Intervention mittels Western-Immunoblot-Methode ( $\mathrm{n}=6$ pro Gruppe). B) Verhältnis des phosphorylierten HDAC5-Anteils im Sham-, TAC- und Shunt-Modell zur Calsequestrin-Expression 7 Tage nach Intervention im Balken-Diagramm ( $n=6$ pro Gruppe).

Um HDAC5 zu untersuchen wurde dessen phosphorylierter Anteil in das Verhältnis zur CalsequestrinExpression gesetzt. Diese Untersuchung wurde 7 Tage nach Intervention im TAC- und Shunt-Modell durchgeführt. Hier wurden keine signifikanten Veränderungen im Shunt-Modell beobachtet (8 \%). Im Gegensatz hierzu kam es im TAC-Modell zu einem signifikanten Anstieg der phosphorylierten HDACForm um $107 \%(P<0,05) 7$ Tage nach Intervention. 


\subsubsection{Akt}

A) Akt und pAkt nach 24 Stunden
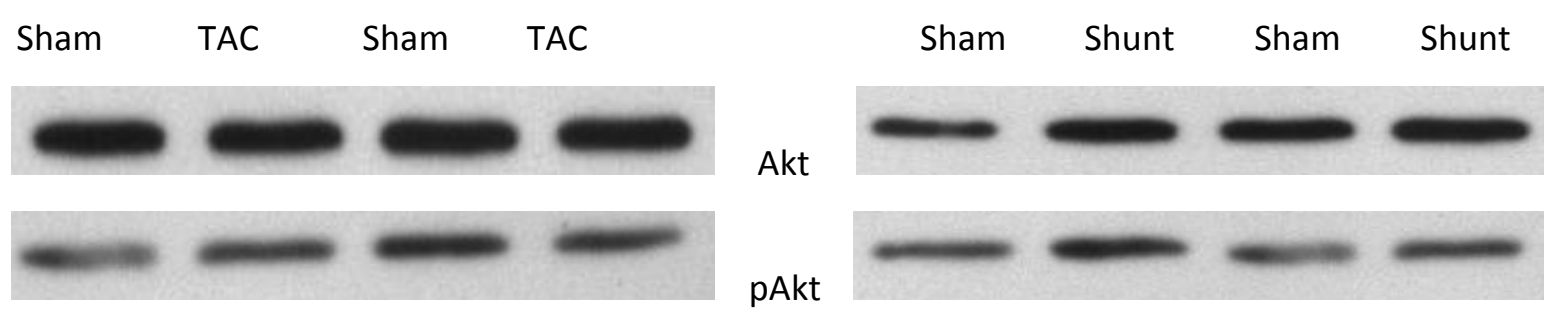

B) Akt und pAkt nach 7 Tagen
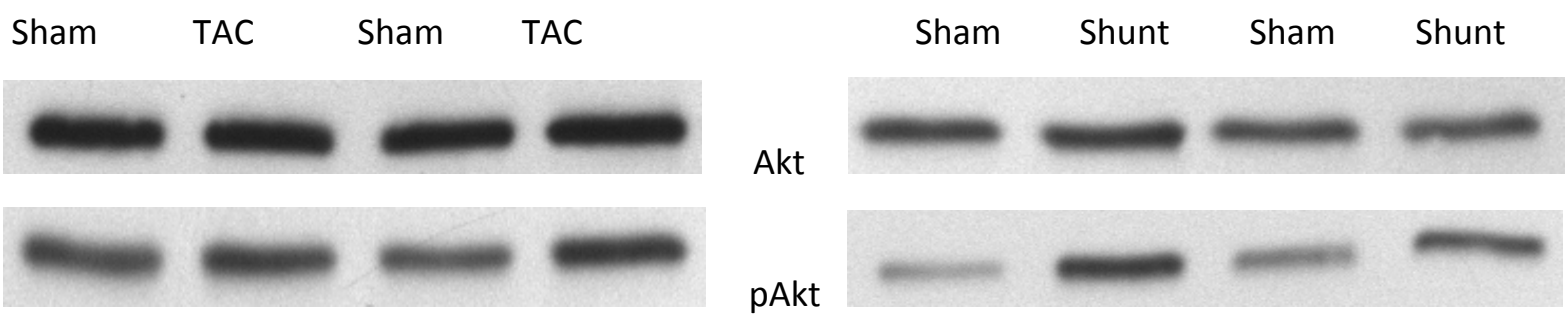

C) pAkt/Akt nach 24 Stunden

D) pAkt/Akt nach 7 Tagen
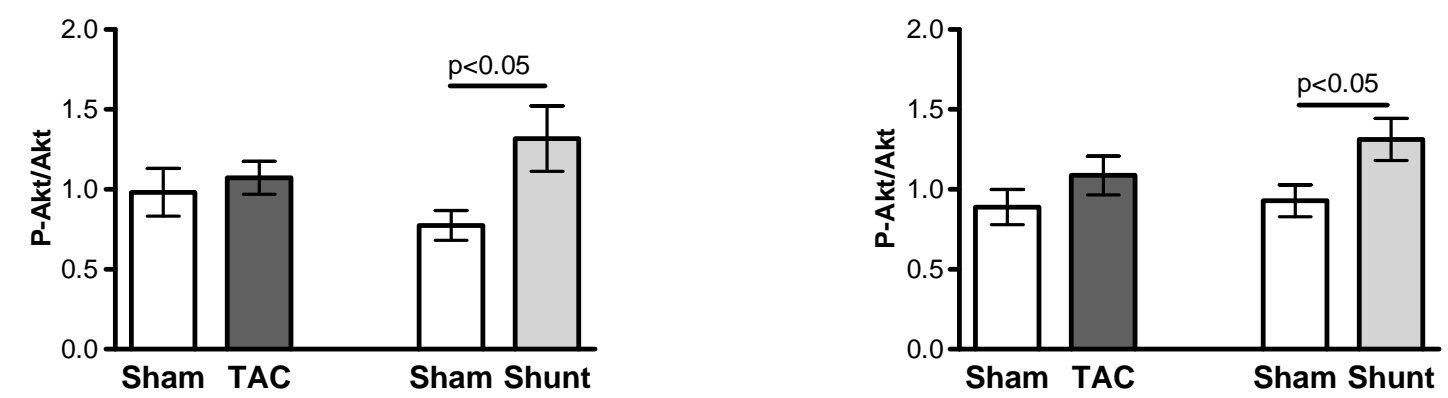

Abbildung 26: Darstellung des Proteins Akt und seiner phosphorylierten Form im Sham-, TAC- und ShuntModell mittels Western-Immunoblot-Methode ( $n=6$ pro Gruppe): A) 24 Stunden nach Intervention, B) 7 Tage nach Intervention. Verhältnis des phosphorylierten Akt-Anteils im Sham-, TAC- und Shunt-Modell zur AktGesamtexpression im Balken-Diagramm ( $n=6$ pro Gruppe): C) 24 Stunden nach Intervention, D) 7 Tage nach Intervention.

Es stellte sich im Akt-Signalweg keine Veränderung der Gesamtmenge des Akt-Proteins dar. Daher wurde auch hier das Verhältnis des phosphorylierten Anteils zur Gesamtexpression des Proteins ermittelt. Im TAC-Modell war weder nach 24 Stunden noch nach 7 Tagen eine signifikante Veränderung zu beobachten. Im Shunt-Modell hingegen wurde zu beiden Zeitpunkten ein signifikanter Anstieg der Phosphorylierung von Akt nachgewiesen (24 Stunden: $70 \%, \mathrm{P}<0,05 ; 7$ Tage: $41 \%, \mathrm{P}<0,05$ ). Somit zeigt der Akt-Signalweg im Shunt-Modell eine permanente Aktivierung. 


\section{Diskussion}

\subsection{Hypertrophie}

\subsubsection{Wandspannungen im TAC- und Shunt-Modell}

Der makroskopische Phänotyp der exzentrischen bzw. der konzentrischen Hypertrophie bei Vorlastbzw. Nachlasterhöhung ist gut verstanden. Die molekularen Veränderungen und Mechanismen bei einer druck- bzw. volumeninduzierten Hypertrophie und Herzinsuffizienz sind bisher nur wenig bekannt. Viele wissenschaftliche Arbeiten setzen sich mit der Klärung der molekularen Mechanismen auseinander, allerdings ist allen bisherigen Studien gemein, dass entweder nur ein Modell untersucht oder eine vergleichbare Belastung beider Modelle nicht gezeigt wurde. Ziel dieser Arbeit war es durch Messung der Wandspannung ein vergleichbares Belastungsniveau beider Modelle zu generieren und dann den kardialen Phänotyp sowie die zugrundeliegenden Mechanismen zu untersuchen. Im TAC-Modell zeigten sich eine deutliche Steigerung der systolischen Wandspannung sowie eine geringe Steigerung der diastolischen Wandspannung. Der Anstieg der diastolischen Wandspannung ist wahrscheinlich durch eine leicht reduzierte Auswurfleistung des Herzens zu erklären. Auch im TAC-Modell findet sich eine geringe nicht-signifikante Steigerung des enddiastolischen Volumens, was zu einem Anstieg der diastolischen Wandspannung führt. Das TAC-Modell ist somit ein Nachlastmodell mit einer geringen Vorlasterhöhung. Im Shunt-Modell war keine Veränderung der systolischen Wandspannung, aber ein deutlicher Wandspannungsanstieg in der Diastole zu sehen.

Zum direkten Vergleich wurde die Wandspannung über den gesamten kardialen Kontraktionszyklus gemittelt. Dabei zeigte sich, dass die Zunahme der Wandspannung durch Intervention in beiden Modellen etwa gleich groß war (TAC-Modell: 67 \% $(\mathrm{P}<0,05)$, Shunt-Modell: 69 \% $(\mathrm{P}<0,05))$. Diese Feststellung lässt einen Vergleich der erhobenen Daten bezüglich hypertrophen Geschehens, kardialer Funktion, Remodeling-Prozesse und Überlebens der Versuchstiere zu.

\subsubsection{Kardiale Phänotypen}

Es ist bereits bekannt, dass eine Zunahme des Drucks zu einer kardialen konzentrischen Hypertrophie und eine Volumenbelastung zu einer kardialen exzentrischen Hypertrophie führen (Grossman et al. 1975). Die Ausprägung des entsprechenden kardialen Phänotyps auf Druck bzw. Volumen wurde auch unter den gegebenen Bedingungen der vorliegenden Arbeit beobachtet. Die Normalisierungen der linksventrikulären Gewichte auf die Tibia-Längen der Versuchstiere zeigten bereits nach 7 Tagen signifikante hypertrophe Geschehen in beiden Modellen (TAC: $22 \%$, Shunt: $29 \%$, beide P<0,01 im Vergleich zur Sham-Gruppe, zwischen Shunt- und TAC-Modell bestanden keine signifikanten Änderungen). Hier findet sich somit bei gleicher mechanischer Belastung ein vergleichbares Ausmaß der 
Hypertrophie. Die Analysen der LVEDD bestätigten ebenfalls die vorangegangenen Studien. Bei gleichen mittleren Wandspannungen kam es unter Volumenbelastung nach 24 Stunden zu einer signifikanten Zunahme des LVEDD (18\%, P<0,05), der auch nach 7 Tagen $(31 \%, \mathrm{P}<0,01)$ weiterhin bestand. Die Zunahme des LVEDD unter Volumenbelastung wurde 8 Wochen nach Intervention erneut beobachtet (Toischer et al. 2010). Eine signifikante Zunahme der Septumstärke ist wie erwartet in der vorliegenden Arbeit unter Druckbelastung nachgewiesen worden. Auch diese Entwicklung konnte in Untersuchungen 8 Wochen nach Intervention bestätigt werden (Toischer et al. 2010).

\subsection{BNP}

Auf molekularer Ebene kommt es bei der myokardialen Hypertrophie und im Progress bei der Herzinsuffizienz-Entstehung zu einem Remodeling-Prozess, der durch die Reaktivierung der fetalen Genexpression charakterisiert ist. Dies hat die erhöhte kardiale Expression von ANP und BNP (Chien et al. 1993) und die verringerte Expression der Kalzium-regulierenden ATPase des SR (SERCA2a) (Hasenfuß et al. 1994) zur Folge.

Zur Klärung der Frage, ob die kardiale Expression des Hypertrophiemarkers BNP in vivo bei Vor- bzw. Nachlasterhöhung vergleichbar ist, wurde eine PCR-Untersuchung in den Tiermodellen durchgeführt. Die Ergebnisse zeigten sowohl nach 24 Stunden (507\%, P>0,05) als auch nach 7 Tagen (384 \%, $\mathrm{P}<0,05)$ im Modell der Nachlasterhöhung eine signifikante Zunahme der BNP-Expression. Im Modell der Vorlasterhöhung wurden keine signifikanten Veränderungen beobachtet.

In vorangegangenen Arbeiten wurde bereits sowohl die SERCA2a- als auch die BNP-Expression bei veränderten Lastbedingungen in vitro analysiert. Kögler et al. (2006) führten eine mechanische Dehnung von Kaninchenmuskelstreifen durch. Nach 6 Stunden unter isoliert erhöhter Vorlast zeigte sich keine Veränderung der SERCA2a-Expression im myokardialen Gewebe. 2008 untersuchten Toischer et al. in vitro die BNP-Expression. Hier konnte gezeigt werden, dass die gesteigerte Expression auf eine Nachlasterhöhung oder auf eine neurohumorale Stimulation zurückzuführen ist. Die in-vitroUntersuchungen konnten in Untersuchungen im Rahmen dieser Dissertation in vivo bestätigt und um die Aussage erweitert werden, dass es sowohl nach 24 Stunden als auch nach 7 Tagen im Modell der Vorlasterhöhung nicht zu einem Anstieg der BNP-Expression kommt. Die vorliegenden in-vivoStudien unterstützen weiterhin die These Toischers et al. (2008), da eine deutlich erhöhte linksventrikuläre BNP-Expression im TAC-Modell gezeigt werden konnte.

Es liegen Studien vor, die BNP eine diagnostische und protektive Qualität zusprechen. BNP wird als Hypertrophiemarker eingesetzt und kann bei herzinsuffizienten Patienten als Indikator für den Schweregrad und die Prognose verwendet werden (Wei et al. 1993). Ebenso wird seine therapeutische Relevanz als Vasodilatator und Diuretikum im akuten Stadium der Herzinsuffizienz deutlich (de Denus et al. 2004). 
BNP wirkt nicht nur protektiv, sondern führt durch Beeinflussung der SERCA2a-Expression zur Verschlechterung der Herzfunktion (Kögler et al. 2006). Die linksventrikuläre Expressionssteigerung des BNPs kann hier somit eine ursächliche Rolle in der Herzinsuffizienzentwicklung spielen.

Bei Schädigung des Myokards zeigt sich sowohl eine vermehrte Expression von BNP (Luchner et al. 2001) als auch von dessen Nebenprodukt N-terminal-proBNP (NT-proBNP). Eine Erhöhung wird bei systolischer und diastolischer linksventrikulärer Hypertrophie oder Dysfunktion nachgewiesen. Die Bestimmung des BNP und seines inaktiven Nebenproduktes ist in der Diagnostik einer akuten oder dekompensierten Herzinsuffizienz bereits etabliert (Wei et al. 1993) und korreliert mit NT-proBNP (Mueller et al. 2005).

Weiterhin zeigen klinische Studien Korrelationen zwischen dem Grad der Herzklappenerkrankung und der BNP-Konzentration im Blut. Bei Aortenklappensteonsierung (AS), die eine Nachlasterhöhung mit sich bringt, wird eine erhöhte BNP-Konzentration beobachtet und der Grad der Stenosierung korreliert mit den Symptomen der Erkrankung (Gerber et al. 2003). Sowohl eine Aortenklappeninsuffizienz (AI) als auch eine Mitralklappeninsuffzienz (MI) führen u.a. zu einer Erhöh-ung des linksventrikulären Volumens. Ein Anstieg der BNP-Konzentration ist sowohl bei einer Al (Eimer et al. 2004) als auch bei einer MI zu beobachten. Auch hier korreliert die BNP-Konzentration mit dem Schweregrad der MI (Moe et al. 2007). Die erhöhte BNP-Konzentration wurde in diesen Studien im Blut der Patienten nachgewiesen. In der hier vorliegendenen Arbeit wurde jedoch im Vorlastmodell weder nach 24 Stunden als auch nach 7 Tagen eine signifikante Erhöhung des BNP in einer PCR-Analyse nachgewiesen. Somit ist davon auszugehen, dass der BNP-Anstieg bei einer Mitral- oder Aortenklappeninsuffizienz eher auf eine Katecholamin-, systemische Angiotensin-II-Ausschüttung oder eine erhöhte Produktion in den kardialen Vorhöfen zurückzuführen ist. 


\section{3 Überleben und Funktion}

\subsubsection{Bedeutung der echokardiographischen Befunde}

In der vorliegenden Arbeit wurde ein Anstieg des linksventrikulären Gewichts in beiden Modellen berechnet. Ein Anstieg des kardialen Gewichts ist assoziiert mit einer erhöhten Morbidität und Mortalität (Levy et al. 1990). Neben dem Gewicht des Herzens lassen auch andere Faktoren eine Aussage zu Morbidität und Mortalität zu.

Grossman et al. (1975) zeigten, dass es bei der konzentrischen Hypertrophie zu einer Zunahme des Quotienten von Wandstärke zu linksventrikulärem Radius kommt. Im Vergleich wurde bei der exzentrischen Hypertrophie ein gleichbleibender Wandstärke/linksventrikulärer Radius-Quotient gezeigt. Die Analysen ließen die These zu, dass eine Zunahme des systolischen Drucks zu einer Zunahme der Muskelfaserstärke (konzentrische Hypertrophie) führt und es durch die Zunahme der Wandstärke zum Druckausgleich kommt. Im Gegensatz hierzu ist bei einer Volumenzunahme eine Erweiterung des Ventrikels und keine Zunahme der Wanddicke zu sehen (exzentrische Hypertrophie). Dies ergibt gemäß dem Laplace-Gesetz eine hohe nicht kompensierte Wandspannung. Die exzentrische Hypertrophie galt somit als ungünstige Form der Hypertrophie, wohingegen auf Grund der Kompensation gemäß dem Laplace-Gesetz die konzentrische kardiale Hypertrophie als günstig beschrieben wurde (Linzbach 1960; Grossman et al. 1975). Die Wandspannung galt lange als entscheidender Faktor für die Ausprägung des kardialen Phänotyps.

Im Rahmen dieser Dissertation wurden weiterführende Untersuchungen durchgeführt. Hier zeigte sich (Toischer et al. 2010), dass 125 Tage nach Intervention im Shunt-Modell noch $50 \%$ der Tiere $(P<0,01)$ im Vergleich zur Sham-Gruppe lebten. Im TAC-Modell waren bereits nach 68 Tagen $74 \%$ der Tiere im Vergleich $(P<0,01)$ zur scheinoperierten Gruppe verstorben. $\mathrm{Zu}$ diesem Zeitpunkt lebten noch 80 \% der Shunt-Tiere. Somit zeigt sich eine um 122 \% höhere Überlebensrate der Shunt-Tiere im Vergleich zu den TAC-Tieren $(P<0,05)$. Weitere Untersuchungen zeigten im Nachlastmodell nach 8 Wochen allerdings eine deutliche Einschränkung der FS in den Mäuseherzen. Im Vorlastmodell wurde ebenfalls eine Verminderung der FS dargestellt, die aber nicht das Ausmaß des TAC-Modells annahm (Toischer et al. 2010). Diese Daten zeigen somit, dass bei Vorlasterhöhung (Shunt-Modell) im Vergleich zur Nachlasterhöhung (TAC-Modell) das Überleben besser und die Progredienz der Herzinsuffizienz günstiger ist. Somit kommt es im Shunt-Modell trotz dauerhaft hoher Wandspannung (LaplaceGesetz) zu einer günstigeren Hypertrophie, während im Nachlastmodell -trotz Ausgleichs der Wandspannung- maladaptive Vorgänge stärker ausgeprägt sind. Dies verdeutlicht, dass nicht das Ausmaß der Hypertrophie, sondern eher die Zusammensetzung der zellulären Bestandteile der entscheidende Faktor für die Entwicklung einer Herzinsuffizienz ist. 
Dies ist inzwischen auch aus Studien mit gentechnisch veränderten Mäusen bekannt, in denen nach mechanischer Belastung eine Hypertrophie verhindert wurde, es aber trotzdem mit einer besseren Prognose vereinbar war. Dies wurde zum Beispiel in darauffolgenden Studien durch Inhibition des Calcineurins durch Cyclosporin A (Husi et al. 1994; Clipstone et al. 1994) gesehen. Molkentin et al. (1998) zeigten im Maus-Modell, dass Calcineurin anteilig an der kardialen Hypertrophie-Entwicklung beteiligt ist. Sussman et al. (1998) konnten in einem transgenen Maus-Modell die Inhibition der hypertrophen Kardiomyopathie unter Verwendung von Cyclosporin A zeigen. Hill et al. (2000) bestätigten unter Druckbelastung und Cyclosporin A-Gabe die Inhibition der kardialen Hypertrophie. Shimoyama et al. (1999) führten sowohl in einem druck- als auch in einem volumenbelasteten RattenModell eine Hemmung von Calcineurin mit FK506 durch. Im druckbelasteten Modell wurden keine Hypertrophie, Fibrosierung und Veränderungen der hämodynamischen Parameter beobachtet. Im volumenbelasteten Modell fand sich eine Inhibition der fetale Genexpression.

Des Weiteren sprachen Buitrago et al. (2005) dem Transkriptionsrepressor Nab1 eine Rolle in der Entstehung einer kardialen Hypertrophie zu. Die Überexpression von Nab1 in Kardiomyozyten von transgenen Mäusen führte zur Inhibition des pathologischen kardialen Wachstums durch Suppression der adrenergen Stimuli.

\subsubsection{Inflammation, Apoptose und Fibrose}

Eine Entzündungsreaktion ist im Herzversagen mehrfach beschrieben worden (Oral et al. 2003, Kai et al. 2005, Opie et al. 2006). Dabei kommt es zu einer lokalen Erhöhung von Inflammationsmarkern wie Interleukinen, TNF $\alpha$ (Vanderheyden et al. 1998) oder NFkappaB (Barnes und Karin 1997, Karin und Lin 2002). Diese haben modulatorische Auswirkungen sowohl auf Fibrose (Kai et al. 2005) und Apoptose (Dorn 2009) als auch auf den Phänotyp der Kardiomyozyten (Hilfiker-Kleiner et al. 2010). In der vorliegenden Arbeit konnte gezeigt werden, dass eine Inflammation nur im TAC-Modell, nicht aber im Shunt- Modell auftritt. Dies korreliert mit der schlechteren Prognose des TAC-Modells.

Die Entwicklung einer kardialen Fibrosierung als Reaktion auf eine erhöhte Druckbelastung des Herzens wurde bereits von Brilla und Weber beschrieben (1992). In frühen Stadien der Druckbelastung kommt es zu einer reaktiven Fibrose (Weber et al. 1993), in späteren Stadien stellt sich eine „replacement fibrosis" dar. Der durch Myozyten-Apoptose verursachte Gewebeverlust wird dauerhaft durch fibrotisches Gewebe ersetzt (Weber et al. 1993).

Untersuchungen von Inflammation im TAC-Modell haben gezeigt, dass es zu einer massiven Einwanderung von Makrophagen in das Gewebe kommt, die 3 Tage nach Intervention ihren Höhepunkt erreicht. Adhäsionsmoleküle, proinflammatorische Mediatoren wie Chemokine und Wachstumsfaktoren (z.B. TGFß) werden vermehrt in den ersten 7 Tagen nachgewiesen und führen später zur Fibrosierung des Gewebes (Kai et al. 2005). Die der Arbeit zugrunde liegenden Daten zeigen, dass es im TAC- 
Modell schon früh zu einer Fibrose kommt. Dabei ist vor allem eine frühe perivaskuläre Fibrose zu sehen und es kommt zu einer Verlängerung der Diffussionsstrecke zwischen dem Gefäß und den Kardiomoyzyten. Somit müssen Sauerstoff und Nährstoffe einen weiteren Weg zurücklegen. Dies ist auch mit einer Verschlechterung der Funktion zu vereinbaren (Kai et al. 2005). Im Shunt-Modell ist nach 7 Tagen keine globale Inflammation nachweisbar. Man weiß jedoch, dass zu späteren Zeitpunkten eine Aktivierung der Mastzellen (Levick et al. 2010) und anderer Zytokine zu einer Inflammationsreaktion führt (Chen et al. 2010). Es zeigten sich ebenfalls keine Fibrosezeichen. Inzwischen weiss man, dass es im Shunt früh zu deutlichen Bindegewebsumbauten im Herzen kommt.

Dabei kommt es aber nicht zu einer zusätzlichen Einlagerung von Bindegewebe, sondern zu einem kontrollierten Abbau der bestehenden Matrixstruktur und erneutem Einbau. Dies ermöglicht die Erweiterung des linksventrikulären Durchmessers wie sie für die exzentrische Hypertrophie typisch ist. Hier wird vor allem das Gleichgewicht der Matrix Metalloproteinasen (MMPs) und GewebeInhibitoren der MMPs (TIMPs) beeinflusst und es kommt initial sogar zu einem Kollagen-Verlust (Stewart et al. 2003, Ryan et al. 2007). In einem vorlastgesteigerten Hundemodell (durch eine MI) wurde mittels Gene-Array-Analyse gezeigt, dass eine Reduktion sowohl der nicht-kollagen kodierenden Gene als auch von profibrotischer Faktoren stattfindet und es zu einem persistierenden Verlust von interstitiellem Kollagen kommt (Zheng et al. 2009). Somit mag ein späterer Kollagenverlust eine mögliche Ursache einer Herzinsuffizienzentwicklung im Shunt-Modell sein.

Eine erhöhte Apoptoserate im druckbelasteten Herzen wurde von Condorelli et al. (1999) nachgewiesen. Im druckbelasteten Herz zeigte sich in dieser Arbeit mittels Detektion der aktiven Kaspase 3 und TUNEL-Färbung eine deutlich erhöhte Apoptose der Kardiomyozyten (1933 \%, P<0,001). Im Vergleich verursachte die Volumenbelastung nach 7 Tagen in der vorliegenden Arbeit nur eine signifikant geringe Apoptoserate der Myozyten (700 \%, P<0,001). Ein Zusammenhang zwischen Apoptose, kardialen Remodeling-Prozessen und ventrikulären Dysfunktionen ist bekannt (Diwan et al. 2008, Haudek et al. 2007).

Zusammenfassend kann bei einer kardialen exzentrischen Hypertrophie, die sich bei einer Volumenerhöhung auf das Herz entwickelt, von einer günstigen Form der Hypertrophie gesprochen werden. Die Histologie zeigt eine geringe Apoptoserate und keine signifikant erhöhte Fibrosierung oder Inflammation des Gewebes. Diese Ergebnisse sind mit einer lang andauernden guten kardialen Funktion und einer höheren Lebenserwartung im Vergleich zum TAC-Modell assoziiert. Bei einer konzentrischen Hypertrophie zeigt sich eine erhöhte Apoptoserate der Kardiomyozyten, Fibrosierung und Inflammation in Verbindung mit einer deutlichen kardialen Dysfunktion. Die frühen histologischen Veränderungen im TAC-Modell korrelieren mit einer schlechteren Prognose. 


\subsection{Signalwege}

Zur weiteren Charakterisierung der molekularen Veränderungen und Mechanismen wurden die bekannten kardialen Signalwege im TAC- und Shunt-Modell sowohl nach 24 Stunden und als auch nach 7 Tagen untersucht.

\subsubsection{Signalwege im TAC-Modell}

Im TAC-Modell ist CaMK II $\delta$ sowohl nach 24 Stunden als auch nach 7 Tagen aktiviert. Eine Überexpression der Isoform CaMK IIठ induziert eine kardiale Hypertrophie, die rasch in eine dilatative Kardiomyopathie übergeht und zu ventrikulären Dysfunktionen führt (Maier und Bers 2002). Eine Aktivierung von CaMK II $\delta$ im TAC-Modell ist bereits bekannt (Ling et al. 2009) und korreliert mit der schlechteren Prognose des TAC-Modells im Vergleich zum Shunt-Modell.

CaMK $I I \delta$ ist unter anderem an der Regulation von Apoptoseprozessen beteiligt. Bei in-vitroExperimenten mit Ratte- und Mausherzgewebe konnte nach Angiotensin-II-induzierter CaMK IIInhibition eine verminderte Kardiomyozyten-Apoptoserate beobachtet werden (Palomeque et al. 2009). In darauf folgenden Untersuchungen am CaMK II KO-Modell zeigte sich eine geringere Apoptoserate (Toischer et al. 2010) und eine reduzierte interstitielle Fibrosierung (Backs et al. 2009).

Auch bei in-vivo-Experimenten konnte gezeigt werden, dass eine Inhibition der CaMK II die Prognose verbessert. Im CaMK II KO-Modell wurde drei Wochen nach transverser aortaler Konstriktion eine Reduktion der kardialen Dysfunktionen, der myokardialen Fibrosierungen und der Apoptoseraten sowie ein verbessertes Überleben beobachtet (Backs et al. 2009, Ling et al. 2009). Der Einfluss der CaMK II $\delta$ bei Druckbelastung auf die Apoptose wurde von Toischer et al. (2010) ebenfalls im CaMK II KO-Modell untersucht. Hier zeigte sich eine Verminderung der Apoptoserate, nicht aber der Fibrose, so dass CaMK II als wichtiger Signalweg der nachlastinduzierten Apoptose anzusehen ist. Der 2009 von Backs et al. gesehene Unterschied in der Fibrose ist möglicherweise auf den Myozytenverlust durch die hohe Apoptoserate im nicht-transgenen Tier zurückzuführen.

Die Aktivierung der CaMK II erfolgt durch Erhöhung des intrazellulären Kalziums (Hook und Means 2001). Die CaMK II erhöht aber auch selbst das intrazelluläre Kalzium, so dass es zu einer Art circulus vitiosus mit persistierender CaMK IIס-Aktivierung kommt. Der primäre Mechanismus der Kalziuminduzierten CaMK II-Aktivierung ist noch nicht eindeutig geklärt. Allerdings kommt eine Aktivierung über den LTCC oder ein vermehrtes RYR-Leck in Betracht (Witcher et al. 1991, Hain et al. 1995, Maier und Bers 2002). Beide Mechanismen sind im TAC-Modell aktiviert (Wang ZW 2008, Ling et al. 2009). In der hier vorliegenden Arbeit wurde neben der Analyse der CaMK II auch die biologische Aktivität von HDAC untersucht. Es zeigte sich nach 7 Tagen eine signifikante Aktivitätszunahme von phosphoryliertem HDAC im druckbelasteten Maus-Modell, was mit den Studien von Backs et al. (2009) zu vereinbaren ist. Sie zeigten eine Assoziation von CaMK II mit HDAC4 und somit eine Beteiligung von 
HDAC am pathologischen Kalziumstoffwechsel der Myokardzelle. Der Transkriptionsrepressor HDAC4 (Backs und Olson 2006) dissoziiert nach Phosphorylierung durch CaMK II $\delta$ vom MEF2 Transkriptor ab und wandert nach Bindung an ein 14-3-3 Chaperon-Protein vom Nukleus ins Zytoplasma (Backs et al. 2006). Die Aktivierung von MEF2D wurde als weiterer Faktor im pathologischen kardialen Remodeling-Prozess identifiziert (Kim et al. 2008).

\subsubsection{Signalwege im Shunt-Modell}

Im Vorlastmodell zeigte sich in den Analysen eine persistierende Aktivierung des Akt-Signalweges. Bisherige Studien zum Akt-Signalweg wurden überwiegend im Nachlastmodell betrieben.

DeBosch et al. (2006) zeigten im druckbelasteten Modell bei Akt1 KO-Mäusen ein gesteigertes kardiales Wachstum und eine milde Kontraktilitätseinschränkung. Akt2 KO-Mäuse zeigten ein normales Wachstum als Antwort auf eine Druckbelastung. Akt2 ist somit nicht an der kardialen Wachstumskontrolle beteiligt. In verschiedenen Studien (Shiraishi et al. 2004, Rota et al. 2005) wurden nach einer nukleären Akt-Überexpression die Zunahme der kontraktilen Funktion und der Schutz der Kardiomyozyten vor apoptotischen Stimuli gezeigt, sowie eine kardiale Hypertrophie und eine Kardiomyopathie verhindert. Eine Akt-Aktivierung ist über IGF1 auch in Trainingsmodellen zu sehen (Cantley 2002, Oudit et al. 2004). Diese Untersuchungen führen zu dem Schluss, dass Akt zumindest partiell einen positiven Einfluss auf das Herz hat.

Allerdings gibt es vereinzelt auch Arbeiten, die einen ungünstigen Verlauf unter Akt-Aktivierung zeigen (Shiojima et al 2005). Eine längere Akt-Signalweg-Aktivierung im Druck-Modell resultiert in einigen Studien in einer pathologischen kardialen Hypertrophie (Izymiya et al. 2006). Durch die AktAktivierung kommt es zu einer verminderten mTOR-Expression. Die daraus resultierende reduzierte Ausschüttung von VEGF und Angiotensin II sowie das folgende vermehrte Kardiomyozytenwachstum führen zu einem Missverhältnis zwischen kapillärer Dichte und suffizienter Versorgung der Myozyten (Shiojima et al 2005).

Insgesamt zeigt die Mehrzahl der Studien nach Aktivierung des Akt-Signalweges eine adaptive kardiale Hypertrophie mit einer Zunahme der Kardiomyozytengröße (Walsh 2006) und gleichbleibender oder gar verbesserter kardialer Funktion (Condorelli et al. 2002, Shioi et al. 2002). Eine Zunahme der Zellgröße der Kardiomyozyten und eine Verschlechterung der kardialen Funktion konnte durch Unterdrückung von Akt1 oder Überexpression einer Negativ-Mutante von PI3K verhindert werden (McMullen et al. 2003). Hier passt die Akt-Aktivierung zu dem Bild einer günstigen Hypertrophie im Vorlastmodell. 


\subsection{Ursachen der Herzinsuffizienz}

\subsubsection{Ursachen der Herzinsuffizienz im TAC-Modell}

In der vorliegenden Arbeit wurden die histologischen Ursachen einer Herzinsuffizienz in Form von signifikant erhöhten inflammatorischen, fibrotischen und apoptotischen Anteilen im druckbelasteten Myokard vorgefunden.

Die Apoptose stellt einen sehr wichtigen Faktor in der Herzinsuffizienz dar. Frey und Olson (2003) führten den kardialen Remodeling-Prozess auf Veränderungen im intrazellulären Kalziumstoffwechsel zurück und sprachen ihm eine entscheidende Rolle bei der Entwicklung von kardialen Arrhythmien und ventrikulären Dysfunktionen zu. Der CaMK II-Signalweg ist maßgeblich an der Regulation des Kalziumstoffwechsels beteiligt. Wichtige Schlüsselproteine des intrazellulären KalziumGleichgewichts wie Phospholamban, L-Type-Kanäle (Dzhura et al. 2000) und Ryanodin-Rezeptoren (Wehrens et al. 2004) werden phosphoryliert und aktiviert. Die Veränderung des kardialen Phänotyps im Sinne einer Re-Expression des fetalen Genotyps kommt als weitere Ursache hinzu. Die Erhöhung des BNP ist nur ein erster Marker. Im weiteren Verlauf kommt es zu einer Verringerung der SERCAExpression und zu einem MHC-Isoformshift. Ein Isoformshift konnte im Rahmen dieser Dissertationsarbeit in weiteren Analysen bereits 7 Tage nach transverser aortaler Konstriktion gezeigt werden; eine SERCA-Expressionsreduktion allerdings nicht. Die Herzfunktion war zu diesem Zeitpunkt noch erhalten. Im TAC-Modell führte somit eine Vielzahl an Mechanismen zu einer Herzinsuffizienz.

\subsubsection{Ursachen der Herzinsuffizienz im Shunt-Modell}

Aus dem Vorlastmodell sind bisher kaum mechanistische Ursachen der Herzinsuffizienz bekannt. Als mögliche Ursache kommt eine verringerte interstitielle Kollagenbildung in Betracht (Dell'Italia et al. 1995, Dell'Italia et al. 1997, Stewart et al. 2003). Zheng et al. (2009) fanden in ihren Studien an einem Hundemodell bereits 12 Stunden nach erhöhter Volumenbelastung eine durch Kollagen-Verlust verursachte linksventrikuläre Dilatation. Der Kollagen-Verlust resultierte aus einer verminderten Expression von nicht-kollagenen Genen und einer zunehmenden Expression von profibrotischen Faktoren. Auch im Mausmodell konnte in der vorliegenden Arbeit nach 7 Tagen keine Fibrose gezeigt werden. Eine Aktivierung von Mastzellen und eine daraus resultierende Beeinflussung des MMP-TIMPGleichgewichts scheinen mögliche Ursachen der frühen adaptiven und ggf. aber auch der späten maladaptiven linksventrikulären Dilatation zu sein (Bradham et al. 2002, Polyakova et al. 2004).

Weiterhin wäre die hier gezeigte Apoptose auch ein möglicher Mechanismus der Herzinsuffizienzentwicklung. Bereits 2007 wurde von Dent et al. zu einem späteren Zeitpunkt eine Aktivierung der Apoptose beschrieben. Über Veränderungen der molekularen Zusammensetzung der Kardiomyozy- 
ten (zellulärer Remodeling-Prozess) ist im Shunt-Modell bisher nichts bekannt. Weitere Untersuchungen sind hier notwendig.

\subsection{Mechanoperzeption}

Bei der Regulierung von physiologischen Prozessen am Herzen kommt dem mechanischen Stress eine große Bedeutung zu. Lastveränderungen werden vom Myokard wahrgenommen und in intrazelluläre Signale umgewandelt. Lange Zeit war der Mechanismus der Übersetzung eines mechanischen Signals in eine intrazelluläre Antwort nicht verstanden. Arbeitsgruppen konnten zeigen, dass Stimuli, wie z.B. Lastveränderungen, über die extrazelluläre Matrix auf die Sarkomere des Kardiomyozyten weitergeleitet werden. Es kommt zur Veränderung von Genexpression, zellulären Strukturen und kardialer Funktion (Heineke und Molkentin 2006).

Ein wichtiger Ort der Perzeption von mechanischer Last sind die Myofilamente (Hoshijima 2006, Lange et al. 2006). Die Myofilamente bestehen aus einer Aneinanderreihung von Sarkomeren, die aus unterschiedlichen Banden bestehen. In der Z-Bande sind verschiedene Struktur- und Signalproteine vorhanden (Clark et al. 2002, Hoshijima 2006). Zwischen den Z-Banden erstreckt sich das TitinMolekül (Granzier und Labeit 2004), welches nach Dehnung, wie eine Feder, für die Rückführung in den Ausgangszustand verantwortlich ist. Weiterhin finden sich Aktin- und Myosin-Filamente zwischen den Z-Scheiben. Diese sind in der Systole für die Kontraktion verantwortlich.

Bei Druckerhöhung lastet der mechanische Stress in der Systole auf den Z-Scheiben und den Myosinund Aktin-Filamenten. Bei Volumenerhöhung liegt der mechanische Stress in der Diastole auf den ZScheiben und dem Titin-Molekül.

Ein wichtiges Protein, das an der Perzeption von mechanischer Last im Nachlastmodell beteiligt ist, ist das Muskel-spezifische LIM-Proteine (MLP) Calsarcin. Ein fehlerhaftes MLP führt zu einer schweren Ausprägung einer dilatativen Kardiomyopathie. Calsarcin scheint über die Beeinflussung des Calcineurin-Signalweges eine wichtige Rolle für die nachlastinduzierte Hypertrophie zu haben. Die Calsarcin-Familie sind Sarkomer-Proteine, zu denen Calsarcin1, 2 und 3 gehören. Calsarcin1 ist im Herzund Skelettmuskel zu finden, Calsarcin2 und 3 sind Skelettmuskel-spezifisch (Frey et al. 2000). Calsarcine sind am Z-Streifen des Sarkomers lokalisiert (Frank et al. 2006) und interagieren hier mit einer Vielzahl von Proteinen. Hierzu gehören neben Calcineurin auch a-Aktinin, Cyper, ZASP, Oracle, Telethonin/T-cap, $\gamma$-Filamin (Frey et al. 2000, Frey und Olson 2002) und Myotilin (Gontier et al. 2005). Frey et al. (2008) zeigten, dass Calsarcin2 sowohl in vitro als auch in vivo die Calcineurin-Aktivität inhibiert. Im Calsarcin1 KO-Modell wird unter Druckbelastung eine chronische CalcineurinAktivierung gezeigt, die in einer Hypertrophie mit anschließender Kardiomyopathie resultiert (Frey et al. 2004). Im Umkehrschluss zeigte sich, dass eine Überexpression von Calsarcin1 im Herz bei Angiotensin-II-induzierter kardialer Hypertrophie eine protektive Wirkung hat (Frank et al. 2007). Intrazel- 
lulär kommt es durch die Inhibition von Calsarcin2 zu einer Dephosphorylierung von NFAT durch Calcineurin. Nach Wanderung in den Zellkern aktiviert NFAT das Kalzium-abhängige Genprogramm.

Die Rolle dieser Proteine in der Vorlast-induzierten Hypertrophie sind bisher noch nicht ausreichend untersucht worden. Allerdings zeigt sich bei linksventrikulärer Vorlast-induzierter Hypertrophie auch keine Steigerung der BNP-Expression, so dass eine alternative Signalperzeption und -weitergabe durchaus wahrscheinlich erscheint.

Titin ist eine bedeutsame Komponente des kontraktilen Wahrnehmungs- und Regulationsapparat im Kardiomyozyten und wird auch als Stress-Sensor bezeichnet. Titin ist ein $>1 \mu \mathrm{m}$ langes Filament, welches vom Z-Streifen zur M-Bande im Zentrum des Sarkomers zieht. Es verfügt über drei wichtige Bestandteile. Zunächst ist der dehnbare Anteil des Filaments mit Myosinfilamenten des Sarkomers verbunden und steht in Kontakt mit N2B und den PEVK-Regionen der I-Bande. Bei Veränderung des Splicing-Prozesses von Titin kann es zur Entstehung einer Isoform von N2B kommen, die als N2BA bezeichnet wird und ein längeres PEVK Element besitzt (Bang et al. 2001). Der zweite wichtige Bestandteil liegt an der A-Bande und ist nicht dehnbar (Labeit und Kolmerer 1995). Ihm wird eine regulatorische Fähigkeit in Bezug auf die Filamentstärke zugesprochen (Wang K 1996). Als letztes ist Titin mit der M-Bande verbunden und beinhaltet dort eine Kinase-Domäne (Lange et al. 2005). Einzelne TitinFilamente überlappen sich an der M-Bande und sind so in der Lage zu interagieren (Obermann et al. 1996). Titin kommt vermutlich eine besondere Rolle als Vorlast-Sensor zu. Es besteht aus mehreren Subdomainen. Die N2B-Domaine ist nur im Herzen zu finden (Helmes et al. 1999, Cazorla et al. 2000). An diese Domäne binden sich Signalmoleküle (Miller et al. 2003, Sheikh et al. 2008, Granzier et al. 2009).

Ein KO von Titin-N2B führt zu einer diastolischen Dysfunktion und zu einer Atrophie des Herzens (Radke et al. 2007). Die diastolische Dysfunktion entsteht am ehesten durch die Verkürzung des gesamten Titin-Moleküls. Die Atrophie ist wahrscheinlich durch den Verlust des Titin-N2B-Signalweges zu erklären. Bei der PEVK KO-Maus zeigt sich ebenfalls eine diastolische Dysfunktion, aber auch eine Hypertrophie (Granzier et al. 2009). In dieser Maus ist die Titin-N2B-Region vorhanden und gedehnt. Dies legt einen Einfluss auf die Hypertrophie-Entwicklung bei Titin-Dehnung nahe. Bisher wurden diese Modelle aber noch nicht im Vorlastmodell untersucht.

Die M-Bande des Sarkomers interagiert mit der Titin-muscle-specific ring finger protein (MURF)-1 Verbindung. MURF-1 beeinflusst Proteine, die im Nukleus aktiv sind (Gregorio et al. 2005) und Proteine, die im ATP-Stoffwechsel der Zelle involviert sind (Witt et al. 2005). MURF-1 scheint keine Funktion im physiologischen kardialen Wachstum zu haben, nimmt aber im hypertrophen Gewebe eine inhibitorische Rolle über den Transkriptionsfaktor SRF und mutmaßlich auch über Inhibition von PKC $\varepsilon$ über RACK1 ein (Willis et al. 2007). Auch hier erfolgte noch keine Untersuchung im Vorlastmodell. 


\subsection{Bedeutung der Ergebnisse}

\subsubsection{Bedeutung für die Forschung}

Das TAC-Modell ist für die Forschung bezüglich druckinduzierter Veränderungen am Herzen etabliert. In der vorliegenden Arbeit wurde neben dem TAC-Modell auch das Shunt-Modell verwendet. Die Nutzung des Vorlastmodells ist von großer Bedeutung, da es mit ebenfalls klinisch hoch relevanten kardialen Erkrankungen assoziiert ist (Aorteninsuffizienz, Mitralinsuffizienz). Es liefert eine gute Basis des Krankheitsverständnisses und der histologischen und molekularen Entwicklung.

Die Besonderheit dieser Arbeit ist in der Tatsache zu sehen, dass zu Beginn der Untersuchungen die linksventrikulären Wandspannungen sowohl im TAC- als auch im Shunt-Modell gleich waren. Somit konnte ein wichtiger Faktor, der einen Vergleich der beiden Modelle in vergangenen Untersuchungen limitiert hat, in dieser Arbeit ausgeschaltet werden. Die meisten bekannten Signalmechanismen sind bisher nur im Nachlastmodell nicht aber im Vorlastmodell untersucht worden. Die Unterschiede in der Signalaktivierung und der BNP-Expression zeigen, dass es bei Erhöhung der Vorlast zu einer deutlich unterschiedlichen Signalerfassung kommt. In Genexpressionsmessungen durch mRNA-ChipAnalysen konnte weiterhin gezeigt werden, dass das Expressionsmuster nach Vorlasterhöhung nur zu einem geringen Teil mit dem Expressionsmuster nach Nachlasterhöhung identisch ist. Dies unterstreicht die Unterschiede zwischen den beiden Modellen.

Bei der Analyse von mechanischer Last im Herzen ist zu empfehlen, sowohl das Nachlastmodell (TACModell) als auch das Vorlastmodell (Shunt-Modell) zu untersuchen. Vermutlich zeigt sich in Modellen oder transgenen Tieren, die bisher nur mit dem Nachlastmodell phänotypisiert wurden, im Vorlastmodell ein relevanter Befund. Weiterhin sind bei der Untersuchung von isolierten gedehnten Zellen die Lastverhältnisse ebenfalls als relevant anzusehen. Die Dehnung in der Zellkulturschale erfolgt meist nicht rhythmisch zu einem bestimmten Zeitpunkt in der Systole oder Diastole. Hier wird empfohlen, die Zellen elektrisch zu stimulieren und sie dann in der Systole oder der Diastole einem Dehnungsreiz auszusetzen. Yamamoto et al. (1997) konnten mit dieser Methode Unterschiede in den Signalwegen und der BNP-Expression zeigen.

\subsubsection{Bedeutung für die Klinik}

Die deutlichen Unterschiede in der Signalperzeption und -weiterleitung zeigen, dass eine globale Therapie der Hypertrophie und Herzinsuffizienz nur begrenzt möglich ist. Die CaMK II ist inzwischen als ein mögliches Therapieziel der Herzinsuffizienzentwicklung angesehen. Allerdings würde eine Inhibition der CaMK II nur bei Patienten mit Nachlasterhöhung logische Konsequenz sein, da es bei Patienten mit Vorlasterhöhung zu keiner Aktivierung dieses Signalweges kommt. Somit ist eine lastabhängige Therapie der Herzinsuffizienz zu empfehlen. Im Volumenmodell muss noch nach einem 
guten Ziel für eine Intervention gesucht werden, da die Aktivierung von Akt eher als positiv anzusehen ist. 


\section{Zusammenfassung}

Die Herzinsuffizienz ist in der Gruppe der kardiovaskulären Erkrankungen die häufigste Erkrankung. Die mechanische Lasterhöhung ist ein wesentlicher Bestandteil der Hypertrophie und der Herzinsuffizienzentwicklung. Bei mechanischer Last ist zwischen Vor- und Nachlast zu differenzieren und die molekularen Mechanismen sind kaum bekannt. In bisherigen Studien wurde nur ein Modell betrachtet oder eine vergleichbare Belastung der beiden Modelle nicht gezeigt. In dieser Arbeit wurden der kardiale Remodeling-Prozess und die zugrunde liegenden Signalwege im Vorlastmodell (aortokavaler Shunt) und im Nachlastmodell (transverse aortale Konstriktion) bei gleicher mittlerer Wandspannungserhöhung, d.h. bei gleicher Belastung untersucht.

Initial wurde die Wandspannung in beiden Modellen nach 6 Stunden verglichen. Diese sind im Mittel in beiden Modellen gleichartig erhöht (Shunt: + 69 \%, TAC: + 67 \%). Dies ermöglichte der hier vorliegenden Arbeit vergleichende Analysen bezüglich des kardialen Remodelings und der molekularen Mechanismen.

Die Hypertrophie war nach 7 Tagen in beiden Modellen vergleichbar stark ausgeprägt (Shunt: + $29 \%$, TAC: + $22 \%)$. Die Unterschiede zwischen beiden Hypertrophieformen zeigten sich beispielsweise in der differenziellen BNP-Expression. Diese ist bis 7 Tage nach Intervention nur im Nachlastmodell, nicht aber im Vorlastmodell erhöht.

Die histologischen Befunde im Nachlastmodell sind die erhöhte kardiale Inflammation, Fibrosierung und Apoptose. Das Vorlastmodell weist histologisch nach 7 Tagen keine signifikante Veränderung bezüglich der Inflammation und Fibrosierung und im Vergleich zum TAC-Modell nur eine signifikante geringere Zunahme der Apoptose auf.

Die adaptiven und maladaptiven Signalwege wurden nach 24 Stunden und nach 7 Tagen mittels der Western Immunoblot-Methode untersucht. Im TAC-Modell ist der CaMK IID-Signalweg zu beiden Zeitpunkten aktiviert. Zudem wurde 7 Tagen nach Intervention eine signifikante Zunahme der HDACPhosphorylierung beobachtet. Der CaMK IIס-HDAC-Signalweg ist als maladaptiv bekannt. Im Vorlastmodell zeigte sich eine persistente Akt-Aktivierung. Eine Aktivierung des Akt-Signalweges ist eher als günstig anzusehen.

Insgesamt konnte in dieser Arbeit gezeigt werden, dass es unter Vorlast- und Nachlasterhöhung bei gleicher Wandspannung zu unterschiedlichen Signalaktivierungen kommt. Dabei ist eine Vorlasterhöhung mit einer günstigeren Prognose versehen. Dies impliziert, dass bei Untersuchung von lastabhängigen Prozessen eine Differenzierung zwischen Vorlast und Nachlast nötig ist. Ebenfalls ist im Falle einer in Zukunft möglichen Therapie der Herzinsuffizienz die Belastungssituation mit einzubeziehen, da es hier zu unterschiedlichen Signalaktivierungsmustern kommt. 


\section{Literaturverzeichnis}

Akazawa H, Komuro I (2003): Roles of Cardiac Transcription Factors in Cardiac Hypertrophy. Circ Res 92(10), 1079-1088.

Alpert NR, Gordon MS (1962): Myofibrillar adenosine triphosphatase activity in congestive heart failure. Am J Physiol 202(5), 940-946.

Antos CL, McKinsey TA, Frey N, Kutschke W, McAnally J, Shelton JM, Richardson JA, Hill JA, Olson EN (2002): Activated glycogen synthase-3 beta suppresses cardiac hypertrophy in vivo. Proc Natl Acad Sci U S A 99(2), 907-12.

Anversa P, Levicky V, Beghi C, McDonald SL, Kikkawa Y (1983): Morphometry of exercise-induced right ventricular hypertrophy in the rat. Circ Res 52(1), 57-64.

Anversa P, Hiler B, Ricci R, Guideri G, Olivetti G (1986): Myocyte cell loss and myocyte hypertrophy in the aging rat heart. J Am Coll Cardiol 8(6), 1441-8.

Arnolda L, McGrath BP, Johnston Cl (1991): Vasopressin and angiotensin II contribute equally to the increased afterload in rabbits with heart failure. Cardiovasc Res 25(1), 68-72.

Backs J, Olson EN (2006): Control of cardiac growth by histone acetylation/deacetylation. Circ Res 98(1), 15-24.

Backs J, Song K, Bezprozvannaya S, Chang S, Olson EN (2006): CaM kinase II selectively signals to histone deacetylase 4 during cardiomyocyte hypertrophy. J Clin Invest 116(7), 1853-1864.

Backs J, Backs T, Bezprozvannaya S, McKinsey TA, Olson EN (2008): Histone deacetylase 5 acquires calcium/calmodulindependent kinase II responsiveness by oligomerization with histone deacetylase 4. Mol Cell Biol 28(10), 3437-45.

Backs J, Backs T, Neef S, Kreusser MM, Lehmann LH, Patrick DM, Grueter CE, Qi X, Richardson JA, Hill JA, Katus HA, Bassel-Duby R, Maier LS, Olson EN (2009): The delta isoform of CaM kinase II is required for pathological cardiac hypertrophy and remodeling after pressure overload. Proc Natl Acad Sci U S A 106(7), 2342-2347.

Bang ML, Centner T, Fornoff F, Geach AJ, Gotthardt M, McNabb M, Witt CC, Labeit D, Gregorio CC, Granzier H, Labeit S (2001): The complete gene sequence of titin, expression of an unusual approximately 700-kDa titin isoform, and its interaction with obscurin identify a novel Z-line to I-band linking system. Circ Res 89(11), 1065-72.

Barnes PJ, Karin M (1997): Nuclear factor-kappaB: a pivotal transcription factor in chronic inflammatory diseases. N Engl J Med 336(15), 1066-71.

Berenji K, Drazner MH, Rothermel BA, Hill JA (2005): Does load-induced ventricular hypertrophy progress to systolic heart failure? Am J Physiol Heart Circ Physiol 289(1), H8-H16.

Bers DM: Excitation-Contraction Coupling and Cardiac Contractile Force. 2. Auflage; Kluwer Academic Publisher, Dordrecht 2001.

Bers DM, Weber CR (2002): Na/Ca exchanger function in intact ventricular myocytes. Ann N Y Acad Sci $\underline{976}$, 500-512.

Bers DM, Despa S (2006): Cardiac myocytes Ca2+ and Na+ regulation in normal and failing hearts. J Pharmacol Sci 100(5), 315-22.

Bers DM, Barry WH, Despa S (2003): Intracellular Na+ regulation in cardiac myocytes. Cardiovasc Res 57, 897-912.

Bing OH (1994): Hypothesis: apoptosis may be a mechanism for the transition to heart failure with chronic pressure overload. J Mol Cell Cardiol 26(8), 943-8.

Bradham WS, Bozkurt B, Gunasinghe H, Mann D, Spinale FG (2002): Tumor necrosis factor-alpha and myocardial remodeling in progression of heart failure: a current perspective. Cardiovasc Res 53(4), 822-30.

Braunwald E: HEART DISEASE - a texbook of cardiovascular medicine. Volume 1. 5. Auflage; hrsg. v. Braunwald E W.B. Saunders Company, Philadelphia 1997.

Braz JC, Bueno OF, Liang Q, Wilkins BJ, Dai YS, Parsons S, Braunwart J, Glascock BJ, Klevitsky R, Kimball TF, Hewett TE, Molkentin JD (2003): Targeted inhibition of p38 MAPK promotes hypertrophic cardiomyopathy through upregulation of calcineurin-NFAT signaling. J Clin Invest $\underline{111(10)}, 1475-86$. 
Brenner B, Eisenberg E (1987): The mechanism of muscle contraction. Biochemical, mechanical, and structural approaches to elucidate cross-bridge action in muscle. Basic Res Cardiol 82(Suppl 2), 3-16.

Brilla CG, Weber KT (1992): Reactive and reparative myocardial fibrosis in arterial hypertension in the rats. Cardiovasc Res 26, 671-677.

Bruneau BG, de Bold AJ (1994): Selective changes in natriuretic peptide and early response gene expression in isolated rat atria following stimulation by stretch or endothelin-1. Cardiovasc Res $\underline{28(10)}, 1519-25$.

Bueno OF, De Windt U, Tymitz KM, Witt SA, Kimball TR, Klevitsky R, Hewett TE, Jones SP, Lefer DJ, Peng CF, Kitsis RN, Molkentin JD (2000): The MEK1-ERK1/2 signaling pathway promotes compensated cardiac hypertrophy in transgenic mice. EMBO J 19(23), 6341-50.

Buitrago M, Lorenz K, Maass AH, Oberdorf-Maass S, Keller U, Schmitteckert EM, Ivashchenko Y, Lohse MJ, Engelhardt S (2005): The transcriptional repressor Nab1 is a specific regulator of pathological cardiac hypertrophy. Nat Med $\underline{11(8)}$, 83744.

Cantley LC (2002): The phosphoinositide 3-kinase pathway. Science 296(5573), 1655-7.

Carabello BA (2002): Concentric versus eccentric remodeling. J Card Fail 8 (6 Suppl), S258-63.

Carabello BA, Williams H, Gash AK, Kent R, Belber D, Maurer A, Siegel J, Blasius K, Spann JF (1986): Hemodynamic predictors of outcome in patients undergoing valve replacement. Circulation $\underline{74(6)}, 1309-16$.

Carafoli E (1975): Mitochondria, Ca2+ transport and the regulation of heart contraction and metabolism. J Mol Cell Cardiol 7(2), 83-87.

Caroni P, Carafoli E (1980): An ATP-dependent Ca2+-pumping system in dog heart sarcolemma. Nature 283(5749), 765-767.

Casale PN, Devereux RB, Milner M, Zullo G, Harshfield GA, Pickering TG, Laragh JH (1986): Value of echocardiographic measurement of left ventricular mass in predicting cardiovascular morbid events in hypertensive men. Ann Intern Med 105(2), 173-8.

Cazorla O, Freiburg A, Helmes M, Centner T, McNabb M, Wu Y, Trombitás K, Labeit S, Granzier H (2000): Differential expression of cardiac titin isoforms and modulation of cellular stiffness. Circulation $\underline{121}, 979-988$.

Chen Y, Pat B, Zheng J, Cain L, Powell P, Shi K, Sabri A, Husain A, Dell'italia U (2010): Tumor necrosis factor-alpha produced in cardiomyocytes mediates a predominant myocardial inflammatory response to stretch in early volume overload. J Mol Cell Cardiol 49(1), 70-8.

Chien KR (2003): Genotype, phenotype: upstairs, downstairs in the family of cardiomyopathies. J Clin Invest. 111, 175-178.

Chien KR, Zhu H, Knowlton KU, Miller-Hance W, van Bilsen M, O’Brian TX, Evans SM (1993): Transcriptional regulation during cardiac growth and development. Annu Rev Physiol 55, 77-95.

Clark KA, McElhinny AS, Beckerle MC, and Gregorio CC (2002): Striated muscle cytoarchitecture: an intricate web of form and function. Annu Rev Cell Dev Biol $\underline{18}, 637-706$.

Clerk A, Michael A, Sugden PH (1998): Stimulation of the p38 mitogen-activated protein kinase pathway in neonatal rat ventricular myocytes by the $\mathrm{G}$ protein-coupled receptor agonists, endothelin-1 and phenylephrine: a role in cardiac myocyte hypertrophy? J Cell Biol 142(2), 523-35.

Clipstone NA, Fiorentino DF, Crabtree GR (1994): Molecular analysis of the interaction of calcineurin with drugimmunophilin complexes. J Biol Chem 269, 26431-26437.

Cohn JN, Levine TB, Olivari MT, Garberg V, Lura D, Francis GS, Simon AB, Rector T (1984): Plasma norepinephrine as a guide to prognosis in patients with chronic congestive heart failure. N Engl J Med 311(13), 819-823.

Communal C, Singh K, Pimentel DR, Colucci WS (1998): Norepinephrine stimulates apoptosis in adult rat ventricular myocytes by activation of the beta-adrenergic pathway. Circulation $\underline{98(13)}$, 1329-34. 
Condorelli G, Morisco C, Stassi G, Notte A, Farina F, Sgaramella G, de Rienzo A, Roncarati R, Trimarco B, Lembo G (1999): Increased cardiomyocyte apoptosis and changes in proapoptotic and antiapoptotic genes bax and bcl-2 during left ventricular adaptations to chronic pressure overload in the rat. Circulation 99(23), 3071-8.

Condorelli G, Drusco A, Stassi G, Roncarati R, laccarino G, Russo MA, Gu Y, Chung C, Latronico M, Napoli C, Sadoshima J, Croce CM, Ross J Jr (2002): Akt induces enhanced myocardial contractility and cell size in vivo in transgenic mice. Proc Natl Acad Sci U S A $\underline{99}$, 12333-12338.

Cowie MR, Wood DA, Coats AJ, Thompson SG, Poole-Wilson PA, Suresh V, Sutton GC (1999): Incidence and aetiology of heart failure: a population-based study. Eur Heart J 20(6), 421-428.

Crespo LM, Grantham CJ, Cannell MB (1990): Kinetics, stoichiometry and role of the Na-Ca exchange mechanism in isolated cardiac myocytes. Nature 345(6276), 618-621.

Dash R, Frank KF, Carr AN, Moravec CS, Kranias EG (2001): Gender influences on sarcoplasmic reticulum Ca2+-handling in failing human myocardium. J Mol Cell Cardiol 33(7), 1345-1353.

Davis RJ (2000): Signal transduction by the JNK group of MAP kinases. Cell 103(2), 239-52.

de Bold AJ (1985): Atrial natriuretic factor: a hormone produced by the heart. Science 230(4727), 767-770.

de Bold AJ, Borenstein HB, Veress AT, Sonnenberg H (1981): A rapid and potent natriuretic response to intravenous injection of atrial myocardial extract in rats. Life Sci 28(1), 89-94.

DeBosch B, Sambandam N, Weinheimer C, Courtois M, Muslin AJ (2006): Akt2 regulates cardiac metabolism and cardiomyocyte survival. J Biol Chem 281(43), 32841-51.

de Denus S, Pharand C, Williamson DR (2004): Brain natriuretic peptide in the management of heart failure. Chest $\underline{125}$, $652-668$.

Dell Italia L, Meng QC, Balcells E, Straeter-Knowlen IM, Hankes GH, Dillon R, Cartee RE, Orr R, Bishop SP, Oparil S, et al. (1995): Increased ACE and chymase-like activity in cardiac tissue of dogs with chronic mitral regurgitation. Am J Physiol 269, H2065-H2073.

Dell'Italia U, Balcells E, Meng QC, Su X, Schultz D, Bishop SP, Machida N, Straeter-Knowlen IM, Hankes GH, Dillon R, Cartee RE, Oparil S (1997): Volume-overload cardiac hypertrophy is unaffected by ACE inhibitor treatment in dogs. Am J Physiol 273(2 Pt 2), H961-70.

Dent MR, Das S, Dhalla NS (2007): Alterations in both death and survival signals for apoptosis in heart failure due to volume overload. J Mol Cell Cardiol 43, 726-732.

Denvir MA, MacFarlane NG, Cobbe SM, Miller DJ (1995): Sarcoplasmic reticulum and myofilament function in chemicallytreated ventricular trabeculae from patients with heart failure. Cardiovasc Res 30(3), 377-385.

Diwan A, Wansapura J, Syed FM, Matkovich SJ, Lorenz JN, Dorn GW (2008): Nixmediated apoptosis links myocardial fibrosis, cardiac remodeling, and hypertrophy decompensation. Circulation $\underline{117}$, 396-404.

Dorn GW 2nd. (2009): Apoptotic and non-apoptotic programmed cardiomyocyte death in ventricular remodelling. Cardiovasc Res 81(3), 465-73.

Dzhura I, Wu Y, Colbran RJ, Balser JR, Anderson ME (2000): Calmodulin kinase determines calcium-dependent facilitation of L-type calcium channels. Nat Cell Biol 2(3), 173-7.

Eimer MJ, Ekery DL, Rigolin VH, Bonow RO, Carnethon MR, Cotts WG (2004): Elevated B-type natriuretic peptide in asymptomatic men with chronic aortic regurgitation and preserved left ventricular systolic function. Am J Cardiol 94(5), 676-8.

Esposito G, Rapacciuolo A, Naga Prasad SV, Takaoka H, Thomas SA, Koch WJ, Rockman HA (2002): Genetic Alterations That Inhibit In Vivo Pressure-Overload Hypertrophy Prevent Cardiac Dysfunction Despite Increased Wall Stress. Circulation 105, 85-92. 
Fiedler B, Lohmann SM, Smolenski A, Linnemuller S, Pieske B, Schroder F, Molkentin JD, Drexler H, Wollert KC (2002): Inhibition of calcineurin-NFAT hypertrophy signaling by cGMP-dependent protein kinase type I in cardiac myocytes. Proc Natl Acad Sci U S A 99(17), 11363-8.

Flesch M, Schwinger RHG, Schiffer F, Frank K, Sudkamp M, Kuhn-Regnier F, Arnold G, Bohm M (1996): Evidence for Functional Relevance of an Enhanced Expression of the Na+-Ca2+ Exchanger in Failing Human Myocardium. Circulation 94 , $992-$ 1002.

Francis GS, Benedict C, Johnstone DE, Kirlin PC, Nicklas J, Liang CS, Kubo SH, Rudin Toretsky E, Yusuf S (1990): Comparison of neuroendocrine activation in patients with left ventricular dysfunction with and without congestive heart failure. A substudy of the Studies of Left Ventricular Dysfunction (SOLVD). Circulation 82(5), 1724-1729.

Frank D, Kuhn C, Katus HA, Frey N (2006): The sarcomeric Z-disc: a nodal point in signalling and disease. J Mol Med 84(6), 446-68.

Frank D, Kuhn C, van Eickels M, Gehring D, Hanselmann C, Lippl S, Will R, Katus HA, Frey N (2007): Calsarcin-1 protects against angiotensin-II induced cardiac hypertrophy. Circulation 116(22), 2587-96.

Frey N, Olson EN (2002): Calsarcin-3, a novel skeletal muscle-specific member of the calsarcin family, interacts with multiple Z-disc proteins. J Biol Chem 277(16), 13998-4004.

Frey N, Olson EN (2003): Cardiac hypertrophy: The good, the bad, and the ugly. Annu Rev Physiol 65 , 45-79.

Frey N, Richardson JA and Olson EN (2000): Calsarcins, a novel family of sarcomeric calcineurin-binding proteins. Proc Natl Acad Sci USA 97, 14632-14637.

Frey N, Barrientos T, Shelton JM, Frank D, Rütten H, Gehring D, Kuhn C, Lutz M, Rothermel B, Bassel-Duby R, Richardson JA, Katus HA, Hill JA, Olson EN (2004): Mice lacking calsarcin-1 are sensitized to calcineurin signaling and show accelerated cardiomyopathy in response to pathological biomechanical stress. Nat Med 10(12), 1336-43.

Frey N, Frank D, Lippl S, Kuhn C, Kögler H, Barrientos T, Rohr C, Will R, Müller OJ, Weiler H, Bassel-Duby R, Katus HA, Olson EN (2008): Calsarcin-2 deficiency increases exercise capacity in mice through calcineurin/NFAT activation. J Clin Invest 118(11), 3598-608.

Garcia R, Diebold S (1990): Simple, rapid, and effective method of producing aortocaval shunts in the rat. Cardiovasc Res 24(5), 430-2.

Garrington TP, Johnson GL (1999): Organization and regulation of mitogen-activated protein kinase signaling pathways. Curr Opin Cell Biol 11(2), 211-8.

Gerber IL, Stewart RA, Legget ME, West TM, French RL, Sutton TM, Yandle TG, French JK, Richards AM, White HD (2003): Increased plasma natriuretic peptide levels reflect symptom onset in aortic stenosis. Circulation 107(14), 1884-90.

Gerdes AM, Campbell SE, Hilbelink DR (1988): Structural remodeling of cardiac myocytes in rats with arteriovenous fistulas. Lab Invest 59(6), 857-61.

Gontier Y, Taivainen A, Fontao L, Sonnenberg A, van der Flier A, Carpen O, Faulkner G, Borradori L (2005): The Z-disc proteins myotilin and FATZ-1 interact with each other and are connected to the sarcolemma via muscle-specific filamins. J Cell Sci 118(Pt 16), 3739-49.

Granzier HL, Labeit S (2004): The giant protein titin: a major player in myocardial mechanics, signaling, and disease. Circ Res 94, 284-295.

Granzier HL, Radke MH, Peng J, Westermann D, Nelson OL, Rost K, King NM, Yu Q, Tschope C, McNabb M, Larson DF, Labeit S, Gotthardt M (2009): Truncation of titin's elastic PEVK region leads to cardiomyopathy with diastolic dysfunction. Circ Res $\underline{105}, 557-564$.

Gregorio CC, Perry CN, McElhinny AS (2005): Functional properties of the titin/connectin-associated proteins, the musclespecific RING-finger proteins (MURFs), in striated muscle. J Muscle Res Cell Motil 26, 389-400. 
Grossman W, Jones D, McLaurin L (1975): Wall stress and patterns of hypertrophy in the human left ventricle. J Clin Invest 56, 56-64.

Györke S, Fill M (1993): Ryanodine receptor adaptation: control mechanism of Ca2+-induced Ca2+ release in heart. Science 260(5109), 807-809.

Hain J, Onoue H, Mayrleitner M, Fleischer S, Schindler H (1995): Phosphorylation modulates the function of the calcium release channel of sarcoplasmic reticulum from cardiac muscle. J Biol Chem 270(5), 2074-81.

Hajjar RJ, Grossman W, Gwathmey JK (1992): Responsiveness of the myofilaments to Ca2+ in human heart failure: implications for Ca2+ and force regulation. Basic Res Cardiol 87(Suppl 1), 143-159.

Haq S, Choukroun G, Lim H, Tymitz KM, del Monte F, Gwathmey J, Grazette L, Michael A, Hajjar RJ, Force T, Molkentin JD (2001): Differential Activation of Signal Transduction Pathways in Human Hearts With Hypertrophy Versus Advanced Heart Failure. Circulation $\underline{103}, 670-677$.

Hasenfuß G, Reinecke H, Studer R, Meyer M, Pieske B, Holtz J, Holubarsch C, Posival H, Just H, Drexler H (1994): Relation between myocardial function and expression of sarcoplasmic reticulum Ca2_-ATPase in failing and nonfailing human myocardium. Circ Res $\underline{75}$, 434-442.

Hashambhoy YL, Greenstein JL, Winslow RL (2010): Role of CaMKII in RyR leak, EC coupling and action potential duration: a computational model. J Mol Cell Cardiol 49(4), 617-24.

Haudek SB, Taffet GE, Schneider MD, Mann DL (2007): TNF provokes cardiomyocyte apoptosis and cardiac remodeling through activation of multiple cell death pathways. J Clin Invest $\underline{117}$, 2692-2701.

Hein S, Arnon E, Kostin S, Schönburg M, Elsässer A, Polyakova V, Bauer EP, Klövekorn WP, Schaper J (2003): Progression from compensated hypertrophy to failure in the pressure-overloaded human heart: structural deterioration and compensatory mechanisms. Circulation 107(7), 984-91.

Heineke J, Molkentin JD (2006): Regulation of cardiac hypertrophy by intracellular signalling pathways. Nat Rev Mol Cell Biol 7(8), 589-600.

Heling A, Zimmermann R, Kostin S, Maeno Y, Hein S, Devaux B, Bauer E, Klövekorn WP, Schlepper M, Schaper W, Schaper J (2000): Increased Expression of Cytoskeletal, Linkage, and Extracellular Proteins in Failing Human Myocardium. Circ Res $86,846-853$.

Helmes M, Trombitás K, Centner T, Kellermayer M, Labeit S, Linke WA, Granzier H (1999): Mechanically driven contourlength adjustment in rat cardiac titin's unique N2B sequence: titin is an adjustable spring. Circ Res 84(11):1339-52.

Herold G und Mitarbeiter: Herold Innere Medizin 2010. hrsg. v. Herold G. ; Köln 2010.

Hilfiker-Kleiner D, Shukla P, Klein G, Schaefer A, Stapel B, Hoch M, Müller W, Scherr M, Theilmeier G, Ernst M, Hilfiker A, Drexler H (2010): Continuous glycoprotein-130-mediated signal transducer and activator of transcription-3 activation promotes inflammation, left ventricular rupture, and adverse outcome in subacute myocardial infarction. Circulation $\underline{122(2)}$, 145-55.

Hill JA, Karimi M, Kutschke W, Davisson RL, Zimmerman K, Wang Z, Kerber RE, Weiss RM (2000): Cardiac hypertrophy is not a required compensatory response to short-term pressure overload. Circulation 101, 2863-2869.

Hill JA, Rothermel B, Yoo KD, Cabuay B, Demetroulis E, Weiss RM, Kutschke W, Bassel-Duby R, Williams RS (2002): Targeted inhibition of calcineurin in pressure-overload cardiac hypertrophy. Preservation of systolic function. J Biol Chem 277(12), 10251-5.

Hobbs RE (2004): Guidelines for the diagnosis and management of heart failure. Am J Ther 11(6), 467-72.

Hood WP Jr, Rackley CE, Rolett EL (1968): Wall stress in the normal and hypertrophied human left ventricle. Am J Cardiol $\underline{22(4)}$, 550-558.

Hook SS, Means AR (2001): Ca2+/CaM-dependent kinases: From activation to function. Ann Rev Pharmacol Toxicol $\underline{41}$, 471505. 
Hoppe UC, Erdmann E (2001): Leitlinien zur Therapie der chronischen Herzinsuffizienz. Z Kardiol 90, 218-237.

Hoshijima M (2006): Mechanical stress-strain sensors embedded in cardiac cytoskeleton: $Z$ disk, titin, and associated structures. Am J Physiol Heart Circ Physiol 290(4), H1313-25.

Hosoda K, Nakao K, Mukoyama M, Saito Y, Jougasaki M, Shirakami G, Suga S, Ogawa Y, Yasue H, Imura H (1991): Expression of brain natriuretic peptide gene in human heart. Production in the ventricle. Hypertension $\underline{17}(6 \mathrm{Pt} 2), 1152-1155$.

Hunt SA, Baker DW, Chin MH, Cinquegrani MP, Feldman AM, Francis GS, Ganiats TG, Goldstein S, Gregoratos G, Jessup ML, Noble RJ, Packer M, Silver MA, Stevenson LW, Gibbons RJ, Antman EM, Alpert JS, Faxon DP, Fuster V, Jacobs AK, Hiratzka LF, Russell RO, Smith SC Jr; American College of Cardiology/American Heart Association (2001): ACC/AHA guidelines for the evaluation and management of chronic heart failure in the adult: executive summary. A report of the American College of Cardiology/American Heart Association Task Force on Practice Guidelines (Committee to revise the 1995 Guidelines for the Evaluation and Management of Heart Failure). J Am Coll Cardiol 38(7), 2101-13.

Husi H, Luyten MA, Zurini MG (1994): Mapping of the immunophilinimmunosuppressant site of interaction on calcineurin. J Biol Chem 269, $14199-14204$.

Izumiya Y, Shiojima I, Sato K, Sawyer DB, Colucci WS, Walsh K (2006): Vascular endothelial growth factor blockade promotes the transition from compensatory cardiac hypertrophy to failure in response to pressure overload. Hypertension 47(5), 887-93.

Kääb S, Dixon J, Duc J, Ashen D, Näbauer M, Beuckelmann DJ, Steinbeck G, McKinnon D, Tomaselli GF (1998): Molecular Basis of Transient Outward Potassium Current Downregulation in Human Heart Failure. A Decrease in Kv4.3 mRNA Correlates With a Reduction in Current Density. Circulation $\underline{98}, 1383-1393$.

Kai H, Kuwahara F, Tokuda K, Imaizumi T (2005): Diastolic dysfunction in hypertensive hearts: roles of perivascular inflammation and reactive myocardial fibrosis. Hypertens Res $\underline{28}, 483-490$.

Kaiser RA, Liang Q, Bueno O, Huang Y, Lackey T, Klevitsky R, Hewett TE, Molkentin JD (2005): Genetic inhibition or activation of JNK1/2 protects the myocardium from ischemia-reperfusion-induced cell death in vivo. J Biol Chem 280(38), 326028.

Kajstura J, Leri A, Finato N, Di Loreto C, Beltrami CA, Anversa P (1998): Myocyte proliferation in end-stage cardiac failure in humans. Proc Natl Acad Sci U S A 95(15), 8801-5.

Karin M, Lin A (2002): NF-kappaB at the crossroads of life and death. Nat Immunol 3(3), 221-7.

Kass RS, Sanguinetti MC (1984): Inactivation of calcium channel current in the calf cardiac Purkinje fiber. Evidence for voltage- and calcium-mediated mechanisms. J Gen Physiol 84(5), 705-26.

Kim Y, Phan D, van Rooij E, Wang DZ, McAnally J, Qi X, Richardson JA, Hill JA, Bassel-Duby R, Olson EN (2008): The MEF2D transcription factor mediates stress-dependent cardiac remodeling in mice. J Clin Invest 118(1), 124-32.

Kögler H, Schott P, Toischer K, Milting H, Van PN, Kohlhaas M, Grebe C, Kassner A, Domeier E, Teucher N, Seidler T, Knöll R, Maier LS, El-Banayosy A, Körfer R, Hasenfuss G (2006): Relevance of brain natriuretic peptide in preload-dependent regulation of cardiac sarcoplasmic reticulum Ca2+ ATPase expression. Circulation 113(23), 2724-32.

Kranias EG, Di Salvo J (1986): A Phospholamban Protein Phosphatase Activity Associated with Cardiac Sarcoplasmic Reticulum. J Biol Chem 261(22), 10029-10032.

Labeit S, Kolmerer B (1995): Titins: giant proteins in charge of muscle ultrastructure and elasticity. Science $\underline{270}, 293-296$. Lammerding J, Kamm RD, Lee RT (2004): Mechanotransduction in cardiac myocytes. Ann N Y Acad Sci 1015, 53-70. Lämmli UK (1970): Cleavage of structural proteins during assembly of the head of bacteriophage T4. Nature $\underline{227}, 680-685$. Lange S, Xiang F, Yakovenko A, Vihola A, Hackman P, Rostkova E,Kristensen J, Brandmeier B, Franzen G, Hedberg B, Gunnarsson LG, Hughes SM, Marchand S, Sejersen T, Richard I, Edstrom L, Ehler E, Udd B, Gautel M (2005): The kinase domain of titin controls muscle gene expression and protein turnover. Science $\underline{308}, 1599-1603$. 
Lange S, Ehler E, Gautel M (2006): From A to Z and back? Multicompartment proteins in the sarcomere. Trends Cell Biol 16(1), 11-8.

Levick SP, Meléndez GC, Plante E, McLarty JL, Brower GL, Janicki JS (2010): Cardiac mast cells: the centrepiece in adverse myocardial remodelling. Cardiovasc Res [Epub ahead of print]

Levy D, Garrison RJ, Savage DD, Kannel WB, Castelli WP (1990): Prognostic implications of echocardiographically determined left ventricular mass in the Framingham Heart Study. N Engl J Med 322(22), 1561-6.

Levy D, Kenchaiah S, Larson MG, Benjamin EJ, Kupka MJ, Ho KK, Murabito JM, Vasan RS (2002): Long-term trends in the incidence of and survival with heart failure. N Engl J Med 347(18), 1397-402.

Liang Q, Molkentin JD (2003): Redefining the roles of p38 and JNK signaling in cardiac hypertrophy: dichotomy between cultured myocytes and animal models. J Mol Cell Cardiol 35(12), 1385-94.

Liang Q, Bueno OF, Wilkins BJ, Kuan CY, Xia Y, Molkentin JD (2003): c-Jun N-terminal kinases (JNK) antagonize cardiac growth through cross-talk with calcineurin-NFAT signaling. EMBO J 22(19), 5079-89.

Liao P, Georgakopoulos D, Kovacs A, Zheng M, Lerner D, Pu H, Saffitz J, Chien K, Xiao RP, Kass DA, Wang Y (2001): The in vivo role of p38 MAP kinases in cardiac remodeling and restrictive cardiomyopathy. Proc Natl Acad Sci U S A 98(21), 122838.

Lin X, Hänze J, Heese F, Sodmann R, Lang RE (1995): Gene expression of natriuretic peptide receptors in myocardial cells. Circ Res $\underline{77(4)}$, 750-8.

Lindner M, Brandt MC, Sauer H, Hescheler J, Bohle T, Beuckelmann DJ (2002): Calcium sparks in human ventricular cardiomyocytes from patients with terminal heart failure. Cell Calcium 31(4), 175-182.

Ling H, Zhang T, Pereira L, Means CK, Cheng H, Gu Y, Dalton ND, Peterson KL, Chen J, Bers D, Heller Brown J (2009): Requirement for $\mathrm{Ca}_{2} \_$calmodulin-dependent kinase II in the transition from pressure overload induced cardiac hypertrophy to heart failure in mice. J Clin Invest $\underline{119}, 1082-1085$.

Linzbach AJ (1960): Heart failure from the point of view of quantitative anatomy. Am J Cardiol $\underline{5}, 370-382$.

Lim HW, Molkentin JD (2000): Reply to revisiting calcineurin and human heart failure. Nat Med 6(1), 3.

Lips DJ, deWindt L, van Kraaij DJ, Doevendans PA (2003): Molecular determinants of myocardial hypertrophy and failure: alternative pathways for beneficial and maladaptive hypertrophy. Eur Heart J 24(10), 883-96.

Lloyd-Jones DM, Larson MG, Leip EP, Beiser A, D'Agostino RB, Kannel WB, Murabito JM, Vasan RS, Benjamin EJ, Levy D (2002): Framingham Heart Study. Lifetime risk for developing congestive heart failure: the Framingham Heart Study. Circulation 106(24), 3068-72.

Luchner A, Schunkert H (2004): Interactions between the sympathetic nervous system and the cardiac natriuretic peptide system. Cardiovasc Res. 63(3), 443-9.

Luchner A, Muders F, Dietl O, Friedrich E, Blumberg F, Protter AA, Riegger GA, Elsner D (2001): Differential expression of cardiac ANP and BNP in a rabbit model of progressive left ventricular dysfunction. Cardiovasc Res $\underline{51(3)}, 601-7$.

Maier LS, Bers DM (2002): Calcium, calmodulin, and calciumcalmodulin kinase II: heartbeat to heartbeat and beyond. Journal of Molecular and Cellular Cardiology 34, 919-939.

Maier LS, Zhang T, Chen L, DeSantiago J, Brown JH, Bers DM (2003): Transgenic CaMKIIdeltaC overexpression uniquely alters cardiac myocyte Ca2+ handling: reduced SR Ca2+ load and activated SR Ca2+ release. Circ Res 92(8), 904-11.

McKinsey TA, Zhang CL \& Olson EN (2002): MEF2: a calciumdependent regulator of cell division, differentiation and death. Trends in Biochemical Sciences $\underline{27}$, 40-47.

McMurray J (1996): Concise Guide to the Management of Heart Failure - World health Organization/Council on Geriatric Cardiology Task Force on Heart Failure Education. Am J Geriatr Cardiol 5(2), 13-30. 
McMullen JR, Shioi T, Zhang L, Tarnavski O, Sherwood MC, Kang PM, Izumo S (2003): Phosphoinositide 3kinase(p110alpha) plays a critical role for the induction of physiological, but not pathological, cardiac hypertrophy. Proc Natl Acad Sci U S A. 100, 12355-12360.

McMullen JR, Sherwood MC, Tarnavski O, Zhang L, Dorfman AL, Shioi T, Izumo S (2004): Inhibition of mTOR signaling with rapamycin regresses established cardiac hypertrophy induced by pressure overload. Circulation 109(24), 3050-5.

Meerson FZ (1961): Compensatory hyperfunction of the heart and cardiac insufficiency. Circ Res $\underline{10}$, 250-58.

Meguro T, Hong C, Asai K, Takagi G, McKinsey TA, Olson EN, Vatner SF (1999): Cyclosporine attenuates pressureoverloaded hypertrophy in mice while enhancing susceptibility to decompensation and heart failure. Circ Res $\underline{84}, 735-740$.

Miller MK, Bang ML, Witt CC, Labeit D, Trombitas C, Watanabe K, Granzier H, McElhinny AS, Gregorio CC, Labeit S (2003): The muscle ankyrin repeat proteins: CARP, ankrd2/Arpp and DARP as a family of titin filament-based stress response molecules. J Mol Biol 333(5), 951-64.

Moe GW, Howlett J, Januzzi JL, Zowall H; Canadian Multicenter Improved Management of Patients With Congestive Heart Failure (IMPROVE-CHF) Study Investigators (2007): N-terminal pro-B-type natriuretic peptide testing improves the management of patients with suspected acute heart failure: primary results of the Canadian prospective randomized multicenter IMPROVE-CHF study. Circulation 115(24), 3103-10.

Molkentin JD (2004): Calcineurin-NFAT signaling regulates the cardiac hypertrophic response in coordination with the MAPKs. Cardiovasc Res 63(3), 467-75.

Molkentin JD, Lu JR, Antos CL, Markham B, Richardson J, Robbins J, Grant SR, Olson EN (1998): A calcineurin-dependent transcriptional pathway for cardiac hypertrophy. Cell 93(2), 215-228.

Mueller T, Gegenhuber A, Dieplinger B, Poelz W, Haltmayer M (2005): Capability of B-type natriuretic peptide (BNP) and amino-terminal proBNP as indicators of cardiac structural disease in asymptomatic patients with systemic arterial hypertension. Clin Chem 51(12), 2245-51.

Nakajima H, Nakajima HO, Tsai SC, Field U (2004): Expression of mutant p193 and p53 permits cardiomyocyte cell cycle reentry after myocardial infarction in transgenic mice. Circ Res 94(12), 1606-14.

National Institutes of Health Publication (1996): Guide for the Care and Use of Laboratory Animals. www.nap.edu/openbook.php?record_id $=5140$

Nicol RL, Frey N, Pearson G, Cobb M, Richardson J, Olson EN (2001): Activated MEK5 induces serial assembly of sarcomeres and eccentric cardiac hypertrophy. EMBO J 20(11), 2757-67.

Obermann WM, Gautel M, Steiner F, van der Ven PF, Weber K, Furst DO (1996): The structure of the sarcomeric M band: localization of defined domains of myomesin, M-protein, and the 250-kD carboxy-terminal region of titin by immunoelectron microscopy. J Cell Biol $\underline{134}, 1441-1453$.

Ogawa Y, Nakao K, Mukoyama M, Hosoda K, Shirakami G, Arai H, Saito Y, Suga S, Jougasaki M, Imura H (1991): Natriuretic peptides as cardiac hormones in normotensive and spontaneously hypertensive rats. The ventricle is a major site of synthesis and secretion of brain natriuretic peptide. Circ Res 69(2), 491-500.

Oie E, Bjornerheim R, Clausen OP, Attramadal H (2000): Cyclosporin A inhibits cardiac hypertrophy and enhances cardiac dysfunction during postinfarction failure in rats. Am J Physiol Heart Circ Physiol 278(6), H 2115-2123.

Opie L: Mechanisms of Cardiac contraction and relaxation; in: HARRISON'S Principles of internal medicine, 15. Auflage; hrsg. v. Braunwald E, Fauci AS, Kasper D, Hauser SL, Longo D, Jameson JL; McGraw-Hill- Verlag, New York 2001, 360-393.

Opie LH, Commerford PJ, Gersh BJ, Pfeffer MA (2006): Controversies in ventricular remodelling. Lancet 367(9507), 356-67.

Oral H, Sivasubramanian N, Dyke DB, Mehta RH, Grossman PM, Briesmiester K, Fay WP, Pagani FD, Bolling SF, Mann DL, Starling MR (2003): Myocardial proinflammatory cytokine expression and left ventricular remodeling in patients with chronic mitral regurgitation. Circulation 107(6), 831-7. 
Oudit GY, Sun H, Kerfant BG, Crackower MA, Penninger JM, Backx PH (2004): The role of phosphoinositide-3 kinase and PTEN in cardiovascular physiology and disease. J Mol Cell Cardiol 37(2), 449-71.

Palomeque J, Rueda OV, Sapia L, Valverde CA, Salas M, Petroff MV, Mattiazzi A (2009): Angiotensin II-induced oxidative stress resets the $\mathrm{Ca} 2$ _ dependence of $\mathrm{Ca} 2$ _-calmodulin protein kinase II and promotes a death pathway conserved across different species. Circ Res $\underline{105}$, 1204-1212.

Passier R, Zeng H, Frey N, Naya FJ, Nicol RL, McKinsey TA, Overbeek P, Richardson JA, Grant SR, Olson EN (2000): CaM kinase signaling induces cardiac hypertrophy and activates the MEF2 transcription factor in vivo. J Clin Invest 105(10), 1395406.

Petrich BG, Liao P, Wang Y (2002): Using a gene-switch transgenic approach to dissect distinct roles of MAP kinases in heart failure. Cold Spring Harb Symp Quant Biol $\underline{67}$, 429-37.

Pfeffer JM, Pfeffer MA, Braunwald E (1985): Influence of chronic captopril therapy on the infarcted left ventricle of the rat. Circ Res 57, 84-95.

Piacentino V 3rd, Weber CR, Chen X, Weisser-Thomas J, Margulies KB, Bers DM, Houser SR (2003): Cellular Basis of Abnormal Calcium Transients of Failing Human Ventricular Myocytes. Circ Res 92, 651-658.

Pluim BM, Zwinderman AH, van der Laarse A, van der Wall EE (1999): The Athlete's Heart. A Meta- Analysis of Cardiac Structure and Function. Circulation $\underline{100}$, 336-344.

Polyakova V, Hein S, Kostin S, Ziegelhoeffer T, Schaper J (2004): Matrix metalloproteinases and their tissue inhibitors in pressure-overloaded human myocardium during heart failure progression. J Am Coll Cardiol 44(8), 1609-18.

Proud CG (2004): The multifaceted role of mTOR in cellular stress responses. DNA Repair (Amst) 3(8-9), 927-34.

Radke MH, Peng J, Wu Y, McNabb M, Nelson OL, Granzier H, Gotthardt M (2007): Targeted deletion of titin N2B region leads to diastolic dysfunction and cardiac atrophy. Proc Natl Acad Sci U S A $\underline{104}$, 3444-3449.

Razeghi P, Young ME, Alcorn JL, Moravec CS, Frazier OH, Taegtmeyer H (2001): Metabolic Gene Expression in Fetal and Failing Human Heart. Circulation 104, 2923-2931.

Remme WJ, Swedberg K (2001): Guidelines for the diagnosis and treatment of chronic heart failure. Eur Heart J 22, 15271560.

Rettschlag J: Linksventrikuläre Expression verschiedener Housekeeping-Gene bei kardialer Hypertrophie und Herzinsuffizienz. Med. Diss. Berlin 2003

Ringer S (1883): A further Contribution regarding the influence of the different Constituents of the Blood on the Contraction of the Heart. J Physiol $\underline{4}$, 29-42.3.

Rockman HA, Ross RS, Harris AN, Knowlton KU, Steinhelper ME, Field U, Ross J Jr, Chien KR (1991): Segregation of atrialspecific and inducible expression of an atrial natriuretic factor transgene in an in vivo murine model of cardiac hypertrophy. Proc Natl Acad Sci U S A $\underline{88}, 9907$.

Roger VL, Weston SA, Redfield MM, Hellermann-Homan JP, Killian J, Yawn BP, Jacobsen SJ (2004): Trends in heart failure incidence and survival in a community-based population. JAMA 292(3), 344-50.

Rota M, Boni A, Urbanek K, Padin-Iruegas ME, Kajstura TJ, Fiore G, Kubo H, Sonnenblick EH, Musso E, Houser SR, Leri A, Sussman MA, Anversa P (2005): Nuclear targeting of Akt enhances ventricular function and myocyte contractility. Circ Res 97(12), 1332-41.

Rothermel BA, McKinsey TA, Vega RB, Nicol RL, Mammen P, Yang J, Antos CL, Shelton JM, Bassel-Duby R, Olson EN, Williams RS (2001): Myocyte-enriched calcineurin-interacting protein, MCIP1, inhibits cardiac hypertrophy in vivo. Proc Natl Acad Sci U S A 98(6), 3328-33.

Ryan TD, Rothstein EC, Aban I, Tallaj JA, Husain A, Lucchesi PA, Dell'Italia U (2007): Left ventricular eccentric remodeling and matrix loss are mediated by bradykinin and precede cardiomyocyte elongation in rats with volume overload. J Am Coll Cardiol 49(7), 811-21. 
Sadoshima J, Xu Y, Slayter HS, Izumo S (1993): Autocrine release of angiotensin II mediates stretch-induced hypertrophy of cardiac myocytes in vitro. Cell 75(5), 977-984.

Saiki RK, Gelfand DH, Stoffel S, Scharf SJ, Higuchi R, Horn GT, Mullis KB, Erlich HA (1988): Primer-directed enzymatic amplification of DNA with a thermostable DNA polymerase. Science 239(4839), 487-91.

Sanbe A, Gulick J, Hanks MC, Liang Q, Osinska H, Robbins J (2003): Reengineering inducible cardiac-specific transgenesis with an attenuated myosin heavy chain promoter. Circ Res 92(6), 609-16.

Sanna B, Bueno OF, Dai YS, Wilkins BJ, Molkentin JD (2005): Direct and indirect interactions between calcineurin-NFAT and MEK1-extracellular signal-regulated kinase $1 / 2$ signaling pathways regulate cardiac gene expression and cellular growth. Mol Cell Biol. 25(3), 865-78.

Sanna B, Brandt EB, Kaiser RA, Pfluger P, Witt SA, Kimball TR, van Rooij E, De Windt L, Rothenberg ME, Tschop MH, Benoit SC, Molkentin JD (2006): Modulatory calcineurin-interacting proteins 1 and 2 function as calcineurin facilitators in vivo. Proc Natl Acad Sci U S A 103(19), 7327-32.

Schmidt AG, Kadambi VJ, Ball N, Sato Y, Walsh RA, Kranias EG, Hoit BD (2000): Cardiac-specific overexpression of calsequestrin results in left ventricular hypertrophy, depressed force-frequency relation and pulsus alternans in vivo. J Mol Cell Cardiol $\underline{32}, 1735-44$.

Schünke M, Schulte E, Schumacher U, Voll M, Wesker K: Prometheus. LernAtlas der Anatomie. Hals und Innere Organe. Hrsg. Georg Thieme Verlag KG. Stuttgart 2005

Selvetella G, Hirsch E, Notte A, Tarone G, Lembo G (2004): Adaptive and maladaptive hypertrophic pathways: points of convergence and divergence. Cardiovasc Res 63(3), 373-80.

Serneri GG, Boddi M, Cecioni I, Vanni S, Coppo M, Papa ML, Bandinelli B, Bertolozzi I, Polidori G, Toscano T, Maccherini M, Modesti PA (2001): Cardiac angiotensin II formation in the clinical course of heart failure and its relationship with left ventricular function. Circ Res 88(9), 961-8.

Sham JSK, Song LS, Chen Y, Deng LH, Stern MD, Lakatta EG, Cheng H (1998): Termination of Ca2+ release by a local inactivation of ryanodine receptors in cardiac myocytes. Proc Natl Acad Sci U S A $\underline{95}, 15096-15101$.

Shariff S, Straatman L, Allard M, Ignaszewski A (2004): Novel associations of giant cell myocarditis: two case reports and a review of the literature. Can J Cardiol 20(5), 557-61.

Sheikh F, Raskin A, Chu PH, Lange S, Domenighetti AA, Zheng M, Liang X, Zhang T, Yajima T, Gu Y, Dalton ND, Mahata SK, Dorn GW 2nd, Heller-Brown J, Peterson KL, Omens JH, McCulloch AD, Chen J (2008): An FHL1-containing complex within the cardiomyocyte sarcomere mediates hypertrophic biomechanical stress responses in mice. J Clin Invest 118(12), 387080.

Shimoyama M, Hayashi D, Takimoto E, Zou Y, Oka T, Uozumi H, Kudoh S, Shibasaki F, Yazaki Y, Nagai R, Komuro I (1999): Calcineurin plays a critical role in pressure overload-induced cardiac hypertrophy. Circulation 100(24), 2449-54.

Shioi T, McMullen JR, Kang PM, Douglas PS, Obata T, Franke TF, Cantley LC, Izumo S (2002): Akt/protein kinase B promotes organ growth in transgenic mice. Mol Cell Biol 22, 2799-2809.

Shiojima I, Walsh K (2006): Regulation of cardiac growth and coronary angiogenesis by the Akt/PKB signaling pathway. Genes Dev 20, 3347-3365.

Shiojima I, Sato K, Izumiya Y, Schiekofer S, Ito M, Liao R, Colucci WS, Walsh K (2005): Disruption of coordinated cardiac hypertrophy and angiogenesis contributes to the transition to heart failure. J Clin Invest 115(8), 2108-18.

Shiraishi I, Melendez J, Ahn Y, SkavdahI M, Murphy E, Welch S, Schaefer E, Walsh K, Rosenzweig A, Torella D, Nurzynska D, Kajstura J, Leri A, Anversa P, Sussman MA (2004): Nuclear targeting of Akt enhances kinase activity and survival of cardiomyocytes. Circ Res 94(7), 884-91.

Smith PK, Krohn RI, Hermanson GT, Mallia AK, Gartner FH, Provenzano MD, Fujimoto EK, Goeke NM, Olson BJ, Klenk DC (1985): Measurement of protein using bicinchoninic acid. Anal Biochem 150(1), 76-85. 
Solaro RJ, Van Eyk J (1996): Altered interactions among thin filament proteins modulate cardiac function. J Mol Cell Cardiol 28(2), 217-230.

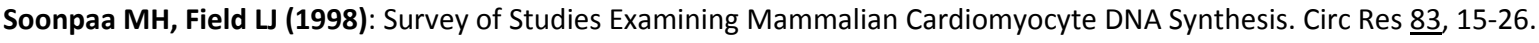

Spinale FG (2007): Myocardial matrix remodeling and the matrix metalloproteinases: influence on cardiac form and function. Physiol Rev $\underline{87(4)}$, 1285-342.

Stewart JA Jr, Wei CC, Brower GL, Rynders PE, Hankes GH, Dillon AR, Lucchesi PA, Janicki JS, Dell'Italia L (2003): Cardiac mast cell- and chymase-mediated matrix metalloproteinase activity and left ventricular remodeling in mitral regurgitation in the dog. J Mol Cell Cardiol 35(3), 311-9.

Studer R, Reinecke H, Bilger J, Eschenhagen T, Bohm M, Hasenfuß G, Just H, Holtz J, Drexler H (1994): Gene expression of the cardiac $\mathrm{Na}(+)-\mathrm{Ca} 2+$ exchanger in end-stage human heart failure. Circ Res 75(3), 443-353.

Sugden PH, Clerk A (1998a): Regulation of mitogen-activated protein kinase cascades in the heart. Adv Enzyme Regul $\underline{38}$, 87-98.

Sugden PH, Clerk A (1998b): "Stress-responsive" mitogen-activated protein kinases (c-Jun N-terminal kinases and p38 mitogen-activated protein kinases) in the myocardium. Circ Res 83(4), 345-52.

Sussman MA, Lim HW, Gude N, Taigen T, Olson EN, Robbins J, Colbert MC, Gualberto A, Wieczorek DF, Molkentin JD (1998): Prevention of cardiac hypertrophy in mice by calcineurin inhibition. Science 281(5383), 1690-3.

Sutton MG, Sharpe N (2000): Left ventricular remodeling after myocardial infarction: pathophysiology and therapy. Circulation $\underline{101}, 2981-2988$.

Tachibana H, Perrino C, Takaoka H, Davis RJ, Naga Prasad SV, Rockman HA (2006): JNK1 is required to preserve cardiac function in the early response to pressure overload. Biochem Biophys Res Commun 343(4), 1060-6.

Tada M (2003): Calcium Cycling Proteins of the Cardiac Sarcoplasmic Reticulum Molecular Regulation of the Phospholamban-SERCA Ca2+ Pump System and Its Pathophysiological Consequences. Circ J 67, 729-737.

Tan LB, Littler WA, Murray RG (1991): Comparison of the haemodynamic effects of dopexamine and dobutamine in patients with severe congestive heart failure. Int J Cardiol 30(2), 203-8.

Toischer K, Kögler H, Tenderich G, Grebe C, Seidler T, Van PN, Jung K, Knöll R, Körfer R, Hasenfuss G (2008): Elevated afterload, neuroendocrine stimulation, and human heart failure increase BNP levels and inhibit preload-dependent SERCA upregulation. Circ Heart Fail 1(4), 265-71.

Toischer K, Rokita AG, Unsöld B, Zhu W, Kararigas G, Sossalla S, Reuter SP, Becker A, Teucher N, Seidler T, Grebe C, Preuss L, Gupta SN, Schmidt K, Lehnart SE, Krüger M, Linke WA, Backs J, Regitz-Zagrosek V, Schäfer K, Field L, Maier LS, Hasenfuss G (2010): Differential cardiac remodeling in preload versus afterload. Circulation 122(10), 993-1003.

Tokudome T, Horio T, Kishimoto I, Soeki T, Mori K, Kawano Y, Kohno M, Garbers DL, Nakao K, Kangawa K (2005): Calcineurin-nuclear factor of activated T cells pathway-dependent cardiac remodeling in mice deficient in guanylyl cyclase $A$, a receptor for atrial and brain natriuretic peptides. Circulation 111(23), 3095-104.

Towbin H, Staehelin T, Gordon J (1979): Electrophoretic transfer of proteins from polyacrylamide gels to nitrocellulose sheets: procedure and some applications. Proc Natl Acad Sci U S A 76, 4350-4354.

Trowbridge IS, Thomas ML (1994): CD45: an emerging role as a protein tyrosine phosphatase required for lymphocyte activation and development. Annu Rev Immunol 12, 85-116.

Vakili BA, Okin PM, Devereux RB (2001): Prognostic implications of left ventricular hypertrophy. Am Heart J 141(3), 334-41. Vanderheyden M, Kersschot E, Paulus WJ (1998): Pro-inflammatory cytokines and endothelium-dependent vasodilation in the forearm. Serial assessment in patients with congestive heart failure. Eur Heart J 19(5), 747-52.

Vega RB, Bassel-Duby R, Olson EN (2003): Control of cardiac growth and function by calcineurin signaling. J Biol Chem $\underline{278(39)}, 36981$. 
Vega RB, Harrison BC, Meadows E, Roberts CR, Papst PJ, Olson EN, McKinsey TA (2004): Protein kinases C and D mediate agonist-dependent cardiac hypertrophy through nuclear export of histone deacetylase 5. Mol Cell Biol 24(19), 8374-85.

Walsh K (2006): Akt signaling and growth of the heart. Circulation $\underline{113}$, 2032-2034.

Wang K (1996): Titin/connectin and nebulin: giant protein rulers of muscle structure and function. Adv Biophys $\underline{33}, 123-$ 134.

Wang ZW (2008): Regulation of synaptic transmission by presynaptic CaMKII and BK channels. Mol Neurobiol $\underline{38(2)}$, 153-66.

Weber KT, Brilla CG, Janicki JS (1993): Myocardial fibrosis: functional significance and regulatory factors. Cardiovasc Res $\underline{27}$, 341-348.

Wei CM, Heublein DM, Perella MA, Lerman A, Rodeheffer RJ, McGregor CG, Edwards WD, Schaff HV, Burnett, JC Jr (1993): Natriuretic peptide system in human heart failure. Circulation $\underline{88}, 1004-1009$.

Wehrens XH, Lehnart SE, Reiken SR, Marks AR (2004): Ca2+/calmodulin-dependent protein kinase II phosphorylation regulates the cardiac ryanodine receptor. Circ Res 94(6), e61-70.

Weston CR, Lambright DG, Davis RJ (2002): Signal transduction. MAP kinase signaling specificity. Science 296(5577), 23457.

Wilkins BJ, Molkentin JD (2004): Calcium-calcineurin signaling in the regulation of cardiac hypertrophy. Biochem Biophys Res Com 322, 1178-1191.

Willis MS, Ike C, Li L, Wang DZ, Glass DJ, Patterson C (2007): Muscle-ring-finger-1, but not muscle-ring-finger-2, regulates cardiac hypertrophy in vivo. Circ Res $\underline{100}$, 456-459.

Witcher DR, Kovacs RJ, Schulman H, Cefali DC, Jones LR (1991): Unique phosphorylation site on the cardiac ryanodine receptor regulates calcium channel activity. J Biol Chem $\underline{266}, 11144-52$.

Witt SH, Granzier H, Witt CC, Labeit S (2005): MURF-1 and MURF-2 target a specific subset of myofibrillar proteins redundantly: towards understanding MURF-dependent muscle ubiquitination. J Mol Biol 350, 713-722.

Yamamoto K, Ikeda U, Shimada K (1997): Natriuretic peptides modulate nitric oxide synthesis in cytokine-stimulated cardiac myocytes. J Mol Cell Cardiol 29(9), 2375-82.

Yang J, Rothermel B, Vega RB, Frey N, McKinsey TA, Olson EN, Bassel-Duby R, Williams RS (2000): Independent signals control expression of the calcineurin inhibitory proteins MCIP1 and MCIP2 in striated muscles. Circ Res 87(12), E61-8.

Yoshimura M, Yasue H, Morita E, Sakaino N, Jougasaki M, Kurose M, Mukoyama M, Saito Y, Nakao K, Imura H (1991): Hemodynamic, renal, and hormonal responses to brain natriuretic peptide infusion in patients with congestive heart failure. Circulation 84(4), 1581-1588.

Zhang T, Brown JH (2004): Role of Ca2+/calmodulin-dependent protein kinase II in cardiac hypertrophy and heart failure. Cardiovasc Res. 63(3), 476-86.

Zhang D, Gaussin V, Taffet GE, Belaguli NS, Yamada M, Schwartz RJ, Michael LH, Overbeek PA, Schneider MD (2000): TAK1 is activated in the myocardium after pressure overload and is sufficient to provoke heart failure in transgenic mice. Nat Med 6(5), 556-63.

Zhang T, Kohlhaas M, Backs J, Mishra S, Phillips W, Dybkova N, Chang S, Ling H, Bers DM, Maier LS, Olson EN, Brown JH (2007): CaMKIIdelta isoforms differentially affect calcium handling but similarly regulate HDAC/MEF2 transcriptional responses. J Biol Chem 282(48), 35078-87.

Zhang T, Maier LS, Dalton ND, Miyamoto S, Ross J Jr, Bers DM, Brown JH (2003): The deltaC isoform of CaMKII is activated in cardiac hypertrophy and induces dilated cardiomyopathy and heart failure. Circ Res 92(8), 912-9.

Zheng J, Chen Y, Pat B, Dell'italia LA, Tillson M, Dillon AR, Powell PC, Shi K, Shah N, Denney T, Husain A, Dell'Italia U (2009): Microarray identifies extensive downregulation of noncollagen extracellular matrix and profibrotic growth factor genes in chronic isolated mitral regurgitation in the dog. Circulation 119(15), 2086-95. 
Zühlke RD, Pitt GS, Deisseroth K, Tsien RW, Reuter H (1999): Calmodulin supports both inactivation and facilitation of Ltype calcium channels. Nature 399(6732), 159-62. 


\section{Abkürzungsverzeichnis}

\begin{tabular}{|c|c|}
\hline ACS & akutes Koronarsyndrom \\
\hline A. dest. & Aqua destillata \\
\hline Akt & Proteinkinase B \\
\hline Al & Aortenklappeninsuffizienz \\
\hline ANP & atriales natriuretisches Peptid \\
\hline AP & Aktionspotenzial \\
\hline AS & Aortenklappenstenose \\
\hline ATP & Adenosintriphosphat \\
\hline $\mathrm{BCA}$ & Bicinchonininsäure \\
\hline BNP & Brain-natriuretisches Peptid \\
\hline bzw. & beziehungsweise \\
\hline $\mathrm{Ca}^{2+}$ & Kalzium \\
\hline CaMK & Kalzium-Calmodulin-abhängige Proteinkinase \\
\hline cMyc & Transkriptionsfaktor \\
\hline $\mathrm{CnA}$ & katalytische Untereinheit von Calcineurin \\
\hline $\mathrm{CnB}$ & regulatorische Untereinheit von Calcineurin \\
\hline CSQ & Calsequestrin \\
\hline $\mathrm{Cu}^{1+/ 2+}$ & Kupfer \\
\hline DAPI & Diamidino-4',6'-phenyl-2-indoledichlorhydrat 5 \\
\hline DNA & Desoxyribonukleinsäure \\
\hline ERK & $\begin{array}{l}\text { Proteinkinase (extracellular signal-regulated kinase/extrazelluläre } \\
\text { Signal-regulierende Kinase) }\end{array}$ \\
\hline elF2B & Transkriptionsfaktor \\
\hline FS & fraktionelle Verkürzungsfraktion (fractional shortening) \\
\hline GAPDH & Glycerinaldehyd-3-Phosphat-Dehydrogenase \\
\hline GPCR & G-Protein-gekoppelter Rezeptor \\
\hline GSK3ß & Proteinkinase (Glykogen-Synthase-Kinase-3ß) \\
\hline HDAC & Histon-Deacetylase \\
\hline HF & Herzfrequenz \\
\hline $\mathrm{HZV}$ & Herzzeitvolumen \\
\hline IGF1 & insulin-like growth factor \\
\hline i.p. & intraperitoneal \\
\hline JNK & Proteinkinase (c-Jun N-terminale Kinase) \\
\hline $\mathrm{K}^{+}$ & Kalium \\
\hline kDa & kiloDalton \\
\hline KHK & koronare Herzerkrankung \\
\hline KO-Modell & Knock-out-Modell \\
\hline LTCC & L-Typ-Kalziumkanal \\
\hline LVEDD & linksventrikulärer enddiastolischer Durchmesser \\
\hline LVESD & linksventrikulärer endsystolischer Durchmesser \\
\hline MAPK & Mitogenaktivierte Kinase \\
\hline MCIP & $\begin{array}{l}\text { endogener Calcineurininhibitor (Modulatory calcineurin-interacting prote- } \\
\text { in/Cacineurin-interagierendes Protein) }\end{array}$ \\
\hline MEF & Transkriptionsfaktor (myocyte enhancer factor) \\
\hline MEK & Proteinkinase (MAPkinase/ERK Kinase 1) \\
\hline MI & Mitralklappeninsuffizienz \\
\hline MKK & mitogenaktivierte ProteinkinaseKinase \\
\hline MLP & Muskel-spezifisches LIM-Protein \\
\hline
\end{tabular}




\begin{tabular}{|c|c|}
\hline MMP & Matrix-Metalloproteinase \\
\hline MS & Mitralklappenstenose \\
\hline mTOR & mammalian target of Raptomycin \\
\hline MURF & muscle-specific ring finger protein \\
\hline$\mu l$ & Mikroliter \\
\hline $\mathrm{Na}^{+}$ & Natrium \\
\hline Nabl1 & Transkriptionsrepressor \\
\hline $\mathrm{N} 2 \mathrm{~B} / \mathrm{N} 2 \mathrm{BA}$ & Titin-Isoformen \\
\hline NCX & Natrium-Kalzium-Austauscher \\
\hline NFAT & Nuclear factor of activated T-cells/Transkriptionsfaktor \\
\hline $\mathrm{nm}$ & Nanometer \\
\hline NT-proBNP & N-terminales proBNP/inaktives Nebenprodukt von BNP \\
\hline NYHA & New York Heart Association \\
\hline PBS & Phosphat-buffered saline/Puffersystem \\
\hline PCR & Polymerase-Kettenreaktion \\
\hline PDK & Phosphoinositol-abhängige Kinase \\
\hline PEVK & Segment, bestehend aus Prolin, Glutamat, Valin und Lysin \\
\hline $\mathrm{PI3K}$ & Enzymfamilie (Phosphatidylinositol-3-Kinase) \\
\hline PKA & Proteinkinase $\mathrm{A}$ \\
\hline PKC & Proteinkinase $\mathrm{C}$ \\
\hline PKD & Proteinkinase D \\
\hline PLB & Phospholamban \\
\hline RACK1 & Rezeptor für Proteinkinase C 1 \\
\hline RNA & Ribonukleinsäure \\
\hline rpm & Umdrehungen pro Minute \\
\hline RT & Raumtemperatur \\
\hline RYR & Ryanodin-Rezeptoren \\
\hline SDS & Natriumdodecylsulfat \\
\hline SDS-PAGE & SDS-Polyacrylamid-Gelelektrophorese \\
\hline SERCA & Sarkoplasmatisches-Retikulum-Kalzium-ATPase \\
\hline Sham-Tiere & scheinoperierte Tiere \\
\hline Shunt-Tiere & Tiere mit Anlage einer aorto-kavalen Verbindung \\
\hline SR & Sarkoplasmatisches Retikulum \\
\hline SRF & Transkriptionsfaktor \\
\hline SV & Schlagvolumen \\
\hline TAC-Tiere & Tiere mit transverser aortaler Konstriktion \\
\hline TAK1 & TGFß-aktivierte Kinase \\
\hline Taq-Polymerase & Enzym des Archaeabakteriums Thermus aquaticus \\
\hline TdT & Terminaldesoxynukleotidyltransferase \\
\hline TGFß & transforming growth factor-ß \\
\hline TIMP & tissue inhibitor of MMP \\
\hline $\mathrm{TnC}$ & Troponin C \\
\hline TNF $\alpha$ & Tumornekrosefaktor $\alpha$ \\
\hline TUNEL-Methode & TdT-mediated dUTP nick end labeling-Methode \\
\hline WHO & Weltgesundheitsorganisation \\
\hline z.B. & zum Beispiel \\
\hline
\end{tabular}




\section{Abbildungs- und Tabellenverzeichnis}

\section{Abbildungsverzeichnis}

Abbildung 1: Elektromechanische Kopplung.

Abbildung 2: Schematische Darstellung der adaptiven und maladaptiven Signalwege. ................................14

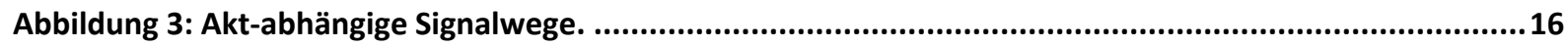

Abbildung 4: Prinzip einer Anlage des aorto-kavalen Shunts. ........................................................20

Abbildung 5: Prinzip einer transversen aortalen Konstriktion. ........................................................21

Abbildung 6: Hämodynamische Verhältnisse 6 Stunden nach Intervention. ............................................35

Abbildung 7: Parameter der hämodynamischen Parameter 6 Stunden nach Intervention............................36

Abbildung 8 : Wandspannungsmessungen 6 Stunden nach Intervention in systolischen Phasen. ..................36

Abbildung 9: Wandspannungsmessungen 6 Stunden nach Intervention in diastolischen Phasen...................37

Abbildung 10: Mittlere Wandspannung 6 Stunden nach Intervention.....................................................38

Abbildung 11: Echokardiographische Messungen 24 Stunden und 7 Tage nach Intervention........................39

Abbildung 12: Gewicht des linken Ventrikels auf die Tibia-Länge normalisiert 7 Tage nach Intervention.......40

Abbildung 13: Fibrosierung 7 Tage nach Intervention...........................................................................41

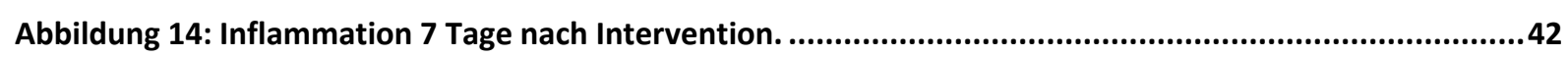

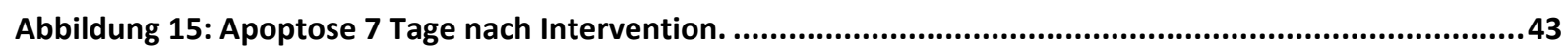

Abbildung 16: Expression des BNP 24 Stunden und 7 Tage nach Intervention.........................................44

Abbildung 17: Darstellung des Proteins GSK3ß 24 Stunden und 7 Tage nach Intervention............................46

Abbildung 18: Darstellung des Proteins JNK 24 Stunden und 7 Tage nach Intervention...............................47

Abbildung 19: Darstellung des Proteins ERK 24 Stunden und 7 Tage nach Intervention................................48

Abbildung 20: Darstellung des Proteins p38 mittels Western-Immunoblot-Methode 24 Stunden und

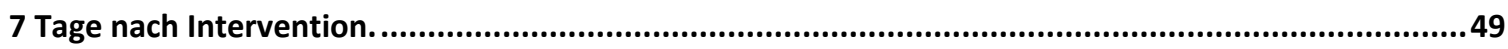

Abbildung 21: Verhältnis des p38 im Balken-Diagramm 24 Stunden und 7 Tage nach Intervention. ..............50

Abbildung 22: Verhältnis von MCIP zur GAPDH-Expression 24 Stunden und 7 Tage nach Intervention. .........51

Abbildung 23: Darstellung des Proteins CaMK II $\delta$ mittels Western-Immunoblot-Methode 24 Stunden

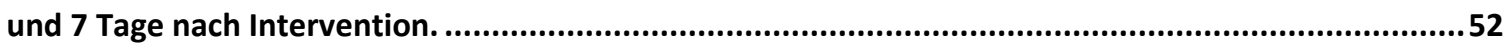

Abbildung 24: Verhältnis des CaMK II $\delta$ im Balken-Diagramm 24 Stunden und 7 Tage nach Intervention.......53

Abbildung 25: Darstellung des phosphorylierten Anteils des Proteins HDAC5, normalisiert auf

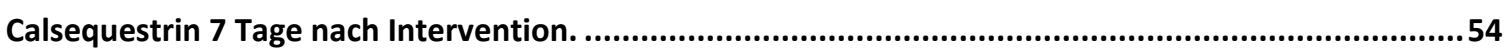

Abbildung 26: Darstellung des Proteins Akt 24 Stunden und 7 Tage nach Intervention. .............................55 


\section{Tabellenverzeichnis}

Tabelle 1: Stoffe und Konzentration/Menge zur Herstellung eines 10 \%igen Trenngels...............................28

Tabelle 2: Stoffe und Konzentration/Menge zur Herstellung eines 4 \%igen Sammelgels. .............................28

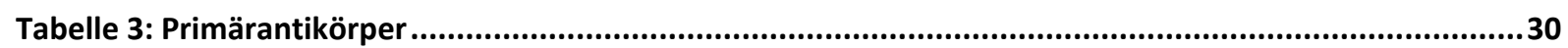

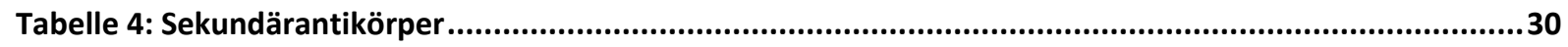

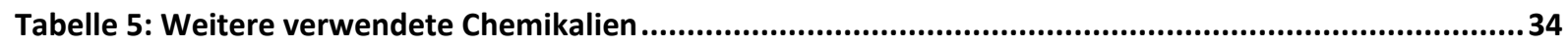




\section{Danksagung}

Herrn Prof. Dr. med. G. Hasenfuß möchte ich für die Überlassung meines Promotionsthemas und die damit verbundene außerordentlich interessante und vielseitige Arbeit im Labor der Kardiologie und Pneumologie der Universitätsmedizin Göttingen danken.

Mein ganz besonderer Dank gilt meinem Betreuer Herrn Dr. med. K. Toischer für eine zu jeder Zeit konstruktive und motivierende Betreuung. Insbesondere danke ich ihm für die vielen Ideen und Anstrengungen, die meine Arbeit bereichert haben.

Weiterhin danke ich Herrn Dr. med. H. Kögler für die Einführung in eine komplexe Thematik und einen guten Einstand im Labor.

Des Weiteren möchte ich mich bei Frau Dr. rer. nat. C. Grebe, Herrn M. Kothe, Frau B. Korf und Frau J. Spitalieri für die Einarbeitung in die Methoden und die Hilfe im Laboralltag bedanken. Auch den hier nicht namentlich aufgeführten Mitarbeiterinnen und Mitarbeitern der Forschungsgruppen in der Kardiologie und Pneumologie der Universitätsmedizin Göttingen danke ich für ihre Hilfe und Unterstützung bei meiner Arbeit in der Abteilung. 